\title{
Identification of AtHD2C as a novel regulator of ABA signaling in Arabidopsis thaliana
}

\author{
Sunandini Sridhar \\ West Virginia University
}

Follow this and additional works at: https://researchrepository.wvu.edu/etd

\section{Recommended Citation}

Sridhar, Sunandini, "Identification of AtHD2C as a novel regulator of ABA signaling in Arabidopsis thaliana" (2005). Graduate Theses, Dissertations, and Problem Reports. 4194.

https://researchrepository.wvu.edu/etd/4194

This Thesis is protected by copyright and/or related rights. It has been brought to you by the The Research Repository @ WVU with permission from the rights-holder(s). You are free to use this Thesis in any way that is permitted by the copyright and related rights legislation that applies to your use. For other uses you must obtain permission from the rights-holder(s) directly, unless additional rights are indicated by a Creative Commons license in the record and/ or on the work itself. This Thesis has been accepted for inclusion in WVU Graduate Theses, Dissertations, and Problem Reports collection by an authorized administrator of The Research Repository @ WVU. For more information, please contact researchrepository@mail.wvu.edu. 
Identification of AtHD2C as a Novel Regulator of ABA Signaling In Arabidopsis thaliana

Sunandini Sridhar

Thesis submitted to the Eberly College of Arts and Sciences

At West Virginia University In partial fulfillment of the requirements

For the degree of

Master of Science

In

Biology

\author{
Keqiang Wu, Ph.D., Chair \\ Jorge Flores, Ph.D \\ Jonathan Cumming, Ph.D \\ Department of Biology
}
Morgantown, West Virginia 2005

Keywords: Histone deacetylase, Arabidopsis thaliana, Abscisic acid, HD2 type histone deacetylase 


\title{
ABSTRACT \\ Identification of AtHD2C as a Novel Regulator of ABA Signaling In Arabidopsis thaliana
}

\author{
Sunandini Sridhar
}

When plants transition from the heterotrophic phase of embryogenesis into the autotrophic phase of sporophytic development, they need to proceed through dormancy and desiccation events. These processes are vital because the commitment to germinate is irreversible, beyond that premature germination would be fatal for the plant. Therefore, maintenance and timely exit from these phases is important. Smooth regulation of this procedure is executed by Abscisic acid (ABA), a plant-specific hormone. In addition, ABA assumes an important role during extreme periods when plants are threatened by abiotic stresses such as drought and high salinity. This report describes $A t H D 2 C$ as a regulator of the ABA controlled events. AtHD2C is a member of the HD2-type histone deacetylase family. A GFP (green florescent protein) co-localization assay revealed that AtHD2C localized to the nucleus in Arabidopsis. Oligonucleotide-directed mutagenesis, that was utilized to create site specific mutations in AtHD2A, identified that the residues important for repression activity reside at the $\mathrm{N}$-terminal pentapeptide and at $\mathrm{H} 25$ of the sequence. A semi-quantitative RT-PCR assay determined the spatial expression profile of the HD2 gene family, with higher transcript accumulation in the reproductive organs. These results indicated an overall physiological significance for the HD2 proteins as well as a possible involvement in embryo development. In continuum with this, seeds overexpressing AtHD2C were insensitive to $\mathrm{ABA}, \mathrm{NaCl}$ and mannitol at germination. This phenotype was supported by ABA-responsive gene expression patterns in the transgenic plants that implicated a negative role for $A t H D 2 C$ in ABA response regulation in this developmental window. Additionally, the AtHD2C transcript accumulation was down-regulated by ABA that was reflected by the downregulation of $A t H D 2 C$ promoter driven GUS. In contrast to its function in the germination-post germination phase, AtHD2C seemed to play a positive role in $\mathrm{ABA}$ response regulation during the vegetative stage. AtHD2C overexpressing mature plants were able to survive extreme osmotic shock and drought conditions. The expression of AtHD2C promoter driven GUS in all vegetative tissues confirmed the presence of AtHD2C in this stage. The predominantly closed stomata and up-regulated ABA-responsive genes support the stress-tolerant phenotype of the 35S:AtHD2C transgenic plants. The information obtained from this investigation delineates a dual role for the $A t H D 2 C$ in the regulation of the ABA response signaling in two developmental stages. 


\section{ACKNOWLEDGEMENTS}

This research study would not have been possible without the support and encouragement of many individuals. I would like to thank my advisor, Dr. Keqiang Wu for initiating and guiding this project. I am extremely grateful to Dr. Jorge Flores and Dr. Jonathan Cumming for their

timely help and valuable advice throughout the course of my research at the department of biology. I would like to thank all my friends and colleagues, especially, Lin Zhang and Dr. Changhe Zhou for their constructive criticism and their invaluable friendship. Finally, I would also like to thank all the graduate students and staff members of the Department of Biology. 


\section{TABLE OF CONTENTS}

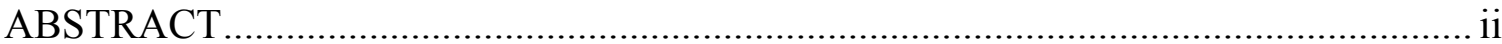

ACKNOWLEDGEMENTS ................................................................................. iii

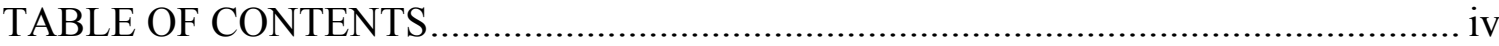

LIST OF TABLES ...................................................................................... vi

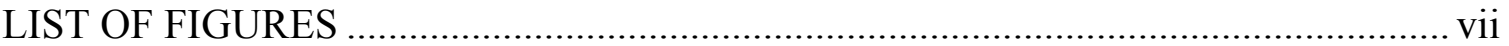

LIST OF ABBREVIATIONS ........................................................................ viii

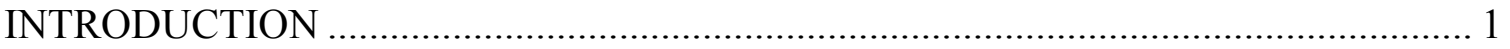

(i) The mechanisms to control gene expression at the transcription level ................................................. 3

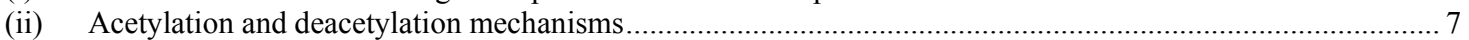

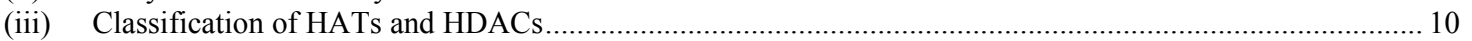

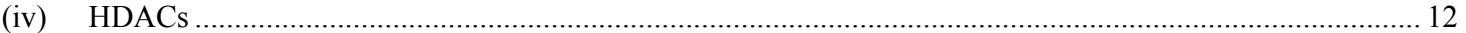

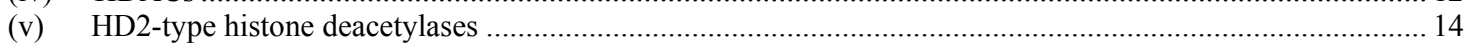

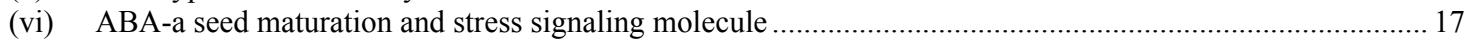

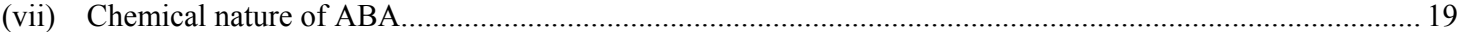

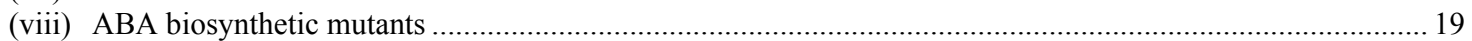

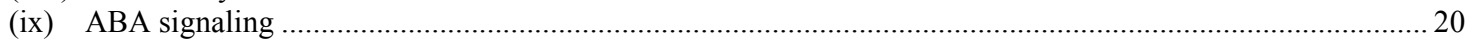

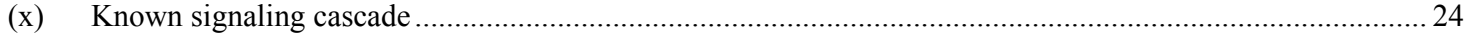

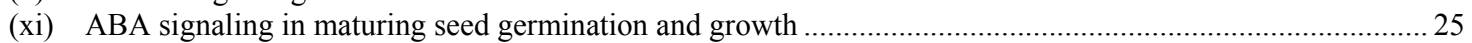

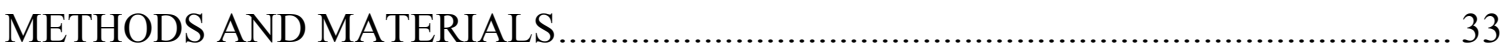

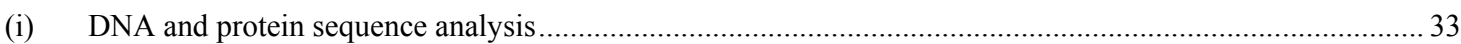

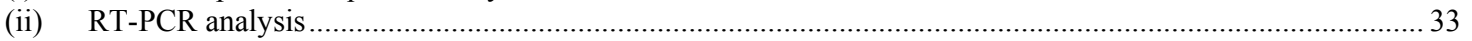

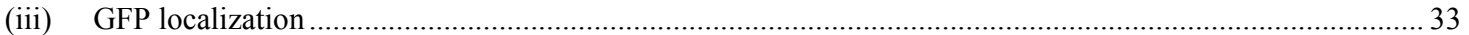

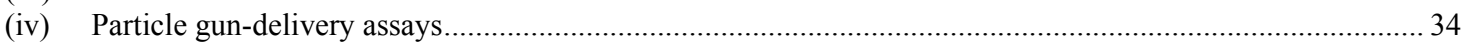

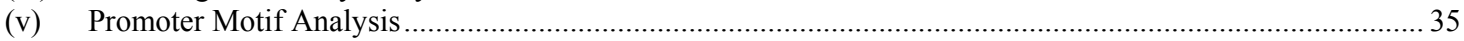

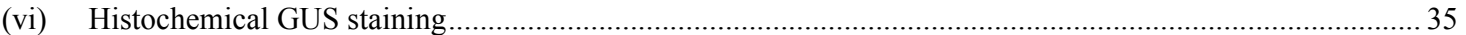

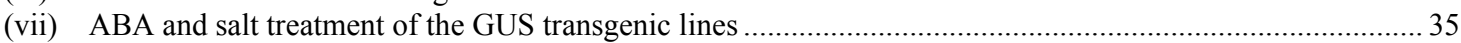

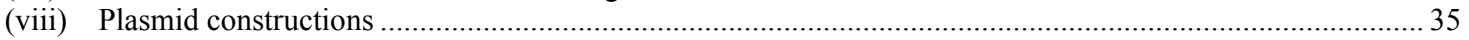

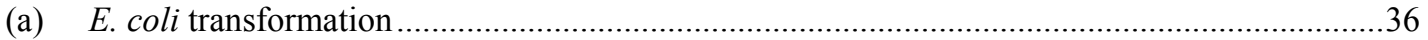

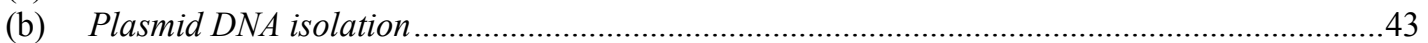

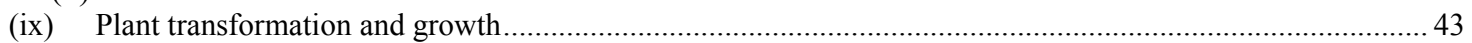

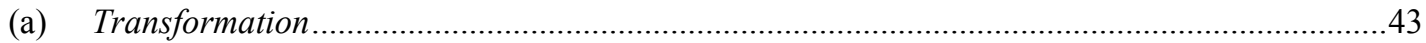

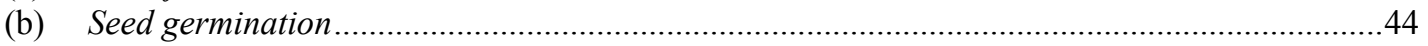

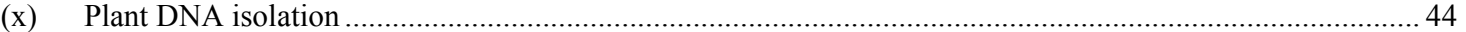

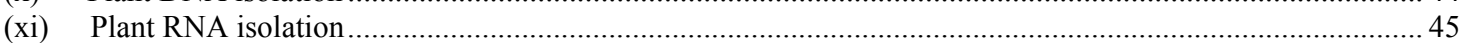

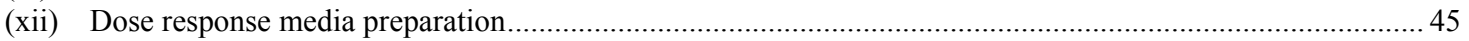

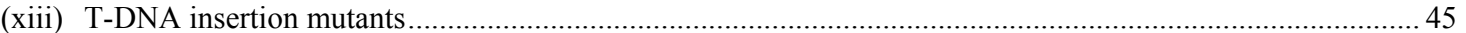

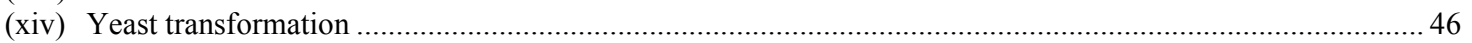

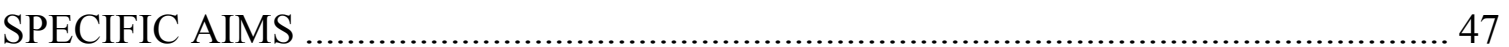

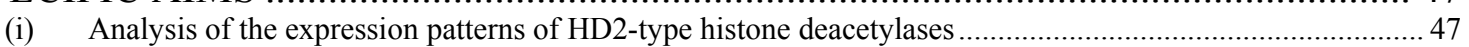

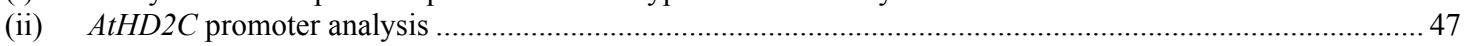

(iii) Analysis of the functional role of HD2-type histone deacetylases in the development of Arabidopsis thaliana,

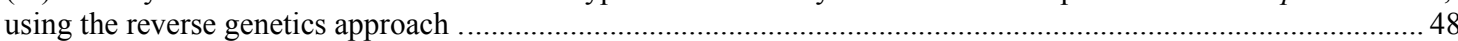


(iv) Investigate physical interaction between AtHD2B/AtHD2C proteins and RPD3 (HDA1) type histone

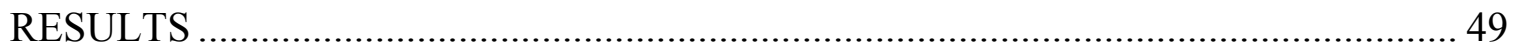

(i) Expression Patterns of the HD2-Type Histone Deacetylases in Arabidopsis .............................................49

(a) Spatial expression profile of the HD2-type histone deacetylase gene family.........................49

(b) HD2C localizes to the nucleus in Arabidopsis ...........................................................52

(c) The N-terminal motif and H25 are essential for AtHD2A mediated Repression ......................56

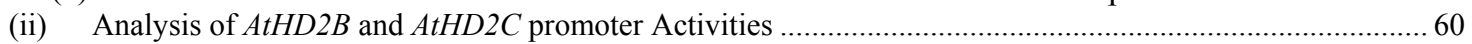

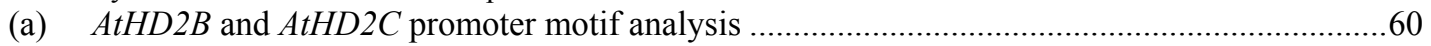

(b) $A t H D 2 B$ promoter and $A t H D 2 C$ promoter driven $G U S$ is expressed in all mature vegetative

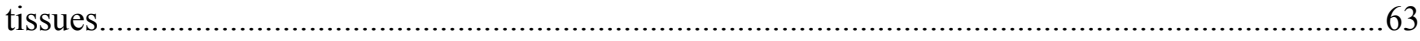

(c) AtHD2C promoter:GUS expression is down-regulated by $\mathrm{ABA}$ and $\mathrm{NaCl}$ in the post-

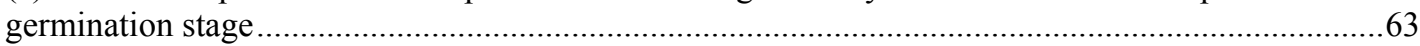

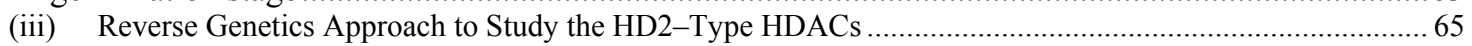

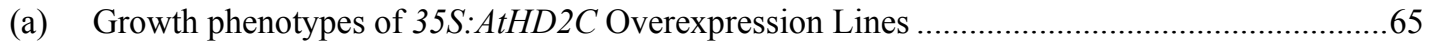

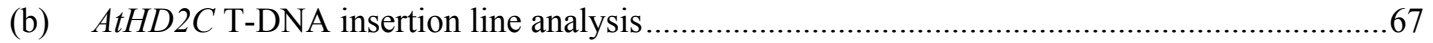

(c) 35S:AtHD2C seeds are insensitive to $\mathrm{ABA}, \mathrm{NaCl}$ and Mannitol during germination and post-

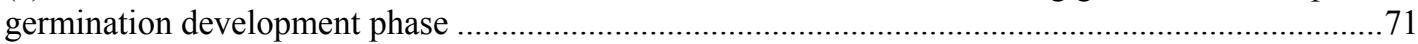

(d) 35S:AtHD2C plants demonstrate vegetative stress tolerance in response to $\mathrm{NaCl}$ and drought 84

(iv) Interaction between HD2-Type HDACs and RPD3-Type HDACs ........................................................93

(a) AtHD2B/AtHD2C and AtHDA1 do not interact..........................................................93

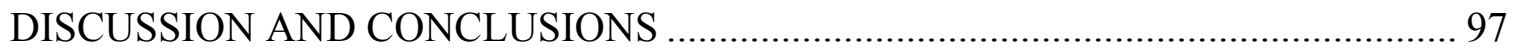

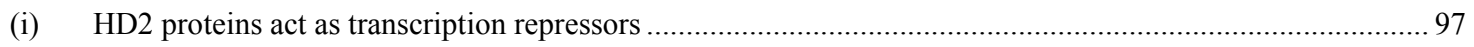

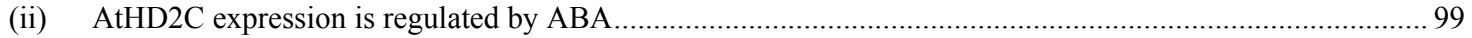

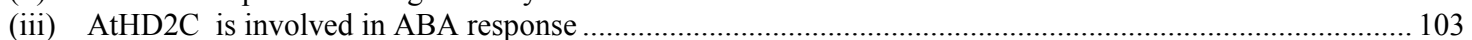

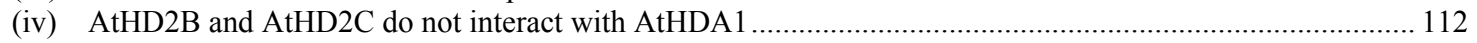

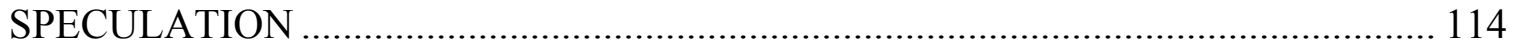

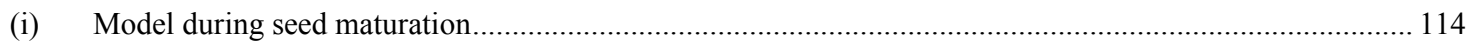

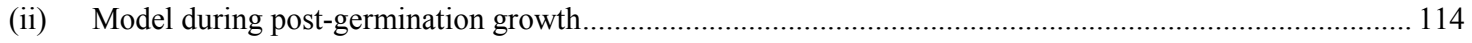

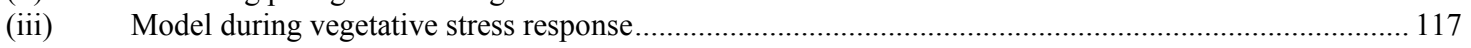

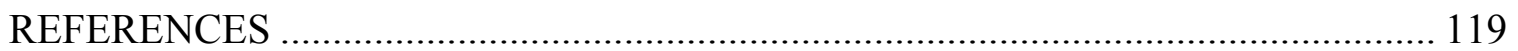




\section{LIST OF TABLES}

Table I. Standard PCR reaction used for all reactions .................................................... 37

Table II. Standard double restriction enzyme digestion for all reactions used ....................... 38

Table III. Standard Ligation reaction used for all reactions ................................................ 39

Table IV. Primers, restriction enzymes, selective media and vectors used in subcloning ....... 40

Table V. Primers and their sequences used for subcloning ......................................... 41

Table VI. $\quad$ Primers sequences used for RT-PCR ....................................................... 42

Table VII. Average percentage of squeezed leaves in WT and 35S:AtHD2C lines ................. 70

Table VIII. Average number of seeds in stunted siliques in WT and 35S:AtHD2C lines......... 70

Table IX. Average percentage of mature stunted siliques in WT and 35S:AtHD2C lines ...... 70

Table X. Percentage of open stomata (adaxial surface) counted for wild-type and transgenic

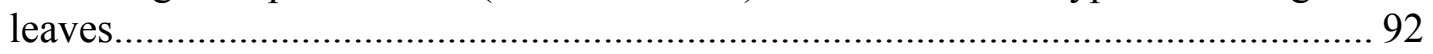




\section{LIST OF FIGURES}

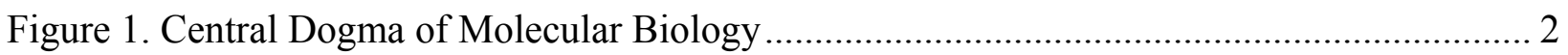

Figure 2 . Compaction of genomic DNA into chromatin and chromosomes. ................................ 4

Figure 3. Organization of a single nucleosome ...................................................................... 6

Figure 4. Post-translation modification sites of Histone proteins which lead to epigenetic

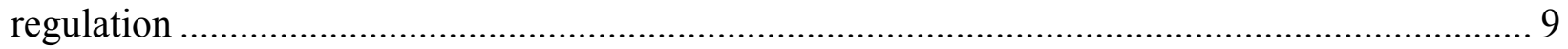

Figure 5. Reversible transition of the chromatin from acetylated to deacetylated state................ 11

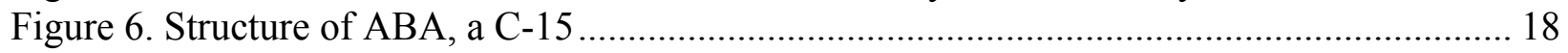

Figure 7. Model for ABA mediated signal cascade in Arabidopsis. .......................................... 23

Figure 8. Model for ABA signaling during embryo-development. ............................................. 27

Figure 9. Model for ABA signaling during germination-post germination phase......................... 30

Figure 10. Model for ABA signaling in stomatal guard cells.................................................... 32

Figure 11. The HD2 gene family of Arabidopsis thaliana.......................................................... 51

Figure 12. PCR and RT-PCR confirmation of the 35S:AtHD2B and 35S:AtHD2C transgenic

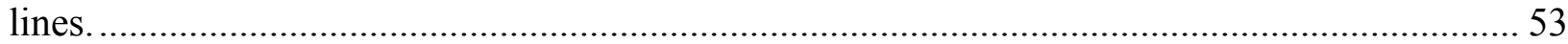

Figure 13. Subcellular localization of AtHD2C …………................................................. 55

Figure 14. Mutation analysis of the essential catalytic residues in the AtHD2A protein.............59

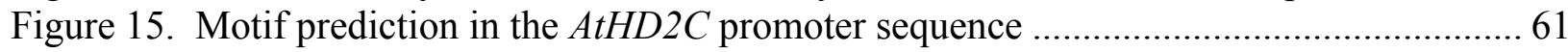

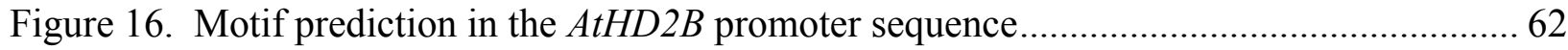

Figure 17 Diagram of $A t H D 2 B$ and $A t H D 2 C$ promoter driven GUS spatial profile. ...................... 64

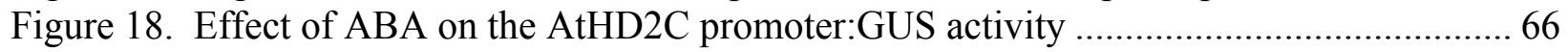

Figure 19. Growth phenotypes of the 35S:AtHD2C overexpression lines ………….................... 69

Figure 20. ABA and stress sensitivity of the SALK_039784 (T-DNA insertion Line) plants in the germination/post-germination and vegetative stages........................................................ 73

Figure 21. ABA sensitivity of the 35S:AtHD2Cl and 35S:AtHD2C2 lines in germination and

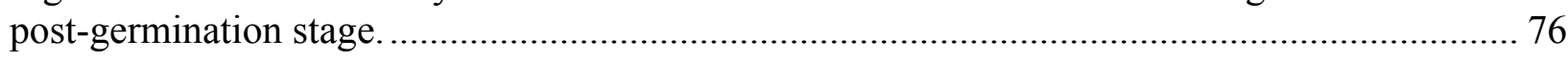

Figure 22. $\mathrm{NaCl}$ sensitivity of the 35S:AtHD2C1 and 35S:AtHD2C2 lines in germination and

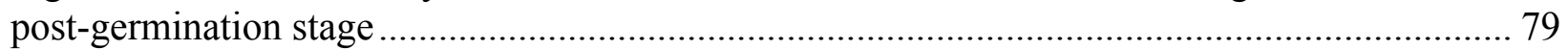

Figure 23. Mannitol sensitivity of the 35S:AtHD2C1 and 35S:AtHD2C2 lines in germination and

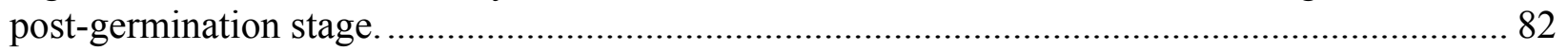

Figure 24. Salt tolerant phenotype of the 35S:AtHD2C plants in the vegetative stage. ................ 87

Figure 25. Drought tolerant of the 35S:AtHD2C plants ............................................................ 90

Figure 26. Stomatal aperture of the WT, 35S:AtHD2C1 and 35S:AtHD2C2 transgenic plants .. 92

Figure 27. Expression of ABA-regulated genes in the vegetative phase in wild-type ................ 94

Figure 28. Yeast two hybrid screen for interaction between AtHD2B/AtHD2C and HDA1 ..... 96

Figure 29. Model for HD2 participation in ABA signaling during embryo-development ......... 115 Figure 30. Model for HD2 participation in ABA signaling during Germination-post germination

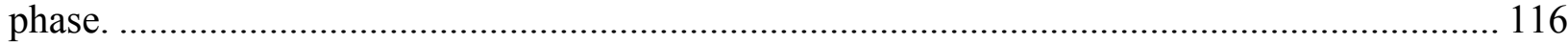

Figure 31. Model for HD2 participation in ABA signaling during vegetative stress response in

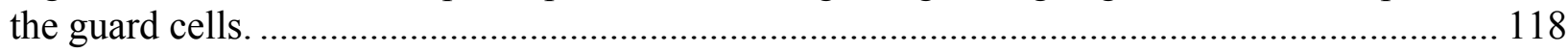




\section{LIST OF ABBREVIATIONS}

HDAC - Histone deacetylase

HAT- Histone acetyl transferases

ABA - Abscisic acid

GUS- Glucuronidase

GFP- Green fluorescent protein

ATHDA1- Reduced potassium dependancy3

ABI- ABA insensitive

WT- Wild type

At- Arabidopsis thaliana

ABRE- ABA responsive element

SKOR- Stelar outward potassium rectifying channel

RD29- Responsive to dehydration

ERA- Enhanced response to ABA

LEA- Late embryogenesis abundant

ICK1- Inhibitor of cyclin dependant kinase

LEC- Leafy cotyledon 


\section{INTRODUCTION}

Abiotic stress is often the cause of huge losses in the agriculture industry as it is a big hindrance to crop productivity. Therefore, it is very desirable to engineer crops with enhanced stress tolerance to drought, salinity, osmotic shock, cold and other oppressing environmental stresses. This comprises one of the main long-term objectives of agronomic research in addition to other motives such as, increasing crop yield or pathogen resistance. To understand how the study of genetics can tell us about the ultimate physiological responses of an organism, we can refer to the central dogma of molecular biology (Figure 1). DNA codes for all the information that is required for the behavioral responses of the plant. Therefore, it is extremely important that the message encrypted in the DNA be processed efficiently into the functional biocatalysts, proteins. Between DNA and proteins there are messenger molecules, RNAs that keep the information processing intact. Hence, the formation of RNA or transcription is crucial for information relay. Consequently, gene expression can be controlled at the very first step of relay, transcription. It can also be controlled at later steps of post-transcription, translation or post-translation (Verbsky, 2001). Many aspects of development involve epigenetic regulation: mitotically and/or meiotically heritable yet reversible changes in gene expression without changes in DNA sequence (Steimer et al, 2004). Many epigenetic changes depend on the recognition of sequence homology at the DNA or RNA level. This recognition can led to transcriptional gene silencing (TGS), that is associated with DNA methylation and/or chromatin modifications, or to post

transcriptional gene silencing (PTGS), either by sequence specific RNA degradation or by 

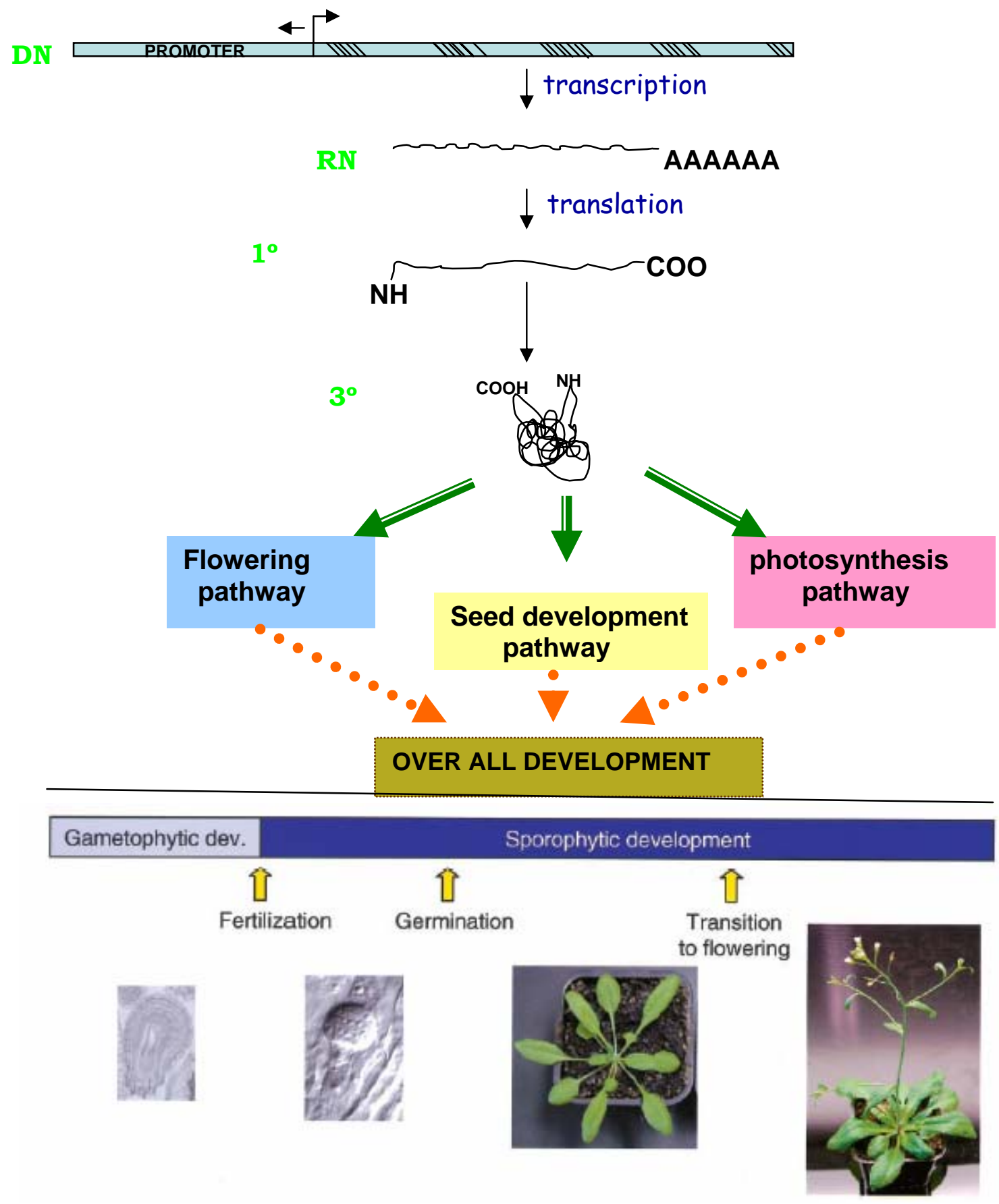

Figure 1 Central Dogma of Molecular Biology 
inhibition of translation. The focus of my study is transcriptional gene silencing and its role in the physiology and development of the plant.

\section{(i) The mechanisms to control gene expression at the transcription level}

The accurate regulation of gene expression in space and time is fundamental for development. Only certain genes need to be expressed at certain times and specific locations. Other genes need to be turned off at these times and locations in order to maintain normal growth transitions (Finnegan E.J, 2001). If all genes in the genome were expressed at the same time, there would be chaos in the biological system as contradicting signals would be generated that would cancel out each other's effect and the net result would be zero development. Therefore, agents that expedite transcriptional repression and activation are essential for maintaining homeostasis in developmental signaling.

To better understand regulation of gene expression, we have to understand that genes are a constituent of nuclear DNA that is compacted into chromatin (Figure 2). Regulation of higher order chromatin structure is directly coupled with regulation of the expression and integrity of the genetic information of plants (Verbsky, 2001) and other eukaryotes. In particular, the packaging of DNA into heterochromatin exerts epigenetic control over important biological processes (Kadonaga et al, 1998). Chromatin is a complex structure built from repeating units, the nucleosomes (Kornberg and Lorch, 1999). These consist of 145 bp of DNA wrapped around an octamer of basic proteins, the core histones. The octamer is formed by histones H2A, H2B, H3 and H4 (Chen and Pikaard, 1997) as depicted in Figure 3. At least two different domains can be distinguished in core histones: a globular domain involved in histone-histone interactions 


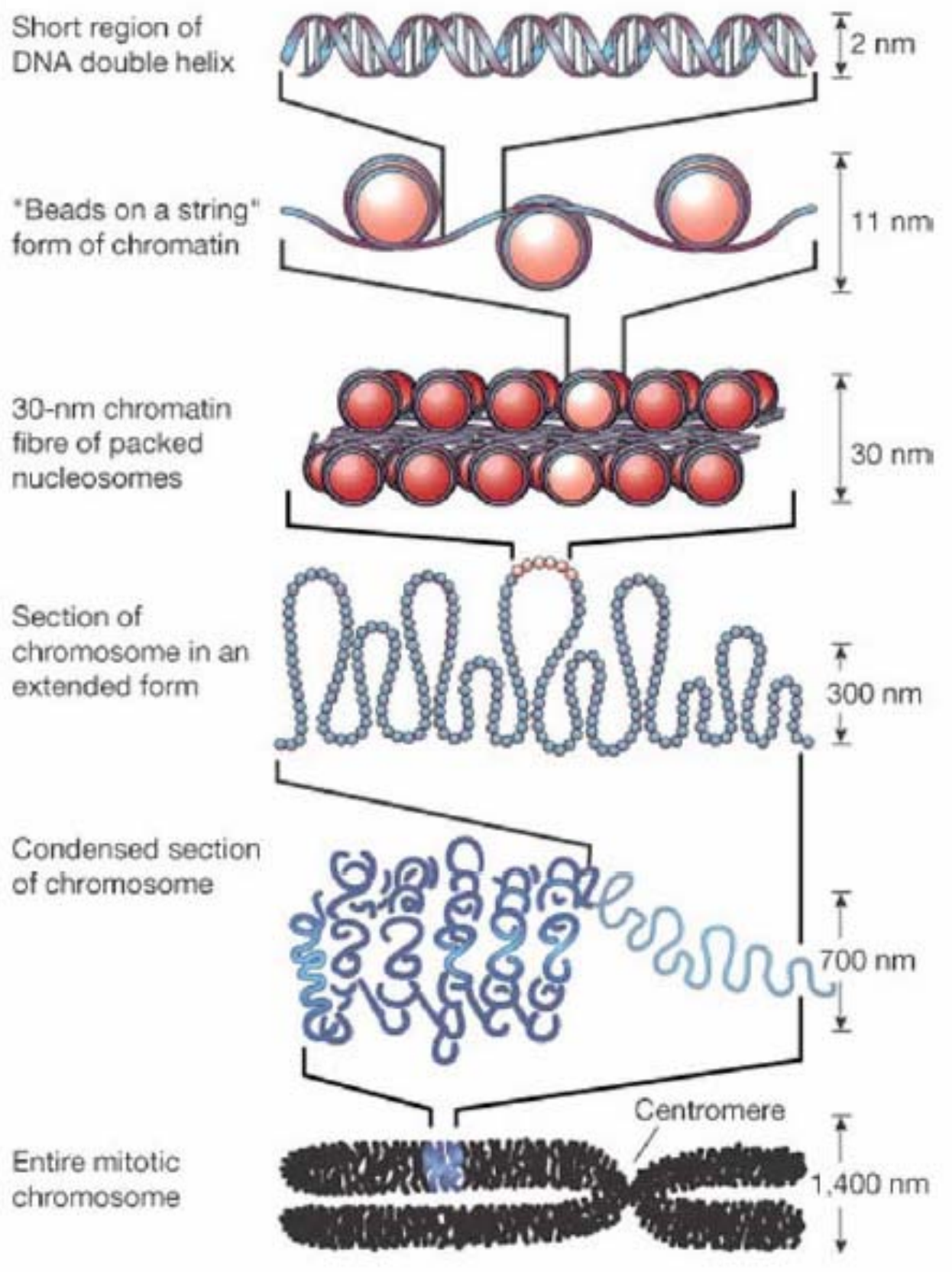

Figure 2 . Compaction of genomic DNA into chromatin and chromosomes.

\footnotetext{
${ }^{1}$ http://www.path.queensu.ca/present/lillicrap/path425transcription2004march.ppt\#256,13, Slide 13
} 
(containing the 'histone fold' motif) and the flexible N-terminal tails of H3 and H4, and N-and C-terminal tails of H2A and H2B (Loidl, 2004). A series of consecutive nucleosomes produces a 'beads on a string' structure or $10 \mathrm{~nm}$ fiber. A further level of compaction is the $30 \mathrm{~nm}$ fiber with six nucleosomes per turn in a solenoid arrangement (Kornberg and Lorch, 1999). The traditional picture of eukaryotic chromatin as a static and largely repressive functional state has, over recent years, changed to a more complex view of chromatin as a highly dynamic state that is essential for regulating cellular functions. Epigenetic regulation of developmental patterning and programming is now recognized to play critical roles in plant growth (Steimer et al, 2004). The dynamic properties of chromatin are mediated by multiprotein complexes with different functions that set marks overlying the stable information of the DNA (Arhinger, 2000; Lusser, 2002; Verbsky, 2001; Kadonaga, 1998). The most prominent factors that influence chromatin structure and function are enzymes that modify the histones and chromatin remodeling machines that utilize ATP (Lusser, 2002; Norton et al, 1989; Alfrey et al, 1964; Struhl et al, 1998). Therefore, in addition to changes in the DNA sequence itself, that led to alteration in transcription rates, the epigenetic modifications mediated by affecting histones is a major mechanism regulating transcription (Steimer et al, 2004).

Histones have been conserved during evolution. However, they are dynamically changed by post-translational modifications (Grunstein, 1992). These modifications include acetylation, methylation, phosphorylation, ubiquitination, glycosylation, ADP ribosylation, carbonylation, sumoylation and biotinylation (Loidl, 2004), that can all cause structural and functional rearrangements in chromatin and are therefore essential elements of the complex 'epigenetic histone code' (Figure 4). 
A

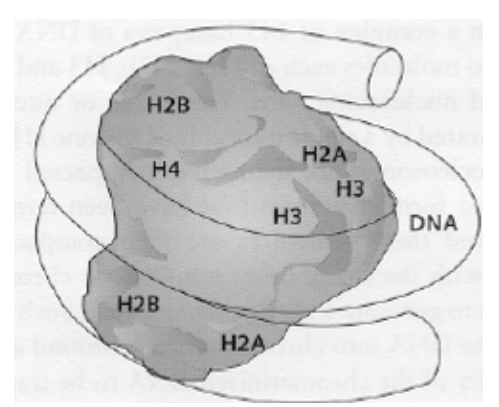

B

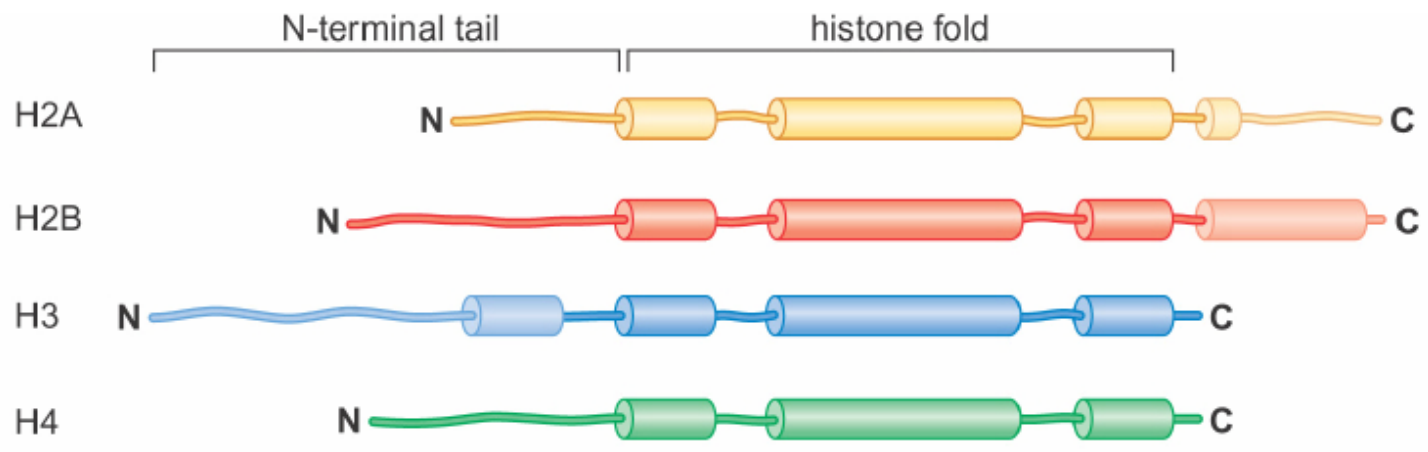

Figure 3. (A) Organization of a single nucleosome: 146bp of DNA wrapped twice around a histone octamer core consisting of H2A, H2B, H3 and H4. Linker DNA is 10 100bp. (B) Structural comparison of the four Histone proteins. The 'Histone fold' is common to all four proteins (Loidl, 2001). 
Also, DNA methylation is one of the ways in that transcription can be regulated. There is ample evidence for an interrelation between DNA methylation and histone modifications (Volpe et al, 2002). The relationships and hierarchy between DNA methylation, H3 methylation, H4 acetylation and heterochromatin assembly has been proposed to play a role in nucleolar dominance (Chen and Pikaard, 1997). As a result, a tentative model was proposed in that four key players act in a coordinated manner. Following DNA replication, maintenance DNA methyltransferase acts on chromatin with acetylated H4 lysine-16. DNA methylation precedes and governs H3 lysine-9 methylation. The chromatin remodeling factor DDM1 could finally trigger the deacetylation of H4 lysine-16 (Soppe et al, 2002). Also, ATP-dependant chromatin remodeling factors use the energy derived from ATP hydrolysis to catalyze nucleosome mobilization, that is a net change in the position of the histone octamer relative to the DNA (Cairns, 1998). All these epigenetic phenomena work in conjunction to expedite transcription regulation.

\section{(ii) Acetylation and deacetylation mechanisms}

Acetylation and deacetylation of nucleosomal core histones has been an intensely investigated field in the recent years. Acetylation at the lysine residues on the amino terminal tail of histones neutralizes the charge of the histone tails, thereby reducing their affinity for DNA (Norton et al, 1989). Consequently, histone acetylation alters nucleosomal conformation and makes it more accessible for the transcription regulatory proteins to contact the chromatin templates (Imhof et $a l, 1997)$. Hypoacetylation on the other hand, is associated with transcriptionaly silent chromatin (Figure 5). These enzymes can be present and functional in the chromatin context ubiquitously, or may be specifically recruited by special repressor complexes (Ahringer, 2000). The enzymes 


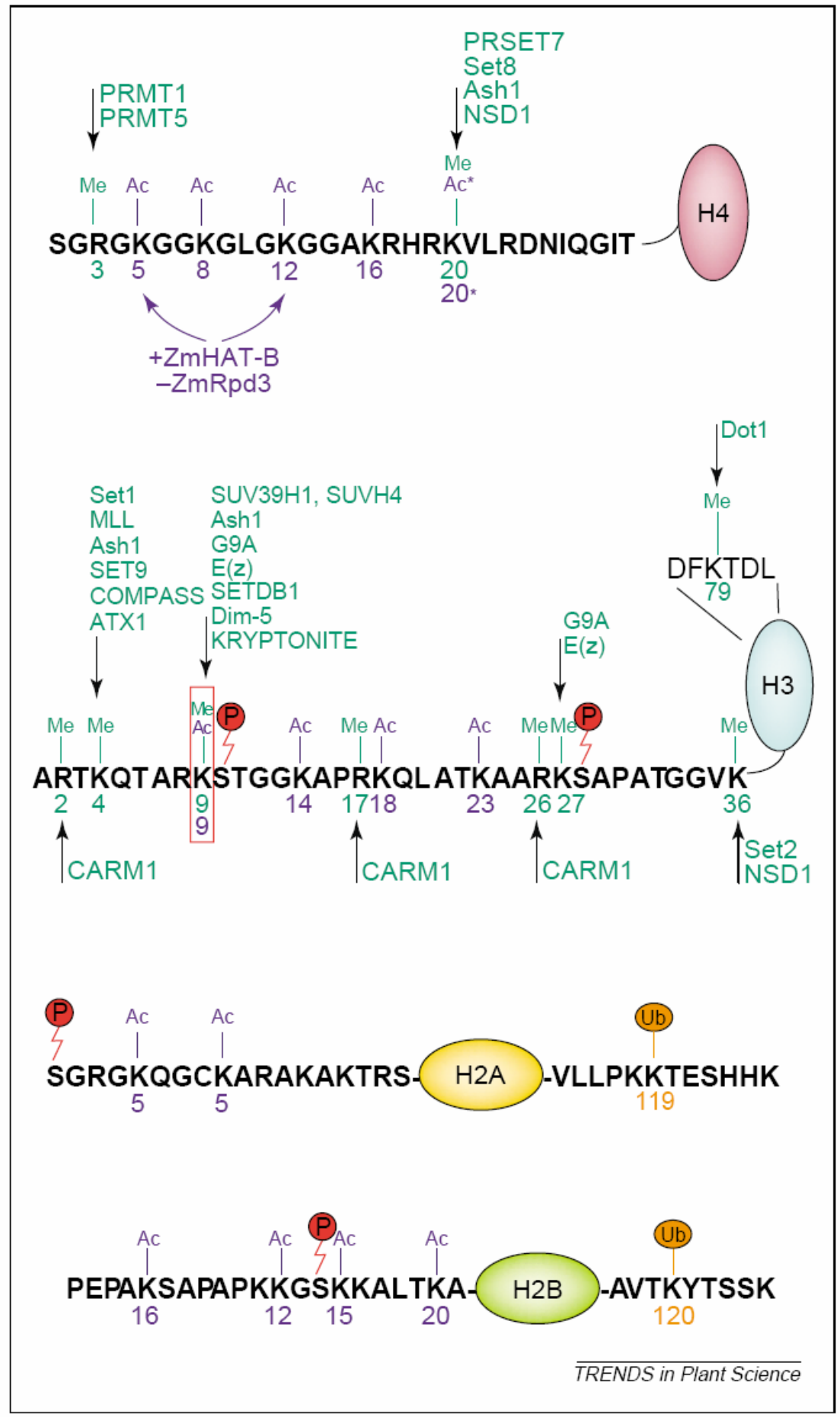


Figure 4. Post-translation modification sites of Histone proteins which lead to epigenetic regulation. Core histones are targets for post-translational modifications at distinct amino acid residues. The modifications depicted are acetylation (Ac, purple), methylation (Me, green), phosphorylation ( $\mathrm{P}, \mathrm{red})$ and ubiquitination ( $\mathrm{Ub}$, orange). Methylating enzymes identified to date include PRMT1, CARM1, PRMT5 , Set1, Set2 , SET7/9 , SET8 , PR-Set7 , SUV39H1, SUVH4 , SETDB1 , G9a , E(z) , KRYPTONITE , dim-5 , Ash1 , MLL , Dot1 , ATX1 and NSD1. In plants, ZmHAT-B has been shown to acetylate specifically lysines (K) 5 and 12 of H4, and the deacetylase ZmRpd3 can specifically deacetylate this distinct acetylation pattern. The plant-specific acetylation of lysine 20 of $\mathrm{H} 4$ is marked with an asterisk (p); methylation of $\mathrm{H} 3$ lysines 14, 18 and 23 has only been detected in plants and are not included in the cartoon. A red frame marks lysine-9 in H3, which can be modified by acetylation as well as methylation (Loidl, 2001). 
that catalyze hyper acetylation are called histone acetyl transferases (HATs) and the ones that catalyze hypoacetylation or removal of acetyl groups from the core histones, are called histone deacetylases (HDACs). Pioneer studies about the classification and function of histone modifying enzymes have been conducted in yeasts, but plants and fungi have also emerged as significant model systems (Graessle, 2001; Lusser, 2001). The molecular mechanism of action of the HATs and HDACs is illustrated in Figure 3.

\section{(iii) Classification of HATs and HDACs}

By sequence analysis, four distinct families of HATs can be distinguished: (i) the GNAT-MYST family; (ii) the p300/CBP coactivator family; (iii) the TAFII250-related family; and (iv) the nuclear receptor coactivator family that is present in vertebrates but not in plants or fungi (Pandey et al, 2002). The HDACs on the other hand, have been classified into two groups in all eukaryotes: (i) members of the ATHDA1/HDA superfamily (Hu et al, 2000; Aravind et al, 1998; Groezinger et al, 1999) and (ii) members of the sirtuin family related to yeast SIR2 (Imai et al, 2000). In contrast to other eukaryotes, plants contain the HD2-type deacetylases, a plant specific class that is unrelated to the other HDAC classes and forms the third HDAC class in plants (Lusser et al, 1997). The HD2 class has arisen from a series of gene duplications and diversions from parent populations. These proteins are thought to have taken over the function of the SIR proteins that are under-represented in plants (Dangl et al, 2001). Due to their unique disposition, this group of proteins forms a very interesting subject for study, with regards to what might be their functional role. 
A

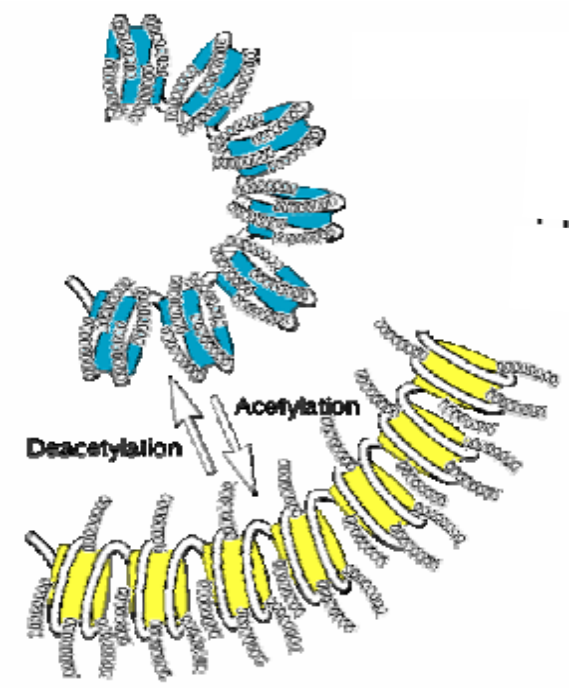

B

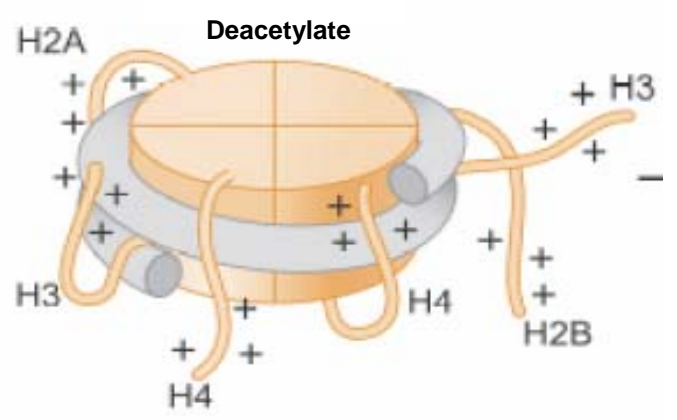

C

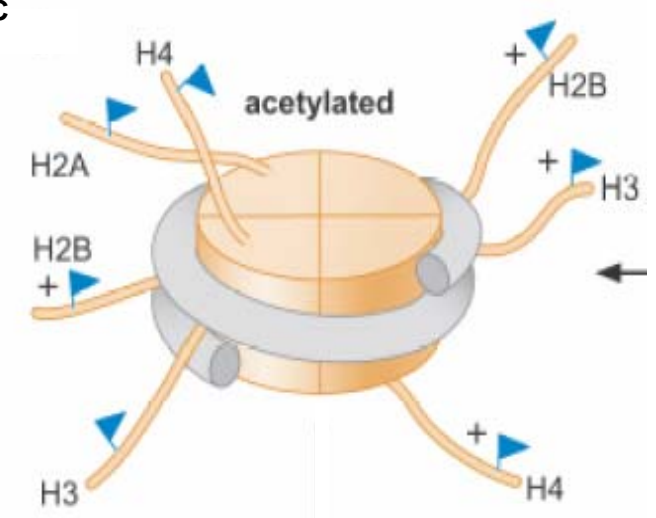

Figure 5. (A) Reversible transition of the chromatin from acetylated to deacetylated state. DNA is negatively charged and histone are positively charged, which leads to the strong histone-DNA interactions. When acetyl groups are added to histone tails, the Histones gain negative charge decreasing their affinity for DNA. Thus the DNA falls of the histone core and is exposed to transcription machinery. (B) Compacted, condensed form or chromatin when DNA is tightly wrapped around the histone octamer, leaving little space for transcriptional activation. (C) Acetylation of N-terminal histone tails leading to transcriptional activation. 


\section{(iv) HDACs}

Histone deacetylases were have been reported in a different biological systems, including several mammalian cell lines and tissues (Taunton et al., 1996), fungi (Waterborg et al, 1982), plants (Sendra et al, 1988) and yeast (Carmen et al, 1999). Several histone deacetylases have been cloned and sequenced (Yang and Seto, 1997; Taunton et al, 1996). Histone deacetylase (HDAC) genes have been isolated and characterised in a number of eukaryotes including humans, mice, chicken (Gallus gallus), fruit-fly (Drosophila melanogaster) and the yeast Saccharomyces cerevisae and Arabidopsis thaliana (Yang and Seto, 2003). It is evident that in all of these organisms, the HDACs form a highly conserved protein family, that encodes isoforms of the enzyme that differ extensively in substrate specificity, intracellular localization and posttranslational modification (Khochbin and Wolffe, 1997).

Three mammalian HDAC isoforms (HDAC1-3) and five yeast HDACs had been identified and several of these were biochemically characterized (Rundlett et al, 1996). These HDACs, taken together with the prokaryotic enzymes acetylspermine deacetylase (ASD) and acetoin utilization protein $(\mathrm{acuC})$, constitute a deacetylase superfamily (Leipe and Landsman, 1997). In yeast, members of this superfamily can be subdivided into two classes based on size and sequence considerations, as well as the observation that AtHDAlp and Hdalp function in biochemically distinct complexes (Robyr et al, 2002). The first class (I) consists of AtHDA1p, Hos $1 \mathrm{p}$, and Hos2p, and the second class contains Hdalp (Fischle et al, 1999). Similarly, in mammals, HDAC1, HDAC2, and HDAC3 conform to class I criteria and three human class II HDAC enzymes, HDAC4, HDAC5, and HDAC6 were found to deacetylate all four core histones in vitro (Groezinger et al, 1999; Fischle et al, 2001). HDAC3, that is the smallest mammalian isoform, can be encoded by at least three different splice variants (Yang et al, 1997) and the 
human HDAC1/HDAC2 proteins are very similar at the amino acid level and are about 60 residues longer than $\mathrm{HDAC} 3$ at the $\mathrm{C}$-termini. This extra domain is quite repetitive and is rich in charged amino acids. An even larger member of the HDAC/AtHDA1 family is the HDA1-p75 component of the HDA histone deacetylase complex in yeast nuclei (Carmen et al,1996; Rundlett et al, 1996). HDA1 is functionally distinct to yeast AtHDA1, that is less sensitive to TSA and contained in the HDB histone deacetylase complex (Rundlett et al, 1996), and HDA1 is not involved in transcriptional regulation of those genes controlled by AtHDA1 (Rundlett et al, 1998). Based on coimmunoprecipitation experiments, these HDACs are not associated with the previously identified NRD and mSin3A complexes that contain HDAC1 and HDAC2, and therefore are likely to be components of distinct complexes that perform alternate functions (Rundlett et al, 1996). The picture appears to be less complicated in Drosophila, that has only two known orthologues of AtHDA1: d-AtHDA1 (De Rubertis et al, 1996), also known as dHDAC1, and dHDAC3 (Johnson et al, 2002). In plants, different $H D A C$ genes have been identified and classified into three distinct gene families (Pandey et al, 2002). The first family, named the $H D A$ gene family, contains members related to the yeast sequences AtHDA1 and HDA1 (Rundlett et al, 1996; Taunton et al, 1996; Rossi et al, 1998; Lechner et al, 2000). This family is further divided into three classes based on their degree of homology with AtHDA1 (class I), HDA1 (class II), or a third group of sequences phylogenetically distinct from the first two classes. The members of the second family of plant $H D A C s$, termed the $S R T$ family, are related to yeast Sir2 (Imai et al, 2000; Frye, 1999). In contrast to other eukaryotes, plants contain a third family of enzymes, the nucleolar-phosphoproteins HD2 (HDT gene family), that appear to be plant-specific (Lusser et al, 1997; Dangl et al, 2001). 
There are three regions of very highly conserved amino acid residues (histidines, aspartates and glycines) that are shared by all members of the HDAC/AtHDA1 family, irrespective of the highly divergent nature of the C-terminal regions (Dangl et al, 2001). These regions are presumed to form part of the active site, since the mutation of conserved aspartate and histidine residues to asparganine or alanine could abolish most, if not all, histone deacetylase activity of HDAC1 (Hassig et al, 1998). In addition, the interactions with the corepressor proteins mSin3A and RpAp48 were lost in all HDAC1 mutants except histidine 141 (Dangl et al, 2001). This suggests that some of the conserved residues are involved in catalysis and others in maintaining the interactions between HDAC1 and other members of the corepressor complex.

\section{(v) HD2-type histone deacetylases}

The HD2-type HDAC gene family was first discovered in maize as a heavy molecular weight acidic nucleolar protein that could be activated/deactivated by phosphorylation (Lusser et al, 1997). Subsequently, this family was uncovered in Arabidopsis thaliana with four genes comprising this group (Wu et al, 2000). A subsequent search with the use of the PSI-BLAST program, that incorporated a conservation profile of two plant histone deacetylases, revealed statistically significant (the probability of a random match was below $10^{-3}$ in each case and was as low as $5 \times 10^{-7}$ for FKB1_SPOFR) sequence similarity to insect proteins identified as FKBP family peptidyl-prolyl cis-trans isomerases (PPIases) and to a trypanosomal RNA-binding protein (Dangl et al, 1997; Altshul et al, 1997). The conserved region included an $\mathrm{NH}_{2}$-terminal domain found in each of these proteins and was distinct from the PPIase domain and the database of expressed sequence tags (ESTs) with these sequences resulted in the characterization of a novel family, that includes proteins from plants, yeast, and two parasitic apicomplexans, Toxoplasma gondii and Cryptosporidium parvum. Thus, this new protein family, HD2, for that 
histone deacetylase activity was predicted, appeared to be widespread among eukaryotes, although the absence of members from vertebrates was conspicuous.

Inspection of the HD2 family alignment shows a number of conserved hydrophobic positions as well as two conserved polar residues (Dangl et al, 2001), namely, an invariant aspartic acid and a histidine, that is replaced by an arginine in the trypanosomal RNA-binding protein Nopp44/46 and in the yeast FKBP (Alnemri et al, 1994). It appears that the invariant aspartic acid is the nucleophile involved directly in lysine deacetylation, that may be facilitated through a charge relay system with the conserved histidine (arginine). Multiple alignment-based secondary structure prediction indicated an all-beta structure for the histone deacetylase domain, without detectable similarity to any known protein fold. The domain organization of the (predicted) histone deacetylases of the HD2 family is of particular interest. In addition to the deacetylase domain, they all contain acidic stretches of various length, that may be diagnostic of nucleolar localization, or of association with basic tails of histones. Besides HD2, nucleolar localization has been shown for the trypanosomal RNA-binding protein Nopp44/46 and for one of the yeast FKBPs, whereas the Spodoptera FKBP46 is a nuclear protein that binds DNA in vitro. The presence of a histone deacetylase and a PPIase in one protein as distinct domains makes functional sense, because in order to be targeted to the specific sites of their action on chromatin, histone deacetylases form complexes with a variety of chromatin-associated proteins. The chaperone-like activity of FKBPs may be required for the proper assembly of such complexes. FK506 binding proteins (FKBPs) are a family of distinct proline isomerases that are targets for a number of clinically important immunosuppressive drugs (Martin et al, 1995). Members of both families catalyze cis/trans isomerization of peptidyl-prolyl bonds that can be a rate-limiting step during protein folding in vitro and in vivo. These proteins are known to play a 
role in stress response pathways in yeast. Alternatively, the FKBP domain of HD2 proteins may be involved in changing the conformation of proline-rich segments in histone $\mathrm{COOH}$-terminal tails, perhaps concomitantly with deacetylation. Additionally, the zinc finger structure at the COOH-terminal of six of the eight HD2 proteins is unique to plant proteins and cannot be observed in the related FKBPs or trapanosomal Nopp44/46 proteins. Because of the nature and spacing of the zinc chelating residues $\left(\mathrm{CX}_{2} \mathrm{CX}_{2-4} \mathrm{FX}_{5} \mathrm{LX}_{2} \mathrm{HX}_{3-5} \mathrm{H}\right)$, they belong to the TFIIIAtype zinc fingers that are involved directly in DNA binding (Takatsuji, 1998). Apart from DNA binding, the zinc fingers can also mediate protein-protein interactions, where individual fingers are sufficient to confer interaction (Mackay and Crossley, 1998). This is well in line with previous results demonstrating that $Z m \mathrm{HD} 2 \mathrm{a}$ was isolated in a $400 \mathrm{KDa}$ protein complex.

In previous studies conducted on the HD2 gene family, one of the members, AtHD2A, was able to mediate transcriptional repression when targeted to the promoter of a reporter gene (Wu et al, 2000). When AtHD2A was knocked out in Arabidopsis thaliana using antisense RNA, the seed development was aborted, indicating that these genes might play a role in seed development. Isolation of HD2 proteins from maize embryos by Lusser et al (2000). implicates that the HD2 family might play a role in the regulation of gene expression essential in embryo development. Additionally, plant growth and yield potential are significantly influenced by various abiotic stresses such as drought, salinity, and cold. A common feature found in plants grown under water stress is a transient increase in the level of the phytohormone abscisic acid (ABA) (Finklestein and Rock, 2002). ABA plays important roles in many aspects of plant growth and development such as embryo maturation, seed dormancy, germination, stomatal aperture, as well as sugar signaling and regulation of expression of stress-responsive genes (Gazzarrini and McCourt, 2001). It is quite interesting to investigate the role of HDACs in 
hormone signaling because little information is available on the involvement of chromatin modifiers in stress signaling.

\section{(vi) ABA-a seed maturation and stress signaling molecule}

When plants transition from heterotrophic to autotrophic growth, the regulation of this phase shift is very tight. Plants have evolved protective mechanisms to ensure their survival under adverse environmental conditions during this transition (Albinsky et al, 1999). Also, plants have developed intrinsic defense mechanisms to tolerate oppressive environmental conditions. The plant hormone abscisic acid (ABA) is the forerunner stress responsive agent that plants produce under these extreme situations. ABA regulates many aspects of plant development and physiology, including seed maturation and dormancy, as well as responses to environmental stress conditions, such as drought, salinity, and low temperature (Fedoroff, 2002; Finkelstein et al, 2002; Himmelbach et al, 2003). Components of the ABA signal transduction pathways (Giraudat, 1995) range from early signaling intermediates such as G proteins and protein kinases/phosphatases, to late stage transcription factors and RNA metabolic proteins (Cowan, 2001). Whereas some components appear to be regulators of multiple ABA responses, few are required for all responses, suggesting that $\mathrm{ABA}$ responses in different cell types or at various developmental stages may differ to certain extent. 
A

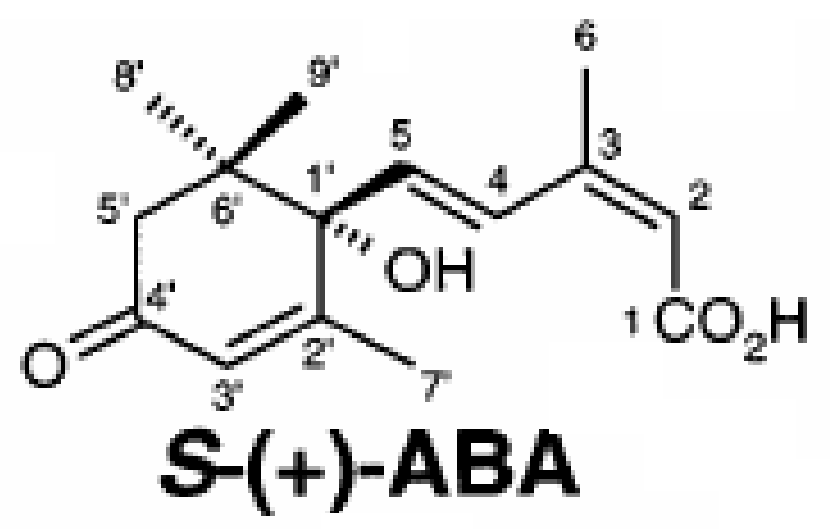

B

\begin{tabular}{|c|c|c|c|}
\hline Name & $\begin{array}{l}\text { Arabidopsis } \\
\text { protein entry } \\
\text { code }\end{array}$ & BAC location & $\begin{array}{l}\text { Predicted cell } \\
\text { localization }\end{array}$ \\
\hline $\begin{array}{l}\text { Zeaxanthin epoxidase } \\
\text { AtZEP }\end{array}$ & At5g67030 & K8A10.10 & Chloroplast \\
\hline $\begin{array}{l}\text { 9-cis-epoxycarotenoid dioxyge } \\
\text { AtNCED1 }\end{array}$ & At3g63520 & MAA21.150 & Cytoplasm \\
\hline $\begin{array}{l}\text { AtNCED2 } \\
\text { AtNCED3 } \\
\text { AtNCED4 } \\
\text { AtNCED5a } \\
\text { AtNCED5b } \\
\text { AtNCED6 }\end{array}$ & $\begin{array}{l}\text { At4g18350 } \\
\text { At3g14440 } \\
\text { At4g19170 } \\
\text { At1g78390 } \\
\text { At1g30100 } \\
\text { At3g24220 }\end{array}$ & $\begin{array}{l}\text { F28J12.10 } \\
\text { MOA2.4 } \\
\text { T18B16.140 } \\
\text { F3F9.10 } \\
\text { T2H7.10 } \\
\text { MUJ8.12 }\end{array}$ & $\begin{array}{l}\text { Cytoplasm } \\
\text { Chloroplast } \\
\text { Chloroplast } \\
\text { Cytoplasm } \\
\text { Chloroplast } \\
\text { Mitochondria }\end{array}$ \\
\hline $\begin{array}{l}\text { Abscisic aldehyde oxidase } \\
\text { AAO1 } \\
\text { AAO2 } \\
\text { AAO3 } \\
\text { AAO4 } \\
\text { Xanthine dehydrogenase } \\
\text { Xanthine dehydrogenase-like } \\
\text { protein }\end{array}$ & $\begin{array}{l}\text { At5g20960 } \\
\text { At3g43600 } \\
\text { At2g27150 } \\
\text { At1g04580 } \\
\text { At4g34900 } \\
\text { At4g34890 }\end{array}$ & $\begin{array}{l}\text { F22D1.130 } \\
\text { F22J12.40 } \\
\text { F20F1.2 } \\
\text { T1G11.17 } \\
\text { F11I11.140 } \\
\text { F11I11.130 }\end{array}$ & $\begin{array}{l}\text { Cytoplasm } \\
\text { Cytoplasm } \\
\text { Cytoplasm }\end{array}$ \\
\hline
\end{tabular}

Figure 6. (A) Structure of ABA, a C-15 compound (Finkelstein and Rock, 2002). (B) Table displaying the different enzymes essential during de novo ABA synthesis in plants (Bray, 2002). 


\section{(vii) Chemical nature of ABA}

ABA is a sesquiterpenoid $\left(\mathrm{C}_{15} \mathrm{H}_{20} \mathrm{O}_{4}\right)$ with one asymmetric, optically active carbon atom at $\mathrm{C}-1$ ' (Finklestein and Rock, 2002). The naturally occurring form is $S-(+)$-ABA (Figure 6). ABA biosynthesis branches from the carotenoid biosynthetic pathway. Many of the genes involved in ABA biosynthesis are members of multi-gene families. Members have identical functions the expression of the genes may control ABA biosynthesis in response to different environmental stimuli or developmental cues and permit regulation of ABA biosynthesis (Holdsworth et al, 1999) in different organs or tissues.

\section{(viii) ABA biosynthetic mutants}

The first-described ABA-deficient mutant of Arabidopsis emerged out of an allelic series of mutations, $a b a$ (now designated $a b a l$ ). These mutant forms were isolated from a suppressor screen of the non-germinating gibberellin- deficient gal mutant (Koornneef et al, 1982). The different enzymes involved in ABA biosynthesis are depicted in Figure 6. The transposontagged, non-dormant wilty mutant of Nicotiana plumbaginifolia (Npaba2) was shown to be orthologous to Arabidopsis abal (Marin et al, 1996), from that the abal gene was first identified. The reduction in AtZEP transcript levels was identified as the molecular basis for two abal mutant alleles (Audran et al, 2001). In seeds of Arabidopsis and tobacco, the $A B A 1 / N p A B A 2$ mRNA level peaks around the middle of development when ABA levels begin to increase. $N p A B A 2$ overexpression in transgenic plants led to increased mRNA levels that increased $\mathrm{ABA}$ levels in mature seeds and delayed germination, while antisense $N p A B A 2$ expression resulted in a reduced $\mathrm{ABA}$ abundance in transgenic seeds and rapid seed germination (Frey et al, 1999). The rice $O s A B A 1$ gene is an orthologue of $A B A 1$ since a transposon-tagged Osabal mutant was viviparous, wilty, and ABA-deficient (Agrawal et al, 2001). Two additional 
Arabidopsis ABA biosynthetic mutants aba2, aba3 (Leon-Kloosterziel et al, 1996) were identified. Screens related to hormones, sugar, salt, or stress has led to discovery of more alleles including $a b a 1, a b a 2$ and $a b a 3$. Protein extracts from $a b a 2$ and $a b a 3$ plants display a reduced ability to convert xanthoxal to ABA (Schwartz et al, 1997). The aba2 mutant is blocked in the conversion of xanthoxal to ABA-aldehyde and aba3 mutant is impaired in the conversion of ABA-aldehyde to ABA (Schwartz et al, 1997). The aao3 mutant is ABA-deficient in leaves and has no detectable AO (Aldehyde Oxidase) activity, but seed dormancy is nearly normal, unlike all other ABA-deficient mutants (Akaba et al., 1998). The epoxy-carotenoid cleavage enzyme (termed NCED, for 9- cis-epoxy-carotenoid dioxygenase) is considered to be the key ABA biosynthetic step, in terms of potential regulation by environmental and developmental cues (Chernys et al, 2000). Ectopic expression of a tomato NCED cDNA causes overproduction of $\mathrm{ABA}$ in tomato and tobacco, that suggests that NCED is rate limiting for ABA biosynthesis (Thompson et al, 2000b). Increased seed dormancy has been reported for transgenic tobacco expressing the bean PvNCED1 (Akaba, 2002). By contrast, drought-intolerant phenotype was evidenced as a result of antisense suppression and T-DNA knockout lines of AtNCED3. It is evident that the de novo production of $\mathrm{ABA}$ is essential for proper seed development and germination. Additionally, it is also a requirement for effective stress signaling in plants when they are faced with environmental challenges.

\section{(ix) ABA signaling}

Once ABA is produced, how does it expedite its physiological effects? Hormone response mutants have traditionally been defined as individuals that resemble mutants with defects in hormone biosynthesis yet can not be restored to a Wild type phenotype by addition of the relevant hormone (Finklestein and Rock, 2002). The genetic screens and selections that have 
been used to date include production of non-dormant seeds (Koornneef et al, 1982), loss or gain of sensitivity to ABA at germination (Koornneef et al, 1984; Finkelstein, 1994; Cutler et al, 1996), seedling growth (Lopez-Molina and Chua, 2000), root growth (Himmelbach et al, 1998), misexpression of reporter genes (Ishitani et al, 1997; Foster and Chua, 1999; Delseny et al, 2001) and screens for suppressors or enhancers of GA-deficient non-germinating lines or $A B A$ INSENSITIVE (ABI) lines (Steber et al, 1998; Beaudoin et al, 2000; Ghassemian et al, 2000). Additional mutants have been isolated with defects in responses to multiple signals, including $\mathrm{ABA}$, via non-ABA-based screens such as salt-resistant germination (Quesada et al, 2000), sugar-resistant seedling growth or gene expression (Arenas-Huertero et al, 2000; Huijser et al, 2000; Laby et al, 2000; Rook et al, 2001), or defects in auxin, brassinosteroid or ethylene response (Wilson et al, 1990; Alonso et al, 1999; Ephritikhine et al, 1999; Li et al, 2001). Broadly speaking, the $\mathrm{ABA}$ response mutants can be categorized into two groups. $\mathrm{ABA}$ hypersensitive mutants include mutations in protein farnesylation agent ERA1, Inositol signaling agent FRY1 and RNA processing and turnover agents $A B H 1, H Y L 1, S A D$ (Finklestein and Somerville, 1990). ABA insensitive mutants include phosphatases, $A B I 1$ and $A B I 2$ and transcription factors $A B I 3, A B I 4$ and $A B I 5$. Another set of mutants isolated in a screen for ABA resistant root-growth was the growth control by ABA (gcal-gca8) mutants (Finklestein et al, 2002). 


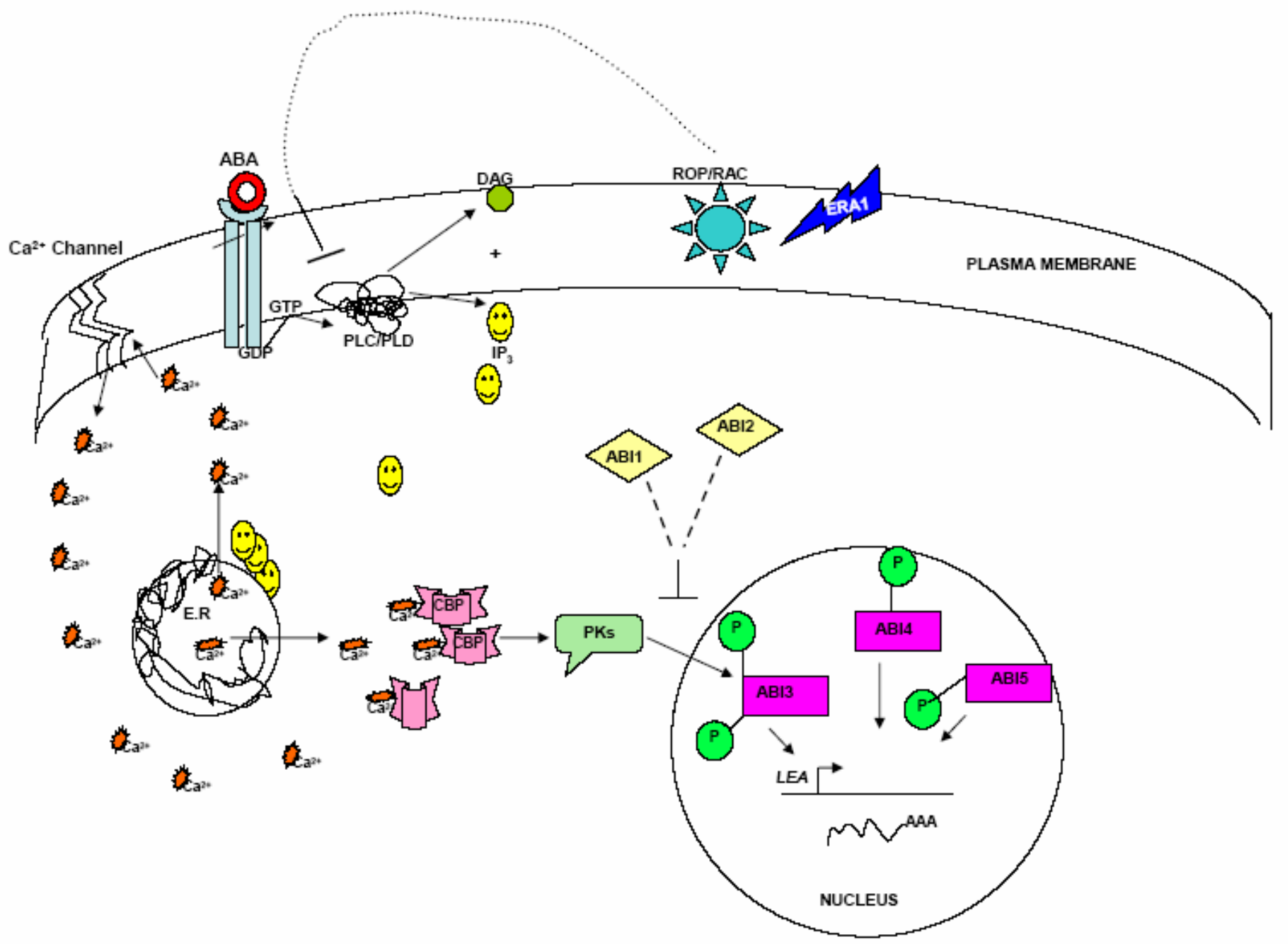


Figure 7. Model for ABA mediated signal cascade in Arabidopsis. Once ABA binds to its receptor (putative) on the membrane, which is a G-protein coupled receptor, it induces the exchange for a GTP molecule. This event activates the PLD/PLC enzymes which produce DAG and IP3. Subsequently, IP3 travels into the cytosol and activates the ER Ca2+channel. $\mathrm{Ca} 2+$ release into the cytosol generates more $\mathrm{Ca} 2+$ channels to open from the plasma membrane. This intracellular $\mathrm{Ca} 2+$ is bound by Calcium binding proteins (CBPs), which can activate the protein kinases (PKs). The activated PKs can travel to the nucleus and phosphorylate the ABI transcription factors, thus activating them, leading to LEA synthesis. ERA1 inhibits this cascade by recruiting the Rop/Rac GTPases to the membrane. Also, the ABI1/ABI2 proteins dephosphorylate the phosphoproteins (PKs?) to inhibit activation of nuclear ABI transcription factors. The arrows indicate activation an the perpendicular bars indicate repression. 


\section{(x) Known signaling cascade}

Biochemical and pharmacological studies have shown that early events in ABA signaling involve participation of GTP binding proteins, phospholipases (Hirayama et al, 1995), protein kinases (Cadenas et al, 1999) and phosphatases (Gosti et al, 1999). Downstream signaling includes transcription factors that expedite signals at the development level. Figure 7 illustrates is a schematic of how the signaling might be regulated at various steps. In the plasma membrane, a putative ABA receptor has been shown to induce PLD (Phospholipase D) activity (Gampala et al, 2001; Fan et al, 1997; Katagiri et al, 2001). Also, transgenic studies have shown that the small GTPase Rop6/AtRac1 can inhibit ABA effects on actin cytoskeleton reorganization in guard cells (Hwang et al, 2001), that might indicate G-protein nature for this putative receptor (Hong et al, 1997). After contact with ABA, this receptor will activate PLD/PLC (Phospholipase C) activity to produce DAG (Diacyl glycerol) and $\mathrm{IP}_{3}$ (Inositol triphosphate). $\mathrm{IP}_{3}$ will induce $\mathrm{Ca}^{2+}$ release from intracellular stores and this will led to $\mathrm{Ca}^{2+}$ induced $\mathrm{Ca}^{2+}$ release from the plasma membrane channels (Hamilton et al, 2000). This $\mathrm{Ca}^{2+}$ elevation will led to the activation of protein kinases that can travel into the nucleus and phosphorylate transcription factors such as ABI4 and ABI5 (Knetsch et al, 1996). Both the ABI4 and ABI5 gene products contain Ser/Thrrich domains that could be sites of phosphorylation (Finkelstein et al, 1998; Finkelstein and Lynch, 2000) and recent studies have demonstrated that ABI5 protein is stabilized by ABA induced phosphorylation (Lopez-Molina et al, 2001). This could further led to the activation of these transcription factors, thus allowing development signals to proceed. The ERA1 protein acts as a negative regulator of this process, by adding farnesyl groups to the GTPases that tether them to the membrane, thus recruiting them to the G protein coupled receptors (Cutler et al, 1996). Additionally, phosphatases such as ABI1 (Gosti et al, 1999; Hagenbeek et al, 2000) and ABI2 
might dephosphorylate protein kinases thereby inactivating them, leding to inactivation of ABI4 and ABI5. Although either ABI4 or ABI5 could be a substrate for dephosphorylation by the ABI PP2Cs, consistent with a negative regulatory role for the PP2Cs, neither interacts with ABI1 in a two-hybrid assay (Nakamura et al, 2001) despite showing strong genetic interactions as digenic mutants (Finkelstein, 1994).

\section{(xi) ABA signaling in maturing seed germination and growth}

When developing embryos undergo a transition into the maturation phase (Holdsworth et al, 1999), they arrest growth by inhibiting cell division and inducing cell enlargement and begin to accumulate storage reserves (Figure 8). This growth phase transition is correlated with a subsequent increase in seed $\mathrm{ABA}$ content that appears to be required for cell cycle arrest at the G1/S transition (Levi et al, 1993; Liu et al, 1994). LEC gene function is required to prevent premature germination at the end of the cell division phase of embryogenesis (Raz et al, 2001). LEC works in conjunction with cyclin-dependent kinase inhibitors such as ICK1. This level of control is achieved by the maternal peak of ABA in the first phase of maturation (Karssen et al, 1983). In the second phase of maturation, the embryonic peak of ABA allows the LEA (late embryogenesis abundant) proteins to accumulate. These signals induce accumulation of protectants such as small hydrophilic proteins, sugars, proline, and glycine-betaine, that serve as storage reserves and prepare the seed for desiccation (Bray, 2002). ABI3, ABI4 and ABI5 are essential for maintaining the dormancy of the seed and LEA synthesis. Ectopic expression of either $A B I 3$ or $A B I 4$ results in ABA hypersensitivity of vegetative tissues, including ABAinducible vegetative expression of several "seed-specific" genes, that is partly dependent on increased ABI5 expression (Parcy et al, 1994; Söderman et al, 20 00). Additionally, ABI3 and 

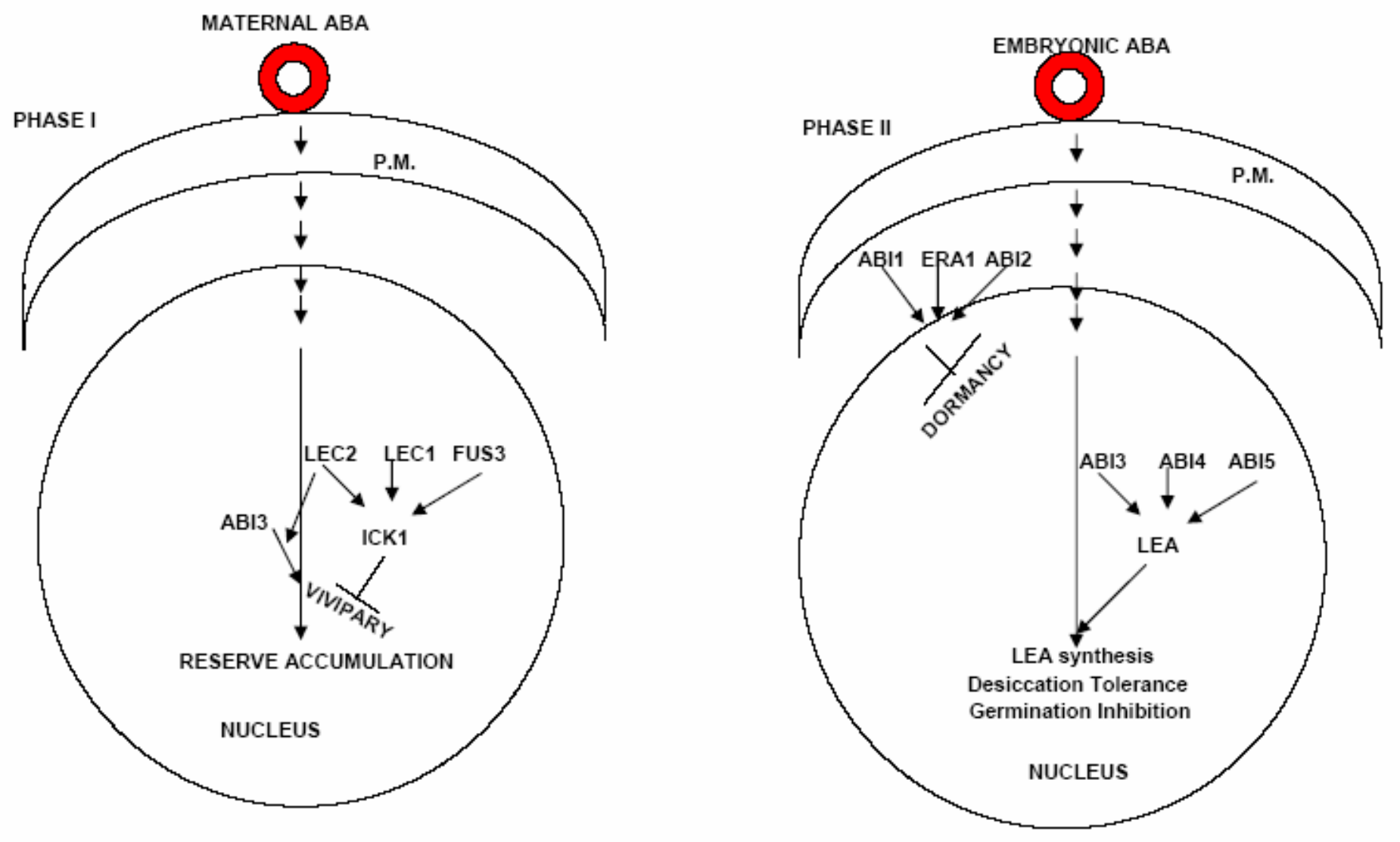
Figure 8. Model for ABA signaling during embryo-development. Left; Phase I of seed maturation when $\mathrm{ABA}$ is of maternal origin. $\mathrm{ABA}$ signals travel through the plasma membrane and cytosol and reach the nucleus probably via a MAP Kinase like pathway. Once in the nucleus, essential transcription factors like LEC, which control cell cycle are activated. Also, reserve accumulation promoting actors like ABI3 are activated. Right; Phase II of seed maturation is initiated by a second peak of ABA contributed by the embryo. This time, nuclear transcription factors ABI4 and ABI5 are activated in addition to LEC1 and ABI3. These factors promote LEA synthesis and desiccation tolerance. This dormancy property is down-regulated by ABI1/ABI2 and ERA1 as they disrupt the signals from reaching the nucleus. The arrows indicate activation an the perpendicular bars indicate repression. 
ABI5 display direct and synergistic interactions in two-hybrid analyses in yeast and transient reporter activation assays in rice protoplasts (Hobo et al, 1999; Gampala et al, 2001; Nakamura et al, 2001).

The commitment to germinate is also controlled by antagonistic interactions between ABA and gibberellins, ethylene, and brassinosteroids (BR) (Finklestein et al, 2002). The ability to induce ABI5 accumulation is strongly correlated with maintenance of desiccation tolerance in these seedlings. ABA, the induced ABI5, and potentially other interacting factors may prevent the loss of desiccation tolerance by delaying escape from phase two of germination under conditions of low moisture (Lopez-Molina et al, 2001). Although the precise roles of the $A B I s$ in regulating lateral root growth are not understood, it is noteworthy that $A B I 5$ is specifically expressed in root tips from emergence onward (Brocard et al, 2002). A putative model for the ABA signal cascade during this phase is presented in Figure 9.

$A B I 3$ expression is localized to the meristem and appears to regulate vegetative quiescence processes, plastid differentiation, and floral determination (Rohde et al, 1999; Kurup et al, 2000). During stress imposition upon plants, there is a concomitant increase in ABA and its signaling molecules. Many of these encode proteins that are structurally similar to some of the LEA proteins that accumulate during the acquisition of desiccation tolerance in seeds, while others encode proteases, presumed chaperonins, enzymes of sugar or other compatible solute metabolism, ion and water-channel proteins, and enzymes that detoxify active oxygen species (Bray, 2004). Drought signals and osmotic shock induce ABA synthesis in the plant system and this has direct effects on stomatal aperture in addition to cell development ABA activates rise in intracellular $\mathrm{Ca}^{2+}$ that led to activation of S-type anion channel activity that ultimately led to the de-polarization of the guard cells (Hwang et al, 2001). The series of chemical events that take place upon ABA activation are diagramed in Figure 10. 


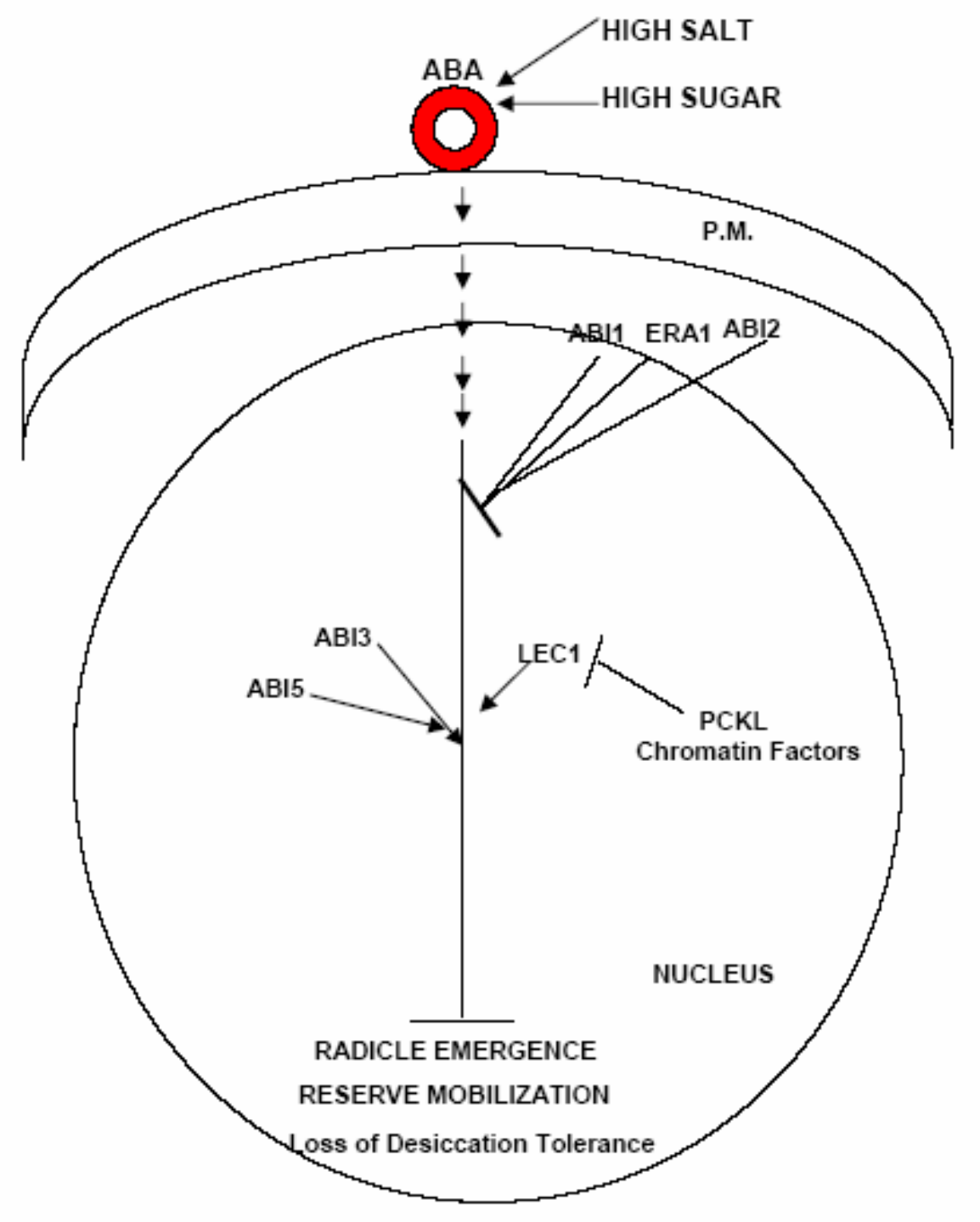


Figure 9. Model for ABA signaling during germination-post germination phase. During this phase transition, ABA signaling has to be down-regulated to allow germination, the PCKL (PcG proteins) are known to repress LEC1 in non-seed maturation growth stages. The arrows indicate activation and the perpendicular bars indicate repression. 


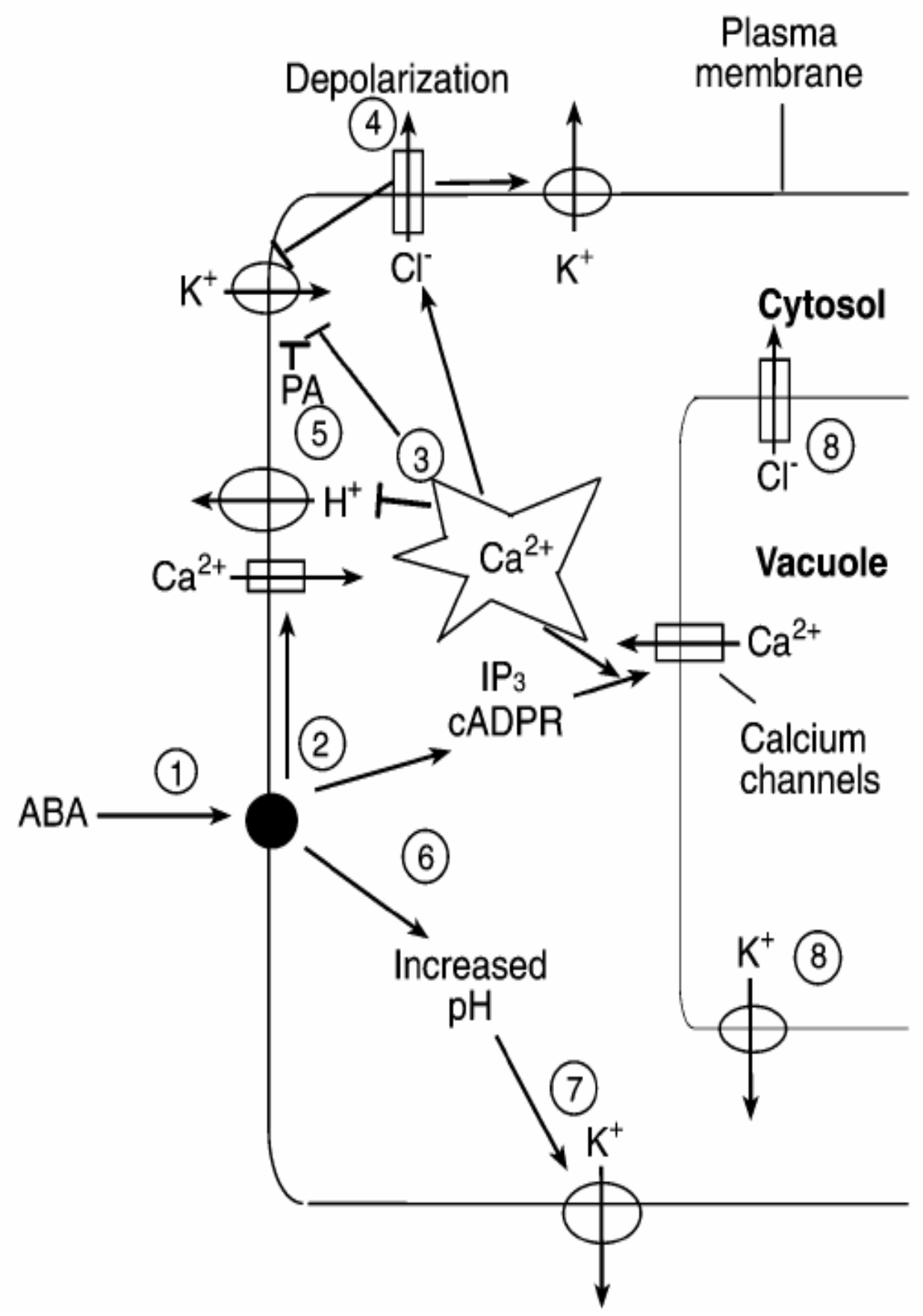


Figure 10. Model for ABA signaling in stomatal guard cells.

(1) ABA binds to as yet uncharacterized receptor(s). Although shown here on the plasma membrane, there is evidence for both intra- and extra-cellular perception. (2) ABA induces oscillating increases in cytosolic via production of reactive oxygen species that contribute to opening of plasma membrane $\mathrm{Ca}^{2+}$ in channels -release from internal stores through three types of $\mathrm{Ca}^{2+}$ channels regulated by IP3 (produced by phospholipase C), cyclic ADPribose (cADPR), and $\mathrm{Ca}^{2+}$ itself. (3) The increased $\mathrm{Ca}^{2+}$ inhibits plasma membrane $\mathrm{H}^{+}$pumps -inhibits $\mathrm{K}^{+}$in channels, and -activates Clout (anion) channels, resulting in depolarization of the membrane. (4) Depolarization activates $\mathrm{K}^{+}$out and further inhibits $\mathrm{K}^{+}$in channels. (5) ABA induces PLDmediated production of phosphatidic acid (PA), which inactivates $\mathrm{K}^{+}$in channels. (6) ABA causes an increase in cytosolic $\mathrm{pH}$ which (7) activates $\mathrm{K}^{+}$out channels and inhibits $\mathrm{H}^{+}$pump activity by depleting the substrate) (8) $\mathrm{K}^{+}$and anions to be released across the plasma membrane are first released into the cytosol from guard cell vacuoles. The net result is that $\mathrm{K}^{+}$and anions leave the guard cell, guard cell turgor decreases, and the stomata close. These electrophysiological and volume changes are accompanied by, and require, reorganization of the actin cytoskeleton and at least a two-fold change in plasma membrane surface area (Finkelstein and Rock, 2002). 


\section{METHODS AND MATERIALS}

\section{(i) DNA and protein sequence analysis}

DNA and protein sequence analysis was carried out using blast searches (Altschult et al 1990) and the vector NTI suite program (InforMax Inc., Bethesda, MD, USA).

\section{(ii) RT-PCR analysis}

One microgram of total RNA was used for the first-strand cDNA synthesis after incubation at $65^{\circ} \mathrm{C}$ for $10 \mathrm{~min}$ as described by Weigel and Glazebrook, (2002). cDNA was synthesized in a volume of $20 \mu 1$ that contained MoMLV RT buffer (Promega, Madison, WI, USA), $10 \mathrm{~mm}$ dithiothreitol, $1.5 \mu \mathrm{m}$ poly (dT) primer, $0.5 \mathrm{~mm}$ dNTPs, $2 \mathrm{U}$ of MoMLV RT at $37^{\circ} \mathrm{C}$ for $1 \mathrm{~h}$. All PCR reactions were performed with $0.5 \mathrm{U}$ of Taq polymerase (PGC Scientific, Gaithersburg, MD, USA), the buffer provided by the supplier, $0.2 \mu \mathrm{M}$ dNTPs, and a pair of primers $(0.1 \mu \mathrm{M}$ each) in a final volume of $20 \mu \mathrm{l}$. PCR parameters differed for each gene: thermocycling conditions were $94^{\circ} \mathrm{C}$ for 2 min followed by $25-40$ cycles of $94^{\circ} \mathrm{C}$ for $1 \mathrm{~min}$, $62-65^{\circ} \mathrm{C}$ for $1 \mathrm{~min}$, and $72^{\circ} \mathrm{C}$ for $2 \mathrm{~min}$, with a final polymerization step at $72^{\circ} \mathrm{C}$ for $10 \mathrm{~min}$. The primers used for RT-PCR are listed in Table VI. The primers used for the HD2 family spatial profiling are listed in Table $\mathrm{V}$ (21N2pr1/21N2pr4, HD2Bpr3/HD2Bpr4, HD2Cpr3/HD2Cpr4, and HD2Dpr1/HD2Dpr2). The primers used for subcloning the HD2 genes and primers used for their RT-PCR profiling are the same.

\section{(iii) GFP localization}

Protoplasts were isolated from Arabidopsis seedlings as described by Wigel and Glazebrook (2002). Transgenic seedlings germinated in the dark to reduce chlorophyll content) were 
macerated and incubated in enzyme solution (Maceroenzyme R10 and Cellulase R10) for 10 minutes. Subsequently, the tissue-enzyme mixture was subjected to vacuum for thirty minutes. The solution was then incubated at room-temperature shaking for 90 minutes at 40 rpm, after that the solution was filtered through a $70-\mu \mathrm{m}$ nylon mesh and ready for use. The fluorescence photographs of protoplasts were taken using an Olympus florescent microscope fitted with fluorescein isothiocyanate filters (excitation filter, $450-490 \mathrm{~nm}$; emission filter, $520 \mathrm{~nm}$; and dichroic mirror, $510 \mathrm{~nm}$ ).

\section{(iv) Particle gun-delivery assays}

Tobacco (SR1) plants were grown in vitro in half-strength MS medium (Murashige and Skoog, 1962) in Magenta boxes (Magenta Corp., Chicago, USA) and kept in a growth chamber at $25^{\circ} \mathrm{C}$. After transfer to fresh medium for 2-3 weeks, uniform-sized leaves (about $3 \mathrm{~cm}$ in width) were cut off from the plants and placed on a medium consisting of MS salts, B5 vitamins (Gamborg et al, 1968), $1 \mathrm{mg}^{-1}$ 6-benzyladenine, $0.1 \mathrm{mg}^{-1}$ naphthalene acetic acid, $3 \%$ sucrose, and $0.25 \%$ Gelrite in a $20 \mathrm{~mm} \times 15 \mathrm{~mm}$ Petri dish. The leaves were preconditioned on this medium for 1 day prior to gene delivery. Plasmid DNA was isolated using the Qiagen Plasmid Midi Kit (Qiagen, Valencia, CA, USA). The reporter plasmid was

mixed with an effector plasmid at a 1: 1 ratio (weight). In the control, the reporter plasmid was mixed with an equal amount of the control plasmid pUC19. A modified particle inflow gun (Brown et al, 1994) was used for DNA delivery to the tobacco leaves. Twenty-four hours after bombardment, GUS gene expression was determined by recording the number of GUS reporter gene expression events as indicated by the number of blue foci per explant (Jefferson et al, 1987). 


\section{(v) Promoter Motif Analysis}

To identify potential stimulus responsive $c i s$-elements in the $A t H D 2 B$ and $A t H D 2 C$ promoter, sequence $3000 \mathrm{bp}$ upstream to the transcription start site of the genomic AtHD2B and AtHD2C was submitted to PlantCARE database at the TAIR cis-element resource website (http://oberon.fvms.ugent.be:8080/PlantCARE/index.html). The motifs of interest were grouped appropriately.

\section{(vi) Histochemical GUS staining}

Transgenic tissue expressing promoter driven GUS was harvested and incubated in $\beta$ glucuronide solution for a period of 12 hours at $37^{\circ} \mathrm{C}$. Whole plants were immersed in $1 \mathrm{mM}$ 5-bromo-4-chloro-3-indolyl-glucuronic acid solution in $100 \mathrm{mM}$ sodium phosphate, $\mathrm{pH} 7.0$, $0.1 \mathrm{mM}$ EDTA, $0.5 \mathrm{mM}$ ferricyanide, $0.5 \mathrm{mM}$ ferrocyanide, and $0.1 \%$ Triton $\mathrm{X}-100$.

\section{(vii) ABA and salt treatment of the GUS transgenic lines}

The AtHD2C promoter:GUS transgenic seedlings were germinated in MS medium free of $\mathrm{ABA}$ or salt. Two to six day old seedlings were transferred onto media containing $100 \mu \mathrm{M}$ of ABA for 6 hours. Also, these seedlings were transferred to medium containing $200 \mathrm{mM} \mathrm{NaCl}$ for 6-12 hours. Subsequent to the treatment, the seedlings were incubated in the X-gluc staining solution at $37^{\circ} \mathrm{C}$ for 12 hours.

\section{(viii) Plasmid constructions}

For each of the plasmid constructs, the general procedure (Sambrook and Russell, 2001) was followed. The sequences to be cloned were amplified by PCR (Table I) from either cDNA templates or from genomic DNA sequences prepared from plant extracts. The primers used to amplify these sequences contained restriction sites in their 5' ends. Simultaneously, the vector 
into that the sequence was to be inserted was digested (Table II) with the same restriction enzymes. Subsequently, the amplified DNA sequences and the digested vector (excised band from gel) were purified using the Qiagen DNA purification kit. The DNA fragments were digested with restriction enzymes and purified once again after digestion. Then the purified vector as well as the cDNA fragments were mixed together in a ligation (Table III) reaction. The ligation reaction was transformed into $E$. coli. The bacteria were plated on LB medium containing either ampicillin or kanamycin and colonies resistant to antibiotics were selected. The transformants were then used to isolate plasmid DNA. This plasmid DNA was digested with restriction enzymes specific to each clone and electrophoresed to identify vector and insert. This would confirm that the colony carried the desired construct. The list of enzymes and primer sequences used for different constructs is provided in Table IV.

\section{(a) E. coli transformation}

Electro-competent cells (Top 10 or DH5- $\alpha$ ) that are pre-prepared were retrieved from their $-80^{\circ} \mathrm{C}$ storage and were thawed on ice. At the same time cuvettes for the transformation are UVsterilized. Subsequently, 1-2 $\mu 1$ of the ligation reaction mix was added into the melted competent cells and mixed. The mixture was then transferred into the cuvette cavity and the cuvette was then placed in the electroporater (Bio-Rad MicroPulser). The cuvette was pulsed with an electric shock for a millisecond. The cuvette was then removed from the electroporater and $1 \mathrm{ml}$ of sterile LB medium was used to wash the cavity of the cuvette. This medium carrying the transformed cells was then incubated with shaking at $37^{\circ} \mathrm{C}$ for 1 hour. Subsequently, the 
Table I Standard PCR reaction used for all reactions

\begin{tabular}{|l|c|c|}
\hline \multicolumn{1}{|c|}{$\begin{array}{c}\text { Contents of } \\
\text { Reaction } \\
\text { Buffer }\end{array}$} & $\begin{array}{c}\text { Supplier } \\
\text { Company }\end{array}$ & Amount \\
\hline $25 \mathrm{mM} \mathrm{MgCl}{ }_{2}$ & Promega & $5 \mu \mathrm{l}$ \\
\hline $2.5 \mathrm{mM} \mathrm{dNTP}$ & Promega & $3 \mu \mathrm{l}$ \\
\hline DNA template & Own & $1 \mu \mathrm{l}$ \\
\hline Primer1 & Invitrogen & $1 \mu \mathrm{l}$ \\
\hline Primer2 & Invitrogen & $1 \mu \mathrm{l}$ \\
\hline Taq Polymerase & Promega & $1 \mu \mathrm{l}$ \\
\hline Distilled Water & Own & $35 \mu \mathrm{l}$ \\
\hline Total Volume & & $50 \mu \mathrm{l}$ \\
\hline
\end{tabular}

Template amount and $\mathrm{MgCl}_{2}$ amount was changed from time to time when the give quantities were not sufficient to give enough PCR product. PCR reaction tubes are set up for required (20-30) amount of cycles at calculated annealing temperature in the automated thermocycler. 
Table II Standard double restriction enzyme digestion for all reactions used

\begin{tabular}{|l|c|c|}
\hline Contents of Reaction & Supplier Company & Amount \\
\hline 10X Reaction Buffer & New England Biolabs & $2 \mu 1$ \\
\hline DNA to be digested & Self-prepared & $8 \mu 1$ \\
\hline Restriction Enzyme 1 & New England Biolabs & $1 \mu 1$ \\
\hline Restriction Enzyme 2 & New England Biolabs & $1 \mu 1$ \\
\hline double distilled Water & Self-prepared & $8 \mu 1$ \\
\hline Total volume & & $20 \mu 1$ \\
\hline
\end{tabular}

If the amount of DNA was increased for the reaction $(20 \mu 1)$ then the reaction volume was increased to $40 \mu 1$. Reaction volume should always be $10 \mathrm{X}$ of that of the reaction buffer. Therefore for $40 \mu 1,4 \mu 1$ of buffer would be added. The reaction buffer is to be chosen carefully considering maximum enzyme efficiency for both enzymes being used. Usually, the Multicore buffer is an all-purpose buffer. Restriction digestion reaction tubes are set at $37^{\circ} \mathrm{C}$ overnight for complete digestion. 
Table III. Standard Ligation reaction used for all reactions

\begin{tabular}{|l|l|c|}
\hline \multicolumn{1}{|c|}{$\begin{array}{c}\text { Contents of } \\
\text { Reaction }\end{array}$} & \multicolumn{1}{|c|}{$\begin{array}{c}\text { Supplier } \\
\text { Company }\end{array}$} & Amount \\
\hline 10X Ligation Buffer & Promega & $1 \mu \mathrm{l}$ \\
\hline $\begin{array}{l}\text { Vector DNA } \\
\text { (digested) }\end{array}$ & Own & $2 \mu 1$ \\
\hline $\begin{array}{l}\text { Insert DNA } \\
\text { (digested) }\end{array}$ & $\begin{array}{l}\text { New England } \\
\text { Biolabs }\end{array}$ & $2 \mu 1$ \\
\hline T4 DNA Ligase & $\begin{array}{l}\text { New England } \\
\text { Biolabs }\end{array}$ & $1 \mu 1$ \\
\hline Distilled Water & Own & $4 \mu 1$ \\
\hline Total Volume & & $10 \mu 1$ \\
\hline
\end{tabular}

Ligation reactions are set up at room temperature for 1 hour or at $4^{\circ} \mathrm{C}$ overnight. 
Table IV. Primers, restriction enzymes, selective media and vectors used in subcloning

\begin{tabular}{|c|c|c|c|c|}
\hline CONSTRUCTS & VECTOR & $\begin{array}{l}\text { SELECTION } \\
\text { Bact/Plants }\end{array}$ & $\begin{array}{c}\text { RESTRICTION } \\
\text { Digest }\end{array}$ & $\begin{array}{l}\text { PRIMER } \\
\text { Pairs }\end{array}$ \\
\hline $35 S: H D 2 B$ & pCAMBIA1302 & $\underline{\mathrm{Kan}} / \mathrm{Hyg}$ & $5^{\prime} \mathrm{NcoI} / 3^{\prime} \mathrm{Bg} I \mathrm{III}$ & $\begin{array}{l}\text { HD2Bpr3 } \\
\text { HD2Bpr4 }\end{array}$ \\
\hline $35 S: H D 2 C$ & pCAMBIA1302 & $\underline{\mathrm{Kan}} / \mathrm{Hyg}$ & $5^{\prime} \mathrm{NcoI} / 3^{\prime} \mathrm{Bg} \mathrm{glII}$ & $\begin{array}{l}\text { HD2Cpr3 } \\
\text { HD2Cpr4 }\end{array}$ \\
\hline HD2Bpro:GUS & pCAMBIA1381 & $\underline{\mathrm{Kan}} / \mathrm{Hyg}$ & 5'SalI/3'NcoI & $\begin{array}{l}\text { HD2Bpropr1 } \\
\text { HD2Cpropr2 }\end{array}$ \\
\hline HD2Cpro:GUS & pCAMBIA1381 & $\underline{\mathrm{Kan}} / \mathrm{Hyg}$ & $\begin{array}{c}5^{\prime} \mathrm{EcoRI} / 3^{\prime} \text { HindII } \\
\text { I }\end{array}$ & $\begin{array}{l}\text { HD2Cprpr3s } \\
\text { HD2Cpropr2 }\end{array}$ \\
\hline$p G 4 B D H D 2 B$ & pGBD21-C3 & Ampicillin & 5'EcoRI/3'BglII & $\begin{array}{l}\text { HD2Bpr7 } \\
\text { HD2Bpr4 }\end{array}$ \\
\hline$p G 4 B D H D 2 C$ & pGBD21-C3 & $\underline{\text { Ampicillin }}$ & $5^{\prime} \mathrm{XmaI} / 3^{\prime} \mathrm{Bg} 1 \mathrm{III}$ & $\begin{array}{l}\text { HD2Cpr3 } \\
\text { HD2Cpr4 }\end{array}$ \\
\hline 35S:GAL4-HD2A(4) & pCAMBIA2300 & $\underline{\text { Kanamycin }}$ & 5'XmaI/3'SacI & $\begin{array}{l}\text { PRM1s } \\
\text { PR4 }\end{array}$ \\
\hline 35S:GAL4-HD2A(H25A) & pCAMBIA2300 & $\underline{\text { Kanamycin }}$ & 5'XmaI/3'SacI & $\begin{array}{l}\text { FM1a/PR1 } \\
\text { RM1S/PR4 }\end{array}$ \\
\hline 35S:GAL4-HD2A(D69A) & pCAMBIA2300 & $\underline{\text { Kanamycin }}$ & 5'XmaI/3'SacI & $\begin{array}{l}\text { FM2a/PR1 } \\
\text { RM2S/PR4 }\end{array}$ \\
\hline
\end{tabular}


Table V Primers and their sequences used for subcloning

\begin{tabular}{|c|c|}
\hline PRIMERS & SEQUENCE \\
\hline $21 \mathrm{~N}_{2} \mathrm{pr} 1$ & 5'atggagttctggggaatttg 3' \\
\hline $21 \mathrm{~N}_{2} \mathrm{pr} 4$ & 5'cgtgcttggecttgttgtgag3' \\
\hline HD2Bpr3 & 5'atggagttctggggtgttgaag3' \\
\hline HD2Bpr4 & 5'tcaagcagctgcactgtgtttg-3' \\
\hline HD2Bpr7 & 5'aattgaattcatggagttctggggagttg3' \\
\hline HD2Cpr3 & 5'atggagttctggggtgttgaag3' \\
\hline HD2Cpr4 & 5'tcaagcagctgcactgtgtttg3' \\
\hline HD2Dpr1 & 5'atggagttttggggtatcg3' \\
\hline HD2Dpr2 & 5'ctactttttgcaagagggac3' \\
\hline UBQpr1 & 5'gatctttgccggaaaacaattggaggatggt3' \\
\hline UBQpr2 & 5'gacttgtcattagaaagaaagagataacagg3' \\
\hline HD2Bpropr1 & 5'aattgtcgacatgcagtgattagggaagag3' \\
\hline HD2Cpropr2 & 5'atatccatggttgttgaacgaggaagagag3' \\
\hline HD2Cprpr3s & 5'aattgaattcgcaaagctaaaagaggaac' \\
\hline HD2Cpropr2 & 5'atataagcttgtgcgaggtagtgtgatc 3 ' \\
\hline HD2Cpr3 & 5'atggagttctggggtgttgaag3' \\
\hline HD2Cpr4 & 5'tcaagcagctgcactgtgtttg3' \\
\hline PRM1s & 5'aattcccgggaattgaagttaaatcaggaaagc3' \\
\hline PR4 & 5'acgtgagctcagaaaccacttcacttggc 3 ' \\
\hline FM1a & 5'ctgagaaacggcgataagaatgcettcttcag3' \\
\hline RM1S & 5'cattcttatcgecgtttctcaggcatcgettg3' \\
\hline FM2a & 5 'tccccaagtggcagaaagctcaaactccttg3 \\
\hline RM2S & 5'gagctttctgccacttggggaaaaggaagtg 3 \\
\hline
\end{tabular}


Table VI Primers sequences used for RT-PCR

\section{SEQUENCES}

\begin{tabular}{|c|c|}
\hline LEC 5 , & 5'ctgataatgccettctgagc 3 ' \\
\hline LEC 3' & 5'tctttaagaggcaagaccc3' \\
\hline RD29B 5 & 5'gataccttccgaccagatagc3' \\
\hline RD29B 3' & 5'cgaaaaccccatagtcccaac3' \\
\hline RAB18 5 & 5'cagctctagctcggaggatg 3 ' \\
\hline RAB18 3' & 5'ccgggaagcttttccttgatc3' \\
\hline ICK1 5 & 5'gaggaaaacgatggaggagac3' \\
\hline ICK1 3' & 5'ctaatggettctccttctcg3' \\
\hline ADH1 5, & 5'aactgcagacggattagaagccgccgagcgggtgacagccetccgagcttgcatgcaacttcttttc3' \\
\hline ADH1 3' & 5 'ttgcaagcttcatggagttgattgtatgcttgg 3 ' \\
\hline ABI1 5 & 5'gccatgtcgagatccattgg3' \\
\hline ABI1 3' & 5'aacgatgcatccccagccac3' \\
\hline ABI2 5 & 5'caagatccattggcgatagatacc 3 ' \\
\hline ABI2 3' & 5'cctcttttctccgeccggaag3' \\
\hline AREB 5 & 5'gaagccagatgtcacctgat3' \\
\hline AREB 3' & 5'caatgtcettcgcaagcatt3' \\
\hline KAT1 5 & 5'cttcatgaaacttagagggcaac3' \\
\hline KAT1 3' & 5'ccactttggctctctctatc $3^{\prime}$ \\
\hline KAT2 5 & 5'aggttgctctgatgcagatc3' \\
\hline KAT2 3' & 5'ccgcattcgtgacctttgtg 3 ' \\
\hline SKOR 5 & 5'gtggctccaaagagcctaaag3' \\
\hline SKOR 3' & 5'acacaagaagcctccggaac3' \\
\hline GFPpr1 & 5'actgtctagaccatggtagatctgact $3{ }^{\prime}$ \\
\hline GFPpr3 & 5'aattgggeccetagctttgtatagttcatcc 3 ' \\
\hline
\end{tabular}


transformed cells are plated onto ampicillin / kanamycin containing LB medium plate (Sambrook and Russell, 2001)

\section{(b) Plasmid DNA isolation}

Transformed colonies were inoculated into $2 \mathrm{ml} \mathrm{LB}$ medium containing selective antibiotics (amp/kan) overnight. Next day, $1.5 \mathrm{ml}$ of culture was spun in eppendorf tubes for 1 minute. Supernatant was poured off and the $200 \mu \mathrm{l}$ of cell resuspension solution was added to the pellet. After dissolving the pellet, $200 \mu \mathrm{l}$ of cell-lysis solution was added. After mixing the solution, neutralization buffer was added. Subsequent to mixing, the tubes were spun for 5 minutes. Supernatant was retrieved and mixed with $0.5 \mathrm{ml}$ of $100 \%$ ethanol. DNA pellet was retrieved and washed with 75\% ethanol (Sambrook and Russell, 2001). Subsequently, the pellet was air-dried and dissolved in $1 \mathrm{X}$ TE buffer and stored in $-20^{\circ} \mathrm{C}$.

\section{(ix) Plant transformation and growth}

(a) Transformation

Arabidopsis thaliana (ecotype Columbia) plants were grown in a growth chamber (16 h of light and $8 \mathrm{~h}$ of darkness at $23^{\circ} \mathrm{C}$ ) after a 2-4-day vernalization period for the seeds sown. These plants were grown for a period of 35 days, until the plants bolted and floral buds opened. Plant transformation plasmids were electroporated into Agrobacterium tumefaciens GV3101 as described by Shaw (1995) and plated on LB medium containing rifampicin/kanamycin/hygromycin and incubated at $30^{\circ} \mathrm{C}$. The Agrobacterium-mediated transformation of $A$. thaliana was performed as described by Clough and Bent (1998). $\mathrm{T}_{1}$ seeds were harvested from the fully grown mature transformed plants and dried at $25^{\circ} \mathrm{C}$. 
Seeds were germinated on sterile medium containing $40 \mu \mathrm{g} \mathrm{ml}^{-1}$ kanamycin or hygromycin to select the transformants. Surviving $T_{1}$ plantlets were transferred to soil to set seeds $\left(T_{2}\right)$.

\section{(b) Seed germination}

For growth under sterile conditions, seeds were surface sterilized (10 min incubation in 5\% $(\mathrm{v} / \mathrm{v})$ sodium hypochlorite, and rinsed thrice with sterile distilled water) and sown on halfstrength Murashige and Skoog (MS) salts (Murashige and Skoog, 1962) supplemented with $1 \%$ sucrose, $\mathrm{pH} 5.7$, and $0.8 \%(\mathrm{w} / \mathrm{v})$ agar in Petri dishes (MS media preparation). For direct germination in soil, the seed sterilization is not necessary and seeds can be directly sown on soil after 2-4 day vernalization period (Weigel and Glazebrook, 2002).

\section{(x) Plant DNA isolation}

For DNA extraction from Arabidopsis, plant tissue was ground with liquid nitrogen, 3-4 times. One $\mathrm{ml}$ of plant DNAzol ${ }^{\circledR}$ (Invitrogen, Carlsbad, CA, USA) was added and the plant tissues were further ground. Once the tissues melted, they were collected in eppendorf tubes and incubated at room temperature for 5 minutes. Subsequently, $600 \mu 1$ of $100 \%$ chloroform (Fisher Scientific, Fairlawn, NJ, USA) was added to the plant extract and mixed. This mixture was incubated for 10 minutes at room temperature and subsequently spun for 10 minutes. The supernatant was retrieved and mixed with $1 \mathrm{ml}$ of $100 \%$ ethanol (Fisher Scientific, Fairlawn, NJ, USA) and incubated for 5 minutes at room temperature. The mixture was spun for 10 minutes to pellet the DNA. The pellet was then washed with Plant DNAzol Wash $(0.75 \mathrm{ml} 100 \%$ ethanol $+1 \mathrm{ml}$ of DNAzol $)$, then with $70 \%$ ethanol and airdried. The DNA was dissolved in sterile distilled water. 


\section{(xi) Plant RNA isolation}

For RNA extraction from Arabidopsis, plant tissue was ground with liquid nitrogen. One ml of TRIzol ${ }^{\circledR}$ (Invitrogen) reagent was added and the tissue was further ground. Once the tissue melted, it was collected in eppendorf tubes and was incubated at room temperature for 5 minutes. Subsequently, $200 \mu 1$ of $100 \%$ chloroform (Fisher Scientific, Fairlawn, NJ, USA) was added to the plant extract and mixed. This mixture was incubated for 10 minutes at room temperature and subsequently spun for 15 minutes at $4^{\circ} \mathrm{C}$. The supernatant was retrieved and mixed with $0.5 \mathrm{ml}$ of Isopropanol (Fisher Scientific, Fairlawn, NJ, USA) and incubated for 10 minutes on at room temperature. The mixture was spun for 10 minutes to pellet the RNA at $4^{\circ} \mathrm{C}$. The pellet was then washed with $70 \%$ ethanol and air-dried. The RNA was dissolved in sterile DEPC treated water.

\section{(xii) Dose response media preparation}

Half-strength Murashige and Skoog (MS) salts (Murashige and Skoog,1962) medium supplemented with $1 \%$ sucrose, $\mathrm{pH} 5.7$, and $0.8 \%(\mathrm{w} / \mathrm{v})$ agar was prepared and, after autoclaving, was cooled to $55^{\circ} \mathrm{C}$. Subsequently, sterile $\mathrm{ABA}$, Nacl and Mannitol preparations of required concentrations were inoculated into the medium in the sterile hood environment. ABA was dissolved in $75 \%$ ethanol to prepare specified concentrations. The medium was mixed thoroughly (120 rotations) before plating.

\section{(xiii) T-DNA insertion mutants}

The desired gene knock-out lines were obtained from the ABRC (http://signal.salk.edu/cgibin/tdnaexpress). T1 seeds were procured initially and subsequently grown for three more 
generations on kanamycin to confirm transgenic lines and homozygosity of these lines. (Concentration of kanamycin used for selection of these mutants is to be kept low $(20 \mu \mathrm{g} / \mathrm{ml}$ ) as these plants have low resistance initially.)

\section{(xiv) Yeast transformation}

HF7c cells were inoculated into $5 \mathrm{ml}$ YPD medium supplemented with $0.2 \%$ adenine and cultured overnight. The next morning, the HF7c culture was transferred into $500 \mathrm{ml}$ YPDA medium and grown to mid-log phase for about $3-4$ hours in $30^{\circ} \mathrm{C}$ with shaking. The OD of the culture was measured until it reached $0.8-1\left(\sim 2 \times .10^{7}\right.$ cells $\left./ \mathrm{ml}\right)$. Subsequently, the culture was spun at 3500-5000 rpm to retrieve cells. The cells were then washed with sterile water with subsequent rounds of spinning. Subsequently, cells were suspended in $1 \mathrm{ml}$ of $100 \mathrm{mM}$ LiAc and then transferred into $1.5 \mathrm{ml}$ eppendorf tubes. In the meantime, the cotransformation mix was prepared by mixing $1 \mu 1$ of Plasmid DNA with $36 \mu 1$ M LiAc, $25 \mu 1$ of boiled and chilled salmon sperm DNA and $50 \mu 1$ of water.

Subsequently, $240 \mu \mathrm{l}$ of $50 \% \mathrm{w} / \mathrm{v}$ PEG was layered on top of the competent HF7c cells, after that the transformation mix was added to the tubes. These contents of the tubes were mixed by gentle pipetting and incubated in a $42^{\circ} \mathrm{C}$ water bath for 15 minutes. Subsequently, cells were mixed with $500 \mu 1$ of sterile water and plated onto SD selective medium (Leu Trp"). This protocol was adapted from Sambrook and Russell (2001). 


\section{SPECIFIC AIMS}

\section{(i) Analysis of the expression patterns of HD2-type histone deacetylases}

(a) Characterization of the spatial expression profile of the HD2-type histone deacetylase gene family in Arabidopsis thaliana. (b) Identification of sub-cellular localization of HD2 proteins, AtHD2B and AtHD2C. (c) Identification of essential residues in AtHD2A protein sequence.

It was unknown whether all the four members of the HD2 gene family would have similar spatial profiles. The HD2 proteins were expected to localize to the nucleus as they are putative transcription factors. In addition, certain conserved histidine and aspartate residues and the N-terminal motif were expected to be essential for catalysis.

\section{(ii) AtHD2C promoter analysis}

(a) Promoter motif prediction to identify putative cis-elements in the AtHD2B and AtHD2C promoter. (b) Generation of AtHD2B promoter:GUS and AtHD2Cpromoter:GUS transgenic lines and examination of the spatial expression profile of the GUS reporter driven by the AtHD2B and AtHD2C promoters in different developmental windows. (c) Analyze the effect of ABA on AtHD2C promoter regulation of GUS expression.

We expected to find ABA-response elements and seed regulation elements in the AtHD2B and $A t H D 2 C$ promoter sequences that would support their involvement in embryo development. The GUS gene spatial expression profile was expected to be similar to the HD2 gene family expression profile analyzed in the first set of experiments. 
(iii) Analysis of the functional role of HD2-type histone deacetylases in the development of Arabidopsis thaliana, using the reverse genetics approach .

(a) Examination of the developmental defects in the AtHD2B and AtHD2C overexpression lines.

(b) Analyze ABA, salt and mannitol sensitivity of the AtHD2C overexpression and T-DNA insertion lines in different developmental stages. (c) Analyze the ABA-inducible gene expression patterns in the AtHD2C overexpression and T-DNA insertion lines in respective developmental stages.

Since the HD2 proteins were found to accumulate in the embryos and AtHD2A overexpression led to down-regulation of 'seed-specific' genes, it was expected that the $A t H D 2 B$ and $A t H D 2 C$ ectopic expression might led to seed-specific effects. Consequently, we expected to observe changed ABA response phenotypes in the overexpression lines.

\section{(iv) Investigate physical interaction between $A t H D 2 B / A t H D 2 C$ proteins and RPD3 (HDA1) type histone deacetylase proteins}

Mammalian systems demonstrated interaction amongst different members of HDAC classes. Based on this report, we expected to find interaction between HD2-type histone deacetylases and class I HDAC (AtHDA1) proteins. 


\section{RESULTS}

\section{(i) Expression Patterns of the HD2-Type Histone Deacetylases in Arabidopsis}

\section{(a) Spatial expression profile of the HD2-type histone deacetylase gene family}

Little information is available with regards to the expression and function of the HD2-type HDACs in Arabidopsis. Antisense knockout of AtHD2A led to aborted seed development, implicating the HD2-proteins to be involved in seed maturation ( $\mathrm{Wu}$ et al, 2000). Protein sequence alignment of the four HD2 family members revealed that all of them contain similar structural organization (Figure 11A) and have an N-terminal domain where catalytic activity is predicted to reside (Aravind and Koonin, 2001). They have an acidic stretch in the central domain that is responsible for phosphorylation-regulation of the protein and possibly for nuclear localization. AtHD2A and AtHD2C contain $\mathrm{Zn}$ fingers in their $\mathrm{C}$-terminal regions whereas AtHD2B and AtHD2D do not contain Zn finger domains. We analyzed the spatial expression profile of the HD2 gene family in Arabidopsis. Different tissues including seedlings (1 week old), mature leaves, stems, flowers and siliques were collected for analysis. Total RNA was isolated from these tissues and gene expression was analyzed using RT-PCR (Weigel and Glazebrook, 2002). It was observed that $H D 2 A, H D 2 B$ and $H D 2 C$ accumulated in all tissues examined with varying quantities in the different tissues (Figure 11B). However, $H D 2 D$ formed the anomaly in this family by exhibiting flower-specific expression with weaker expression in stems. This suggests that some of the HD2 family genes may be differentially expressed in Arabidopsis. These results supported the idea that the HD2-type histone deacetylases may play differential functional roles owing to their different expression patterns. 
A

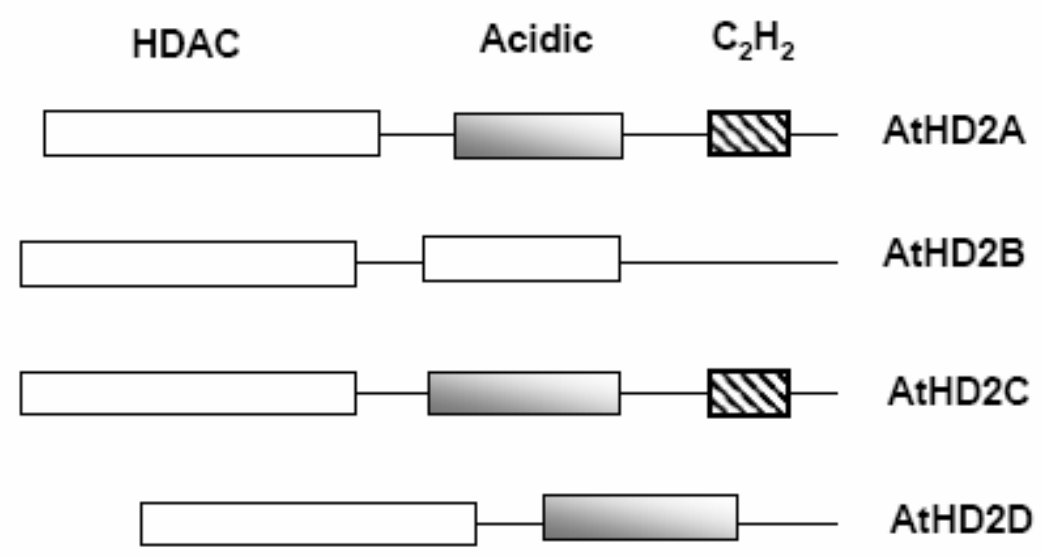

B

\begin{tabular}{l|llll} 
& Leaf & Root & Seedling & Flower \\
AtHD2A & & & Stem \\
AtHD2B & & & \\
AtHD2C & & \\
AtHD2D & & & \\
UBQUITIN & & & \\
\hline
\end{tabular}


Figure 11. The HD2 gene family of Arabidopsis thaliana. (A) Sequence comparison of the four HD2 proteins in Arabidopsis thaliana. The N-terminal, HDAC box represents the catalytic domain of the HD2 proteins. The central box represents the acidic domain rich in $\mathrm{E}$ and $\mathrm{D}$ residues. The $\mathrm{C}$-terminal boxes in AtHD2A and AtHD2C represent $\mathrm{Zn} 2+$ finger domains, which might have a role in recruiting the protein by forming protein-DNA or protein-protein contacts. The figure underscores the fact that the four proteins are very similar in their alignment with differences only due to possession of the $\mathrm{Zn}$ finger motifs by AtHD2A and AtHD2C. (B) An RT-PCR assay to examine the spatial expression profile of the HD2 gene family. RNA was isolated from different plant tissues: leaf, root, stem, flower and seedling. cDNA was prepared from RNA and gene expression was analyzed by PCR using gene specific primers. The figure depicts ubiquitous expression of the HD2 gene family with $A t H D 2 D$ being the exception due to flower and stem specific expression. 


\section{(b) HD2C localizes to the nucleus in Arabidopsis}

The HD2 proteins were first isolated as nucleolar proteins in maize (Lusser et al, 1997). Subsequently, they were identified in Arabidopsis thaliana (Wu et al, 2000). The nuclear/nucleolar localization of the HD2 proteins had not yet been demonstrated in Arabidopsis. The nuclear localization of a protein confirms its status as a transcription factor. Therefore, I decided to test the sub-cellular localization of HD2C. 35S:AtHD2C-GFP and 35S:AtHD2B-GFP constructs were generated and transformed into Arabidopsis to create transgenic plants expressing HD2C-GFP and HD2B-GFP fusion proteins (Table IV). The cDNA sequence of $H D 2 C$ and $H D 2 B$ was fused to the GFP reporter gene driven by the $35 S$ promoter of the cauliflower mosaic virus (Figure 12A and 12D). The constructs were used to transform Arabidopsis (ecotype Columbia) plants as described by Clough and Bent (1998). Four independent AtHD2C-GFP lines (35S: AtHD2C1, 35S:AtHD2C2, 35S:AtHD2C3 and 35S:AtHD2C4) and three independent AtHD2B-GFP lines (35S: AtHD2B1, 35S:AtHD2B2, 35S:AtHD2B3) were further assayed for presence and expression of transgene. Lines expressing higher levels of $H D 2 C$ (35S:AtHD2C1 and 35S:AtHD2C2) were selected for detailed studies. The transgenic lines were confirmed for transgene expression using PCR (Figure 12B and 12E) and RT-PCR (12C and 12F) before functional assays were conducted. Genomic DNA was extracted from Wild-type, 35S:AtHD2C-GFP (1-4) and 35S:AtHD2BGFP (1-3) transgenic lines and used as a template for amplification rounds with three different sets of primers: X- HD2Bpr3/GFPpr3 ( 1.35 kb), Y-HD2Bpr3/HD2Cpr4 ( 800 bp), Z-GFPpr3/GFPpr4 ( 500 bp) and P-HD2Cpr3/HD2Cpr4 ( 800 bp), Q- HD2Cpr3/GFPpr3 ( 1.35 kb). RT-PCR analysis was performed by using RNA samples extracted from 1-week old seedlings that were reverse transcribed to cDNA copies. The cDNA was used as a 
A

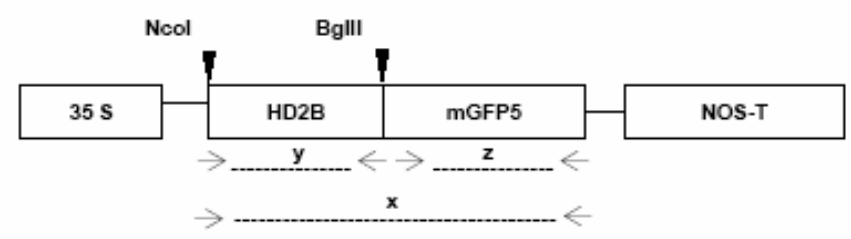

B

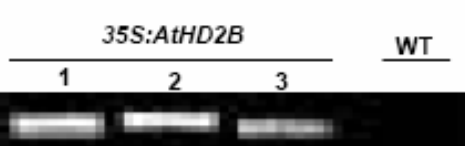

(Y)

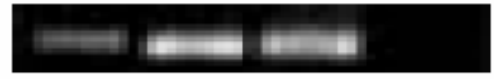

(z)

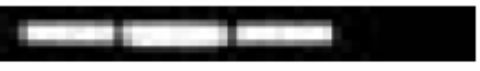

C

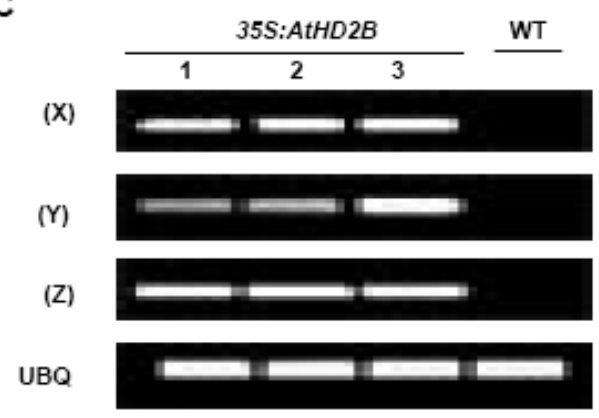

D

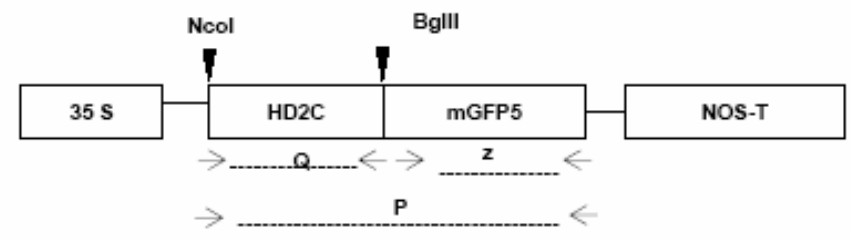

E

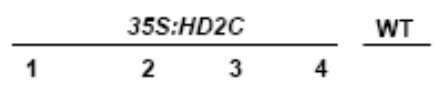

(P)

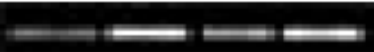

(Q)

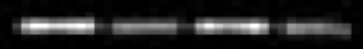

(Z)

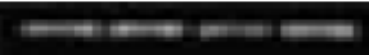

F 35S:HD2C WT

(P)
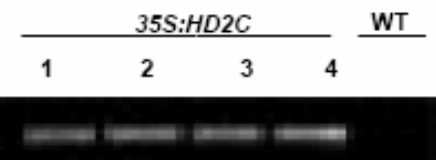

(Q)

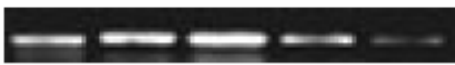

(Z)

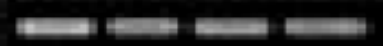

UBQ

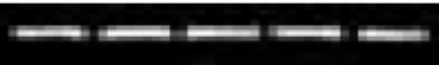


Figure 12. (A) Map of the $35 S: A t H D 2 B$ construct, $A t H D 2 B$ was subcloned upstream to GFP driven by the CaMV $35 \mathrm{~S}$ promoter in the pCAMBIA1302 vector. (B) PCR analysis of Arabidopsis transgenic lines expressing 35S:AtHD2B transgene; Genomic DNA was extracted from wild-type (WT) and 35S:AtHD2B transgenic lines (1-3) and used as a template for PCR amplification with three different sets of primers: X-HD2Bpr3 and GFPpr3 ( 1.35kb), Y-HD2Bpr3 and HD2Bpr4 ( 800bp), Z-GFPpr3 and GFPpr4 ( 500bp). (C) RTPCR analysis to assay levels of expression of the 35S:AtHD2B transgene; $1 \mu \mathrm{g}$ of RNA samples extracted from 1-week old seedlings was reverse transcribed to cDNA. The cDNA was used as a template for amplification with three different sets of primers: $\mathrm{X}, \mathrm{Y}$ and $\mathrm{Z}$. UBIQUITIN served as internal control. (D) Map of the 35S:AtHD2C construct: AtHD2C was subcloned upstream to GFP driven by the CaMv 35S promoter, into the pCAMBIA1302 vector. (E) PCR analysis of Arabidopsis transgenic lines expressing 35S:AtHD2C transgene: Genomic DNA was extracted from wild-type (WT) and 35S:AtHD2C transgenic lines (1-4) and used as a template for PCR amplification with three different sets of primers; PHD2Cpr3 and GFPpr3 ( 1.3kb), Q-HD2Cpr3 and HD2Cpr4 ( 800bp), Z-GFPpr3 and GFPpr4 ( $\sim 500 \mathrm{bp})$. (F) RT-PCR analysis to assay levels of expression of the 35S:AtHD2C transgene; $1 \mu \mathrm{g}$ of RNA samples extracted from 1-week old seedlings were reverse transcribed to cDNA. The cDNA was used as a template for amplification with three different sets of primers; P, Q and Z. UBIQUITIN served as internal control.

*Lines: 1-35S:AtHD2B/C1, 2-35S:AtHD2B/C2, 3-35S:AtHD2B/C3, 4-35S:AtHD2C4 

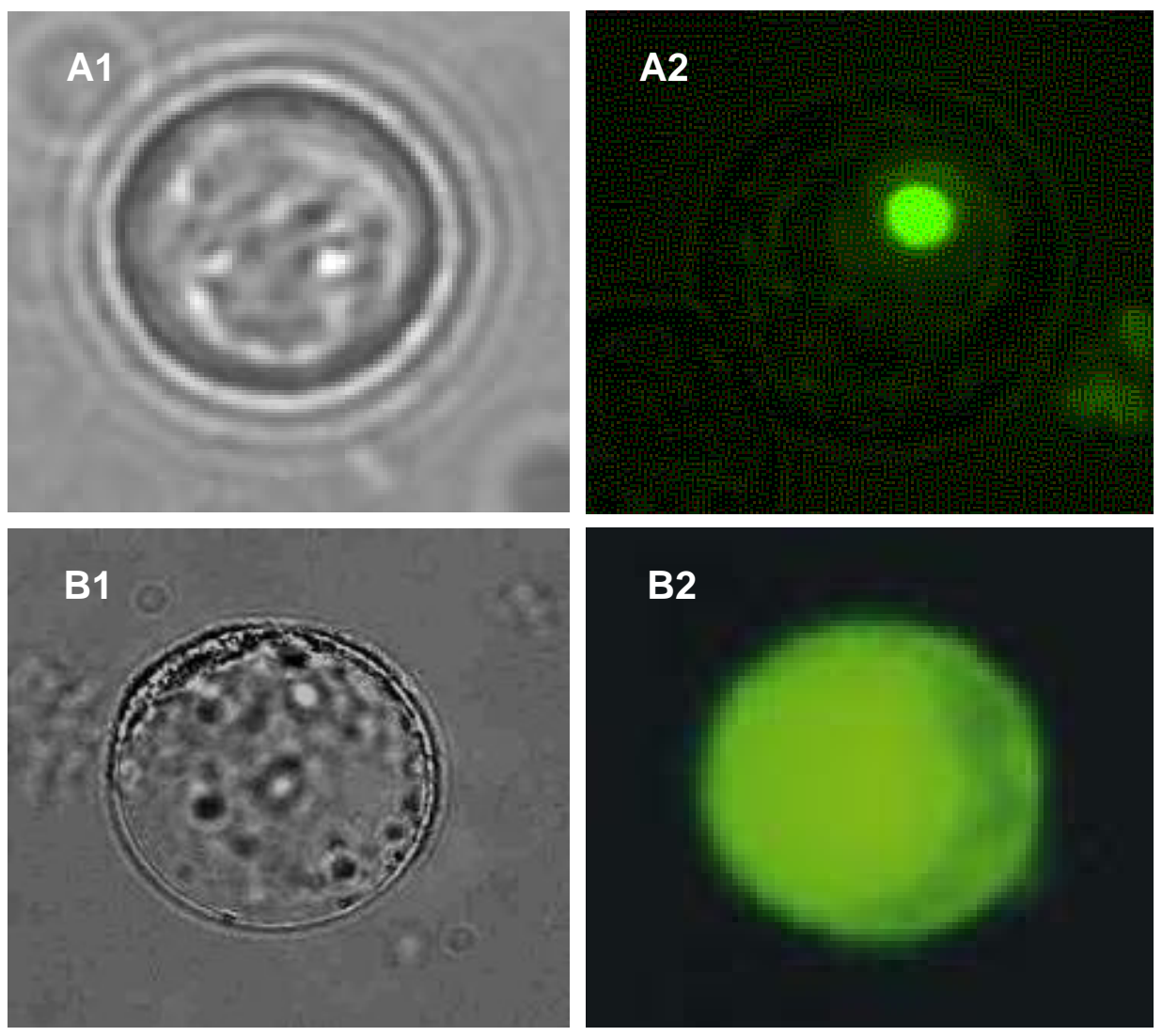

Figure 13. Subcellular localization of AtHD2C, The 35S:AtHD2C-GFP overexpression line was used to isolate transgenic protoplasts and GFP fluorescence was examined by fluorescence microscopy. (A1) Single 35S:AtHD2C-GFP transgenic protoplast under bright light. (A2) nuclear localization of the HD2C protein imaged by GFP fluorescence under UV light. (B1) Single 35S:GFP transgenic protoplast under bright light. (B2) Cytoplasmic localization of the GFP protein from the control line imaged by GFP fluorescence under UV light. 
template for PCR amplification rounds with three different sets of primers: $\mathrm{X}, \mathrm{Y}$ and $\mathrm{Z}$ or $\mathrm{P}$, $\mathrm{Q}$ and Z. Both assays confirmed the presence and expression of AtHD2C transgene in the plants. Subsequently, 35S:AtHD2C $\mathrm{T}_{3}$ homozygous seedlings were selected after subsequent rounds of generation. In the first two generations $\left(T_{1}\right.$ and $\left.T_{2}\right)$, transgenic seeds grown in Hygromycin selective medium germinated in 3:1 (germinated: non-germinated) ratios. The hygromycin resistant seedlings were selected for selfing and subsequent harvest. In the next set of germination $\left(\mathrm{T}_{3}\right)$ on hygromycin selective medium, all seeds germinated giving 100\% hygromycin resistant phenotype. This was used as an indicator for possible homozygosity amongst transgenic plants. AtHD2C1 $\mathrm{T}_{2}$ plants germinated in a ratio of $62: 21(\sim 3: 1)$ and AtHD2C2 $\mathrm{T}_{2}$ plants germinated in a ratio of $77: 15(\sim 3: 1)$. These two lines were further selected for $\mathrm{T}_{3}$ generation seeds that were $100 \%$ resistant to hygromycin. Protoplasts were isolated from these transgenic lines and were examined for GFP florescence signal within the cells. Distinct bright green spots were observed under florescence light in the boundary confining the nuclear space within the cells for both the HD2C-GFP lines (Figure 13A2). This confirmed the nuclear localization of the proteins. Additionally, the bright green spots had sharp boundaries and were localized to a particular region within the nucleus and not diffused throughout. This implicated nucleolar localization, but further analysis is required to confirm this. 35S:GFP transformed plants served as a control as the GFP from these protoplasts was localized throughout the cytoplasm.

\section{(c) The $\mathbf{N}$-terminal motif and $\mathrm{H} 25$ are essential for AtHD2A mediated Repression}

It had been previously demonstrated that $\mathrm{HD} 2 \mathrm{~A}, \mathrm{HD} 2 \mathrm{~B}$, and $\mathrm{HD} 2 \mathrm{C}$ repressed transcription as GAL4 fusion proteins when directed to a promoter containing GAL4-binding sites (Wu et $a l, 2003)$. We wanted to investigate residues that are essential for mediating this repression. 
Therefore, we used site-directed mutagenesis to identify residues in HD2A that are required for gene repression activity. Sequence alignments of all known HD2 proteins revealed that the N-terminal region of HD2 proteins contain an MEFWG motif as well as 18 conserved amino acid residues (Dangl et al, 2000). It was proposed that the invariant aspartic acid is the nucleophile involved directly in lysine deacetylation that may be facilitated through a charge relay system with the conserved histidine (Dangl et al, 2000). To determine the relevance of each of these residues, three mutation constructs were generated: a deletion of the N-terminal EFWG motif ( $\triangle$ AtHD2A) (Figure 14A), a substitution of the Histidine 25 to Alanine (H25A) (Figure14A) and a substitution of Aspartate 69 to Alanine (D69A) (Figure 14A). These mutation constructs were co-transformed with a reporter construct in a transient expression assay and the activity of gene repression was assessed by the level of expression of the GUS reporter. As shown in Figure 14C, deletion of the N-terminal EFWG motif resulted in loss of gene repression activity, whereas the $\mathrm{H} 25 \mathrm{~A}$ mutant yielded decreased gene repression activity compared with Wild-type. The D69A mutant, however, showed little change in gene repression activity compared with Wild-type protein. The experiment was repeated thrice with similar results. These results indicated that the N-terminal EFWG motif is essential for the gene repression activity, and that the amino acid residue $\mathrm{H} 25$ may also be important, but to a lesser extent. 
A

Effector Plasmids
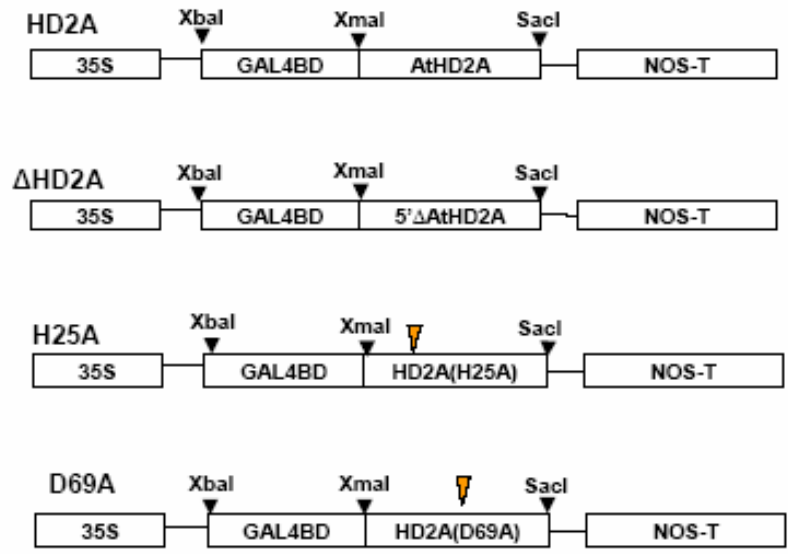

B

\section{Reporter Plasmid}

C

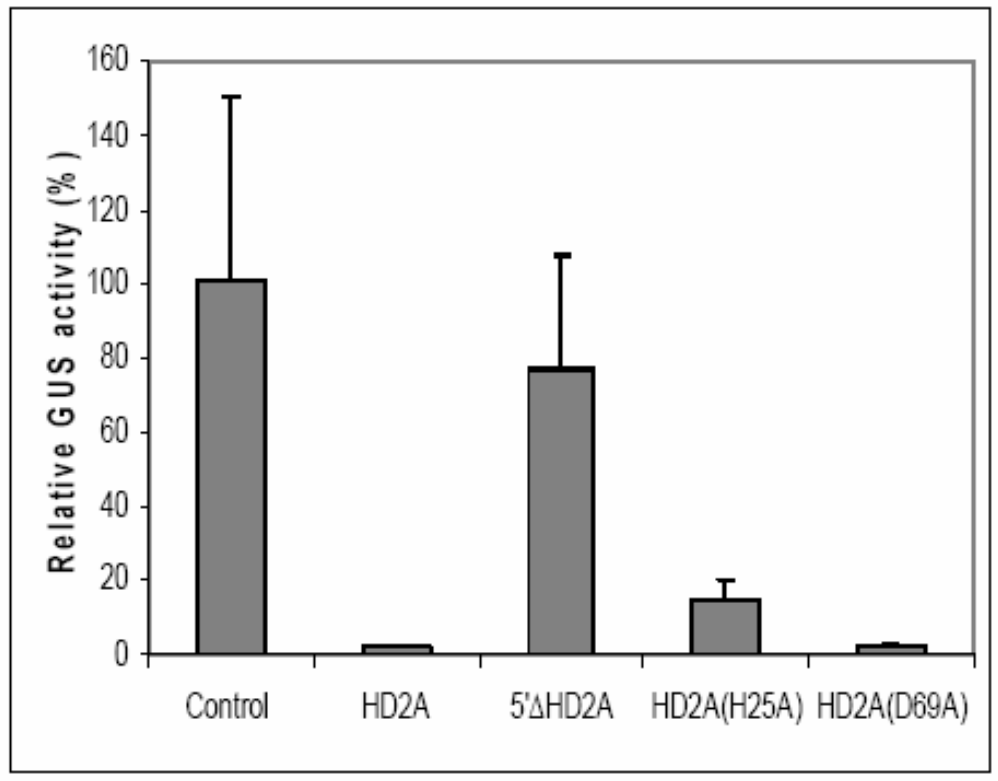

UAS $_{\text {OAL4 }}$-tCUP-GUS

H- 394tCuP GUS NOS-T 
Figure 14. Mutation analysis of the essential catalytic residues in the AtHD2A protein. (A) and (B) Schematic diagram of effector and reporter constructs, respectively, used in a cobombardment assay used to investigate the extent of gene repression caused by the HD2A protein. The effector constructs contain the GAL4 DNA binding domain (GAL4BD) which will bind to the UAS sequence in the UASGAL4-tCUP-GUS reporter and recruit the fused $\mathrm{HD} 2 \mathrm{~A}$ protein to the promoter. $\triangle \mathrm{HD} 2 \mathrm{~A}$ was a deletion in the $\mathrm{N}$-terminal EFWG motif of HD2A protein: $\mathrm{H} 25 \mathrm{~A}$ was a substitution of the conserved histidine motif at position 25 to an alanine residue, D69A was a substitution of the conserved aspartate residue at position 69 to an alanine residue. The orange signs indicate relative positions of the substitutions on the HD2A protein. (C) Repression of the GUS reporter gene expression. D69A displays approximately the same activity as the full length protein. pUC19 served as the control plasmid. Each of the effector plasmids were co-bombarded with the reporter plasmid and GUS activity was measured in a transient expression assay. Bars indicate the SE of three replicates. 


\section{(ii) Analysis of AtHD2B and AtHD2C promoter Activities}

\section{(a) AtHD2B and AtHD2C promoter motif analysis}

A 3000 bp sequence 5' upstream to the transcription start site of the genomic sequences of AtHD2B and AtHD2C was submitted to PlantCARE database (http://oberon.fvms.ugent.be:8080/PlantCARE/index.html) was submitted to PlantCARE (cis acting regulatory elements) in the TAIR database for motif prediction. The AtHD2B and AtHD2C promoter contained motifs for ABA, seed-specific regulation and cell cycle inhibition (Figure 15 and 16). The ABA response motifs found in these promoters are ABREs that are Gbox, elements (Finklestein and Rock, 2002). The ACGT core element that is essential to the ABRE G-box can be found in the $A t H D 2 B$ and $A t H D 2 C$ promoter sequences. Another $c i s$-acting sequence required for ABA-inducibility, RY-element, was found in these two promoters. RY elements are bound by B3 domain proteins such as ABI3 (Ezcurra et al, 2000). The MRE (Myc regulation element) motif was also found within these promoters. This element is bound by the Myc class transcription factors, that have the b-HLH-ZIP domain structure and are ABAinducible (Abe et al, 1997). The presence of the MSA regulator in these promoters suggested that these genes might be targets of cell-cycle mediating proteins (Ito et al, 2001). The positions and sequences of these different elements in the $A t H D 2 B$ and $A t H D 2 C$ promoters is outlined in Figure $15 \mathrm{~A}$ and $15 \mathrm{C}$ Subsequent to this preliminary study, we subcloned $1.7 \mathrm{~kb}$ of the AtHD2B 
A

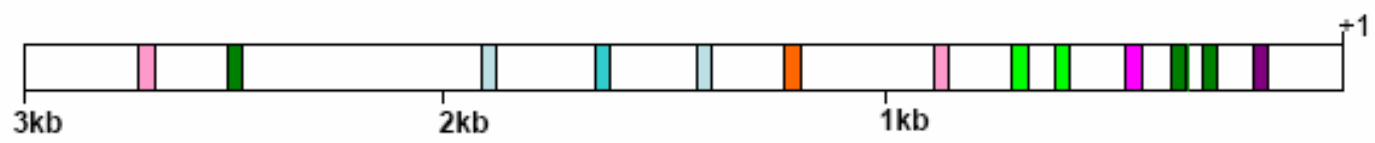

B

\begin{tabular}{llll}
\hline MOTIF NAME & POSITION & SEQUENCE & FUNCTION \\
\hline$\square$ ABRE & 14471980 & $\begin{array}{l}\text { TCTACGTAGT, } \\
\text { AGGGCGTCG }\end{array}$ & ABA responsive element \\
\hline$\square$ MYB & 1246 & CAActg & MYB binding in drought induction \\
\hline$\square$ MRE & 531,546 & AACCaaa, AACCtac & Light regulation element \\
\hline$\square$ c-repeat DRE & 203,217, & $\begin{array}{l}\text { gtgCCGAc, } \\
\text { cctCCGAc, tccCGAC }\end{array}$ & Dehydration response \\
\hline$\square$ MSA & 12868 & TGaAACGgt & Cell cycle regulation \\
\hline$\square$ GCN4 & 720,2764 & ttaGTCA, tcaGTCA & Cis-regulation element in \\
\hline$\square$ Prolamin & 485 & tgCAAGg & Box associated with GCN4 \\
\hline$\square$ RY-element & 1670 & CATGatG & Seed-specific regulator \\
\hline
\end{tabular}

Figure 15. Motif prediction in the $A t H D 2 C$ promoter sequence $3000 \mathrm{bp} 5$, upstream to the transcription start site was submitted to PlantCARE database for identification of putative ciselements. (A) Map of the AtHD2C promoter with the different putative elements depicted in different color codes in their respective positions in the sequence. (B) Table describing the color codes for the cis-elements, indicating their upstream distance relative to the transcription start site $(+1)$, sequence and known function. 
A

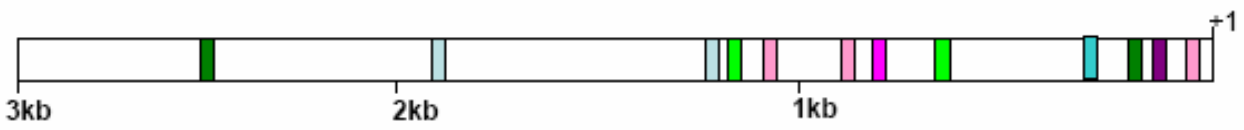

B

\begin{tabular}{llll}
\hline MOTIF NAME & POSITION & SEQUENCE & FUNCTION \\
\hline$\square$ ABRE & 1143 & cCtACGTagg & ABA-responsive element \\
\hline$\square$ MRE & 703,1141 & AACCaaa, AACCtac & Light regulation element \\
\hline$\square$ C-repeat DRE & 205 & TACCgacct & Draught inducible motif \\
\hline$\square$ MSA & 31 & ttgAACGgt & Cell cycle regulation \\
\hline$\square$ GCN4 & 9,1047 & taaGCCA, tggGTCA & $\begin{array}{l}\text { Cis-regulation element in } \\
\text { endosperm expression }\end{array}$ \\
\hline$\square$ Prolamin & 870,1474 & tgtAAAGt, tgaAAGc & Box associated with GCN4 \\
\hline$\square$ RY-element & 244 & CATGcatt & Seed-specific regulator \\
\hline
\end{tabular}

Figure 16. Motif prediction in the $A t H D 2 B$ promoter sequence $3000 \mathrm{bp} 5$ ' upstream to the transcription start site was submitted to PlantCARE database for identification of putative ciselements. (A) Map of the $A t H D 2 B$ promoter with the different putative elements depicted in different color codes in their respective positions in the sequence. (B) Table describing the color codes for the cis-elements, indicating their upstream distance relative to the transcription start site $(+1)$, sequence and known function. 
and $A t H D 2 C$ promoter sequences into the $p C A M B I A 1381$ vector to generate transgenic promoter lines expressing GUS driven by the $A t H D 2 B$ and $A t H D 2 C$ promoter. These transgenic promoter lines were used for subsequent assays.

(b) AtHD2B promoter and $A t H D 2 C$ promoter driven GUS is expressed in all mature vegetative tissues

The $A t H D 2 B$ and $A t H D 2 C$ promoter GUS fusion constructs are depicted in Figure 16. From the previous RT-PCR data, $A t H D 2 B$ and $A t H D 2 C$ expression was detected in all tissue types, e.g., leaves, stems, flowers, siliques and seedlings. Therefore, we examined the expression of the GUS reporter in the AtHD2B promoter:GUS (Figure 17B) and AtHD2C promoter:GUS (Figure 17A) transformed tissues. Figure 17 demonstrates that $G U S$ was strongly expressed in all tissues examined in both $A t H D 2 B$ and $A t H D 2 C$ promoter lines including mature rosette leaves, floral meristems, stems, flowers (anthers, pollen, carpel, sepals) and silique (funiculus and mature seeds), the only exception being petals where there was a conspicuous absence of GUS.

(c) AtHD2C promoter:GUS expression is down-regulated by $\mathrm{ABA}$ and $\mathrm{NaCl}$ in the postgermination stage

To investigate the regulation of $\mathrm{AtHD} 2 \mathrm{C}$ expression in response to ABA at the postgermination stage, AtHD2C promoter:GUS expression was assayed by histochemical $\beta$ glucuronidase staining of the transgenic plants. GUS reporter gene was expressed in all parts of the seedling with weaker staining in the RAM (root apical meristem) (Figure 18A). 
A AtHD2B promoter:GUS

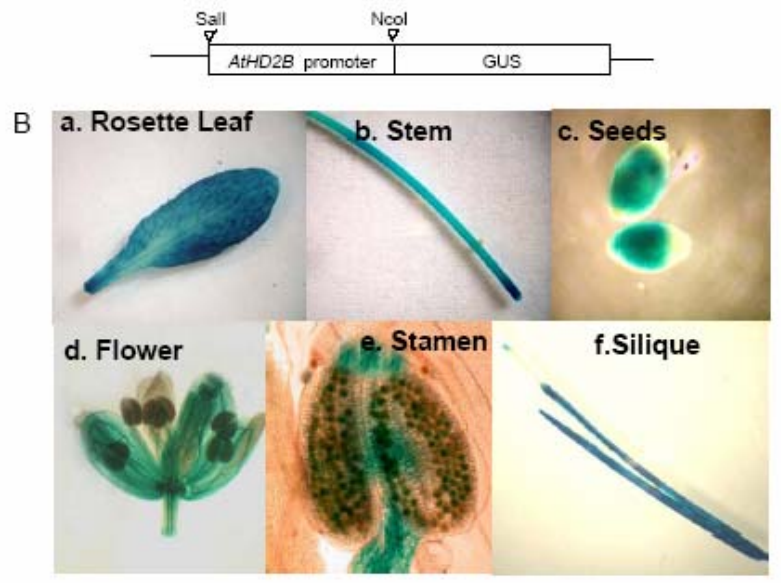

C

AtHD2C promoter:GUS

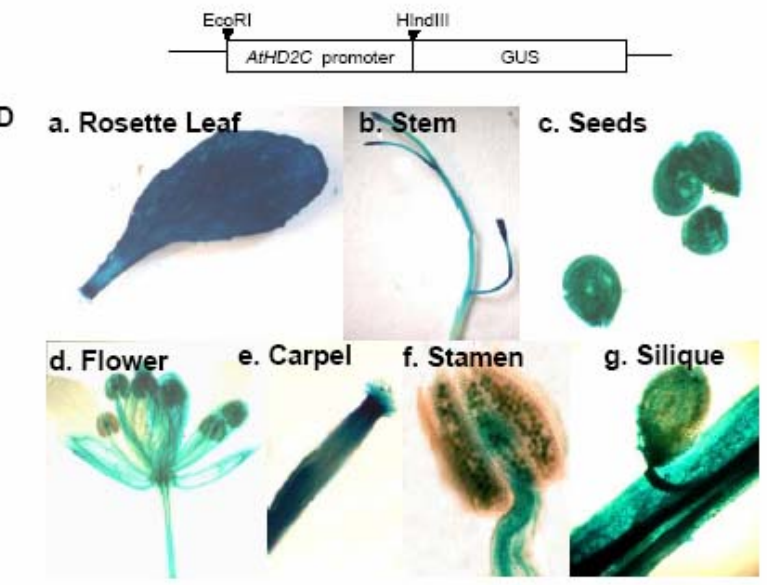

Figure 17 (A) Diagram of AtHD2B promoter:GUS construct. (B) Histochemical GUS staining of the $A t H D 2 B$ promoter activity in vegetative tissues. T3 plants were stained with 5-bromo-4-chloro-3-indolyl--glucuronic acid for $12 \mathrm{hrs}$; Staining of (a) mature rosette leaf, (b) stem, c. post-imbibition seeds-:stained after 2-days stratification, (d) mature flower, (e) stamen and (f) siliques. (C) Diagram of AtHD2C promoter:GUS construct. (D) Histochemical GUS staining of the $A t H D 2 C$ promoter activity in vegetative tissues. Plants were stained with 5-bromo-4-chloro-3-indolyl--glucuronic acid for $12 \mathrm{hrs}$. Staining of (a) mature rosette leaf, (b) stem, (c) post-imbibition seeds, stained after 2-days stratification, (d) mature flower, (e) carpel, (f) stamen and (g) siliques (arrow indicates stained funiculus). 
Interestingly, the $A t H D 2 C$ promoter was induced in the RAM after ABA treatment. Without ABA application there was very little or no GUS accumulation in the RAM. Additionally, AtHD2C promoter activity was quite strong in the shoot apical meristem, both before and after ABA application, as opposed to other seedling parts that showed a slight reduction in staining after ABA application. Thus GUS accumulation at the meristems seems to be an $\mathrm{ABA}$ induced phenomenon implicating a synergistic interaction between $\mathrm{ABA}$ signal mediators and $A t H D 2 C$ promoter expression at specific locations. The AtHD2C promoter:GUS bearing plants, demonstrated downregulation of the GUS accumulation in the seedlings upon $\mathrm{NaCl}$ application (Figure 18B). Also, GUS accumulation in the SAM was maintained after $\mathrm{NaCl}$ treatment (Figure 18B) and was induced in the RAM post-treatment (Figure 18B) that is similar to the response observed for the ABA treated plants. These results indicate that AtHD2C down-regulates $\mathrm{ABA}$ dependant salt stress signaling during germination and post-germination growth stages.

\section{(iii) Reverse Genetics Approach to Study the HD2-Type HDACs}

\section{(a) Growth phenotypes of 35S:AtHD2C Overexpression Lines}

To investigate the function of $\mathrm{AtHD} 2 \mathrm{C}$ in planta, transgenic plants overexpressing $\mathrm{HD} 2 \mathrm{C}$ were generated and T3 plants were selected as described in section I. Compared to wild-type plants, the 35S:AtHD2C-GFP lines exhibited some abnormal phenotypes. The 35S:AtHD2C1 and 35S:AtHD2C2 seeds germinated 6 hours before the wild-type seeds (Figure 19A) and the 
A

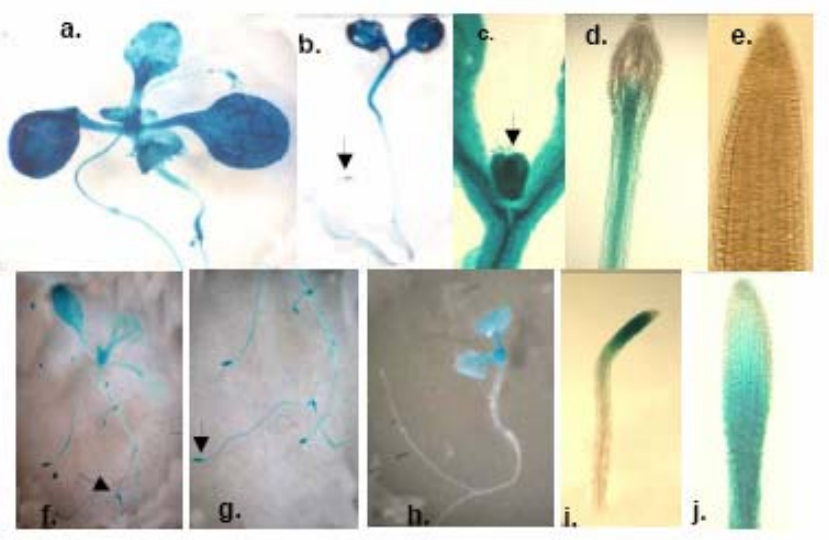

B

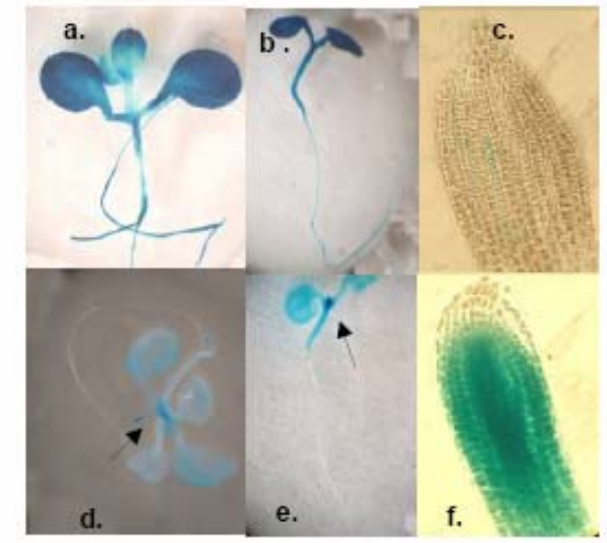

Figure 18. (A) Effect of $\mathrm{ABA}$ on the $A t H D 2 C$ promoter: $G U S$. T3 AtHD2C promoter:GUS transgenic seedlings grown on ABA-free MS medium were transferred to medium containing $100 \mu \mathrm{M}$ ABA for 6 hours and were subsequently collected for staining with 5-bromo-4chloro-3-indolyl--glucuronic acid. (a) 6-day-old seedling (post-germination), (b) 2-day-old sfedling, (c) shoot apical meristem (SAM-arrowhead), (d) Em (embryonic) root, (e) root apical meristem. (f)-(j) tissues incubated on $100 \mu \mathrm{M}$ ABA. (f) 6-day-old seedling (arrowhead points to GUS accumulation in RAM), (g) GUS accumulation in RAM after ABA treatment, (h) 2-day-old seedling, (i) Em (embryonic) root, (j) root apical meristem. (B) Effect of $\mathrm{NaCl}$ on the AtHD2C promoter driven GUS. AtHD2C promoter: $G U S$ transgenic seedlings grown on NaCl-free MS medium were transferred to medium containing $400 \mathrm{mM} \mathrm{NaCl}$ for 12 hours and were subsequently collected for staining with 5-bromo-4-chloro-3-indolyl--glucuronic acid. (a)-(c) tissues grown on $\mathrm{NaCl}$ free medium. (a) 6-day-old seedling (post-germination). (b) 2-day-old seedling. (c) Root apical meristem (RAM). (d)-(f) tissues incubated on $400 \mathrm{mM}$ NaCl. (d) 6-day old-seedling; (e) 2-day-old seedling; (f) Root apical meristem (RAM). 
35S:AtHD2C1 and 35S:AtHD2C2 seedlings demonstrated robust growth and larger sized plants than their wild-type counterparts (Figure 19C). The transgenic plants flowered much earlier than the wild-type plants (Figure 19B) and one prominent abnormality observed in the 35S:AtHD2C transformed plants was the improper development of mature rosette leaves into a 'squeezed' leaf phenotype (Figure 19B). The relative number of the 'squeezed' leaf found in the different lines is listed in Table VI. A large population of siliques in the 35S:AtHD2C1 and 35S:AtHD2C2 transgenic plants were shorter than the normal wild-type siliques (Figure 19, Table IX). Additionally, the seed count was reduced in the transgenic siliques as compared with the wildtype siliques (Table VIII). The empty vector transformed lines (35S:GFP) demonstrated same behavioral patterns as wild-type (data not shown) and served as control. However, these results do not identify a definitive role for HD2C in Arabidopsis development as ectopic expression may cause abnormal hierarchical cascades leading to evident phenotypes.

\section{(b) AtHD2C T-DNA insertion line analysis}

We identified a T-DNA insertion mutant of $H D 2 C$ in the Salk collection of T-DNA lines, SALK_039784 (http://signal.salk.edu/cgi-bin/tdnaexpress). T-DNA insertion lines were selected over subsequent generations by their ability to germinate in the presence of kanamycin. Homozygosity was confirmed by using PCR for three plants of the same SALK_039784 insertion lines (Figure 20B). The T-DNA insertion lies in the sixth exon of AtHD2C (Figure 20A) and is localized at the nucleotide 2116 of the $H D 2 C$ gene (numbering refers to relative nucleotide position to the ATG start codon). This insertion may lead to the disruption of AtHD2C expression. RT-PCR (Figure 20C) failed to detect $H D 2 C$ transcript accumulation in the insertion lines, confirming the knockout of $H D 2 C$ in these lines. 


\section{A}

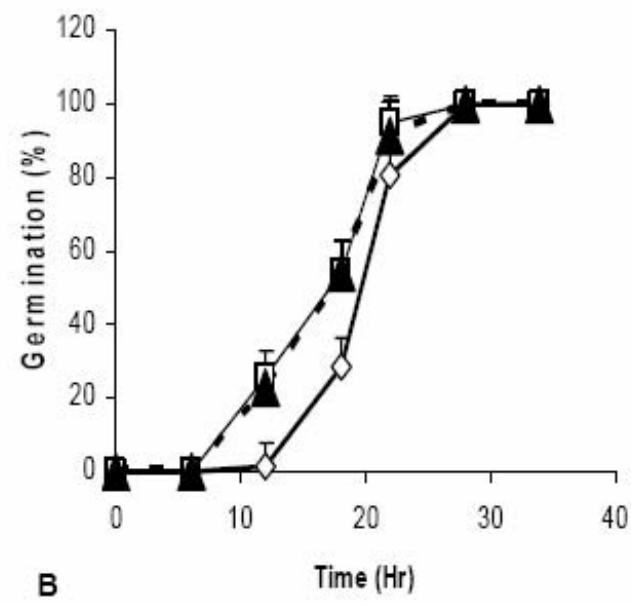

$\rightarrow$ Columbia

- $-35 S: A t H D 2 C 1$

- - 35S:AtHD2C2
C

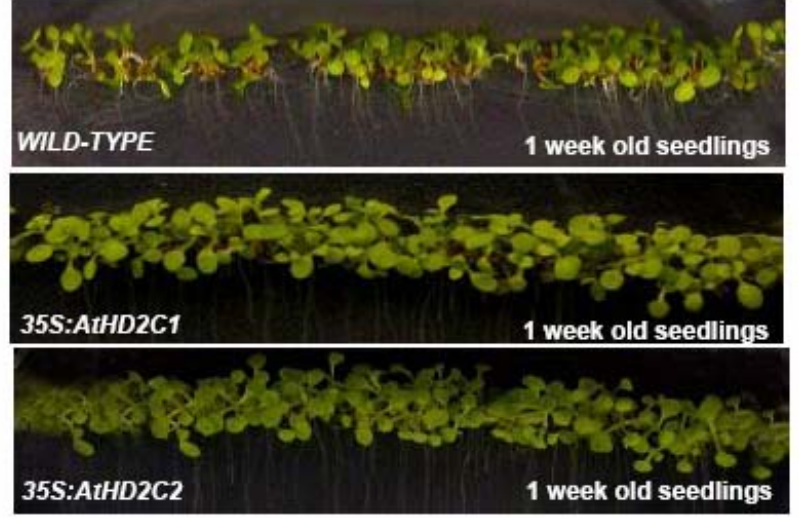

D

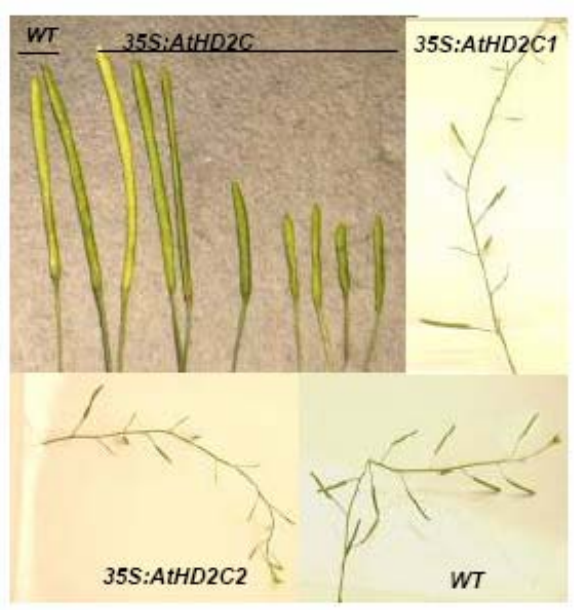

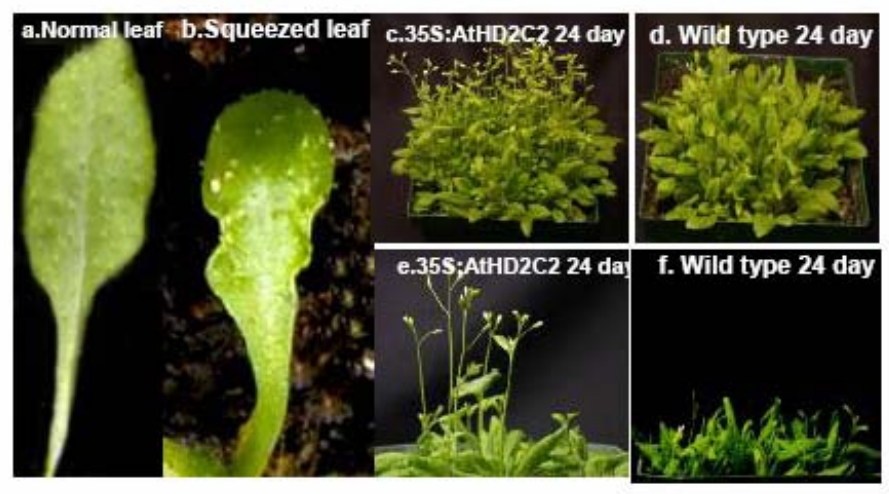


Figure 19. Growth phenotypes of the $A t H D 2 C$ overexpression lines (A) Germination rates of the WT, 35S:AtHD2C1 and 35S:AtHD2C2 transgenic lines on ABA-free medium. 8-week old seeds were plated on ABA-free medium after 2 days of cold treatment and germination (full radicle emergence and cotyledon formation) was scored starting at 0 hours of incubation up to 34 hours post-incubation, counting germination at 6 days intervals. Standard error is plotted for three replicate assays with $\sim 100$ seeds $(n=100)$ in each plate. (B) Abnormalities associated with the transgenic plants: 'Squeezed leaf' in the 35S:AtHD2C1 and 35S:AtHD2C2 transgenic lines. Early flowering phenotype at 24 days after germination (DAG). (C) Growth of the transgenic seedlings on ABA-free medium. Seeds were plated on ABA-free medium after 2 days of cold treatment. Post-germination growth (cotyledon greening/expansion and embryonic root elongation) was monitored and seedling sizes compared. (D) Fully mature siliques in WT, 35S:AtHD2C1 and 35S:AtHD2C2 transgenic lines. 
TABLE VII. Average percentage of 'squeezed' leaves for 20 mature rosettes in wild-type and transgenic plants.

\begin{tabular}{|c|c|c|c|}
\hline \multicolumn{4}{|c|}{ Average percentage ( $\%$ ) f abnorma leaves } \\
\hline Wid type & 35SAtHOLC1 & 35S-AtHD2C2 & 1303 \\
\hline $0.78 \pm 1.34$ & $8.765=2.677$ & $655 \pm 2464$ & $0.95 \pm 1.5687$ \\
\hline \multicolumn{4}{|c|}{$\begin{array}{l}\text { Ind vidual percentages were calculated as the number of } \\
\text { abnomal leaves from the total number of leaves in each rosette. } \\
( \pm) \text { values indicate standard error for } n=20\end{array}$} \\
\hline
\end{tabular}

TABLE VIII. Depicts average number of seeds for 40 mature $s$ ques from wild-type and transgenco plants.

\begin{tabular}{lcr}
\hline \multicolumn{3}{c}{ Average number of seeds } \\
\hline Wild type & $35 S: A t H D 2 C 1$ & $35 S$ AthD2C2 \\
$101 \pm 3.47$ & $62 \pm 5.2$ & $60 \pm 5.365$ \\
\hline$( \pm)$ values indicate standard error for $n=40$ \\
\end{tabular}

TABLE IX Depicts average percentage" of mature stunted s'ques for 20 wid-type and transgenc plants.

\begin{tabular}{|c|c|c|}
\hline \multicolumn{3}{|c|}{ Average percentage $(\gamma)$ of stunted s ques } \\
\hline Wid type & $355.4+H D 2 C 1$ & $359-41 H D 2 C 2$ \\
\hline $6.2051 \pm 1.0507$ & $20.282 \pm 1.458$ & $21.128 \pm 1.3820$ \\
\hline \multicolumn{3}{|c|}{$\begin{array}{l}\text { "Individual percentages were calculated as the number of stunted } \\
\text { siliques from the total number of siliques on each plant. (t) } \\
\text { values indicate standard emor for } n=20\end{array}$} \\
\hline
\end{tabular}


This insertion line was subsequently used for ABA, salt and mannitol sensitivity assays in the seedling stage. The T-DNA insertion line demonstrated similar phenotypic sensitivity as the wild-type plants to treatment with ABA, salt or mannitol (Figure 20D-G). The germination rates and root length elongation efficiency was the same as wild-type. Also, the T-DNA insertion plants were as sensitive to salt and drought in the vegetative stage as the wild-type plants (Figure 20E).

\section{(c) 35S:AtHD2C seeds are insensitive to $\mathrm{ABA}, \mathrm{NaCl}$ and Mannitol during germination and post- germination development phase}

\section{ABA response}

$\mathrm{ABA}$ is instrumental for embryo maturation and maintaining smooth transitions between developmental windows, such as radicle emergence and seedling growth (Hoecker et al, 1995). Based on previous reports describing accumulation of $H D 2 B$ and $H D 2 C$ mRNA in geminating embryos of Arabidopsis and down-regulation of 'seed specific' genes in AtHD2A mutant (Wu et al, 2004), we tested ABA sensitivity of the 35S:AtHD2C plants. The 35S:AtHD2C seeds were not viviparous and did not demonstrate defects in chlorophyll loss or attaining desiccation tolerance as evidenced by the normal maturation and hardening of the seeds. The loss of green color and hardening of seed-coat in normal time-span was the indicator of ABA production in the transgenic seeds. We further examined the sensitivity of the transgenic lines to $\mathrm{ABA}$, during the germination post-germination events of radicle emergence, seedling greening and expansion. 35S:AtHD2C transgenic seeds were 

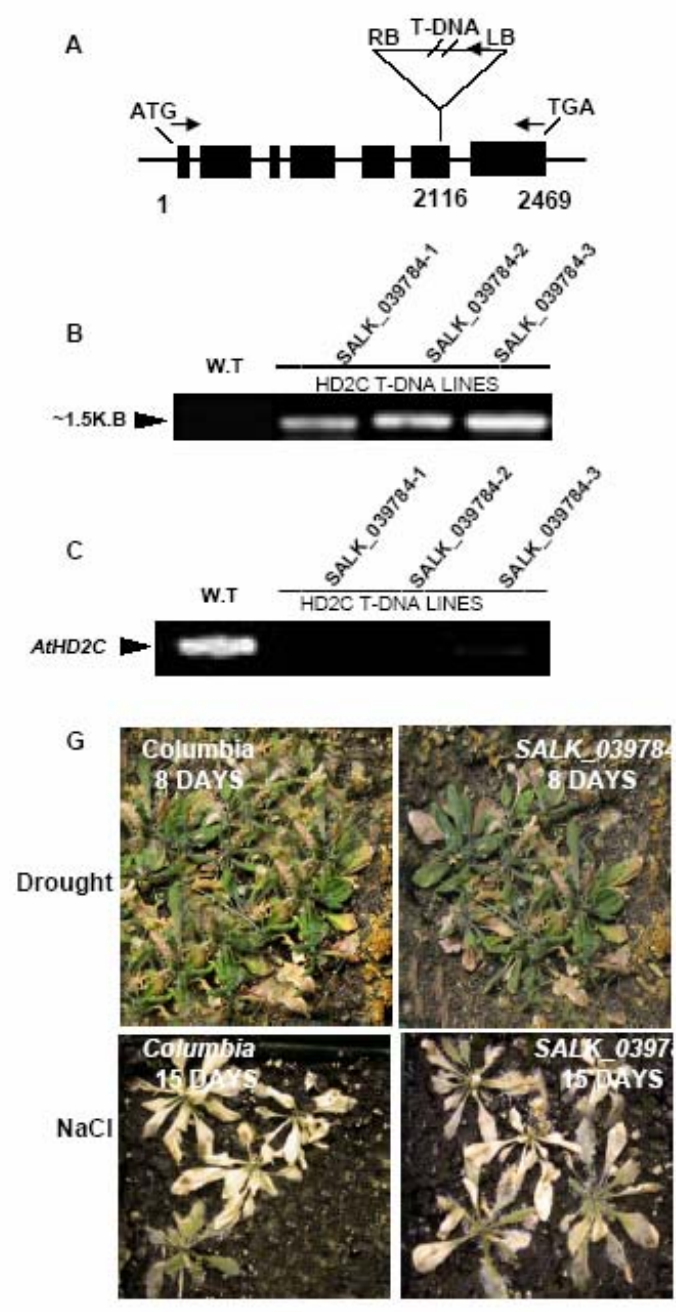

D

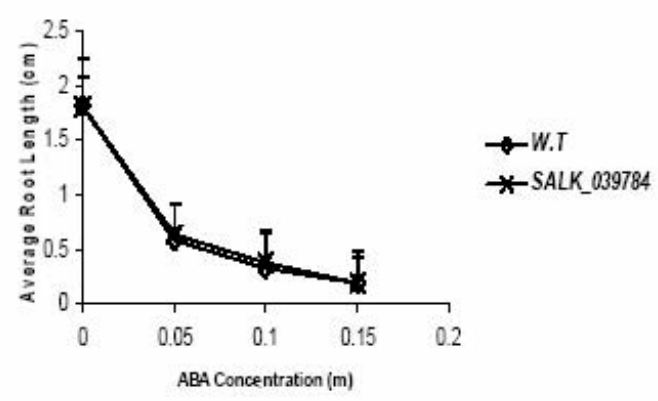

E

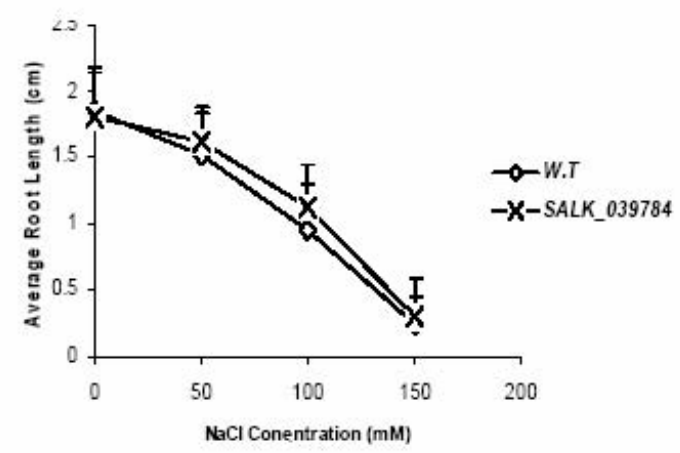

F

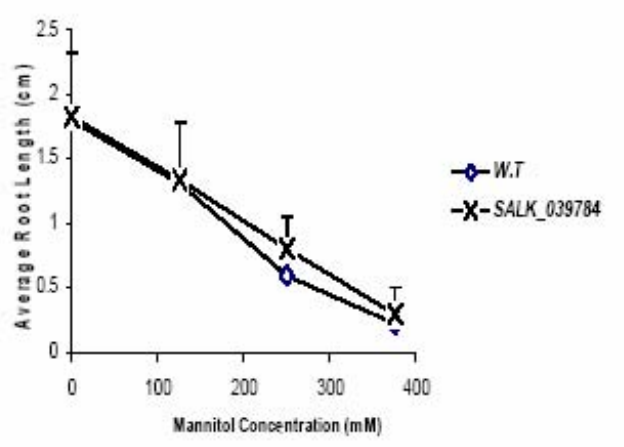


Figure 20. SALK_039784 (T-DNA insertion Line) plants are sensitive to ABA and stress in germination/post-germination and vegetative stages. (A) Map of the AtHD2C gene, black boxes indicating position of exons. The open triangle indicates position of insertion of the TDNA. The arrow inside the triangle indicates T-DNA specific primer used in the PCR analysis. (B) PCR analysis to confirm homozygosity of the insertion lines. Genomic DNA was extracted from T3 plants selected on kanamycin and was used as a template for PCR using the primer pairs a 5' $A t H D 2 C$ specific primer and a 3' T-DNA (Indicated by an arrow inside the triangle) LB primer. Three plants of the same insertion line were examined, i.e., SALK_039784-1, SALK_039784-2, SALK_039784-3. (C) RT-PCR analysis to confirm decrease in $A t H D 2 C$ transcript accumulation. RNA levels of $A t H D 2 C$ were determined by RT-PCR using total RNA isolated from 4-week old plant grown in soil in the 16 hour light photoperiod. (D) Root growth of WT and SALK_039784 (T-DNA insertion Line) seedlings on ABA medium. Seeds were germinated on MS medium containing varying concentrations of ABA ranging from 0-0.2 $\mu \mathrm{M}$. Root elongation was measured 5 days after incubation. The experiments were performed more than three times, sometimes and the results were consistent. The bars represent standard errors $(\mathrm{n}=40)$. (E) Root growth of WT, SALK_039784 (T-DNA insertion Line) seedlings on $\mathrm{NaCl}$ medium. Root elongation was measured 5 days after incubation. The small bars represent standard errors $(n=40)$. (F) Root growth of WT, SALK_039784 (T-DNA insertion Line) seedlings on mannitol medium. (G) Draught and Salt sensitivity of the SALK_039784 (T-DNA insertion Line) plants. 
incubated on medium with $\mathrm{ABA}$ concentrations ranging from $0.05 \mu \mathrm{M}-0.2 \mu \mathrm{M}, 2$ days poststratification. The wild-type plants were able to germinate and form cotyledons on medium with $0.05 \mu \mathrm{M}$ of $\mathrm{ABA}$, but they displayed acute sensitivity to $0.1 \mu \mathrm{M} \mathrm{ABA}$ (Figure $21 \mathrm{~A}$ ). Subsequent to seed-coat breakage and radicle emergence, there was growth arrest with inhibition of cotyledon formation and further development on medium with $0.1 \mu \mathrm{M}$ ABA. On the other hand, the $35 \mathrm{~S}: A t H D 2 C$ transgenic seeds were able to germinate and grow unrestricted at this $\mathrm{ABA}$ concentration and successfully developed healthy cotyledons and true leaves. Like the study conducted by Kang et al, (2002), we wanted to determine the stage specificity of the ABA response. Therefore, we analyzed the ability of the $35 \mathrm{~S}: \mathrm{AtHD} 2 \mathrm{C}$ seeds to germinate and develop embryonic root in the presence of ABA. At $0.1 \mu \mathrm{M}$ concentration of $\mathrm{ABA}, 63 \%$ retardation in the germination rate of the wild-type plants was observed. However, there was only $28 \%$ retardation in the germination rate of the two 35S:AtHD2C transgenic lines (Figure 21C). A $0.05 \mu \mathrm{M}$ concentration of ABA was able to restrict root growth in the wild-type seedlings by a margin of $97.3 \%$. At the same time, the 35S:AtHD2C transgenic seedlings were able to elongate root primordia with a minimal inhibition of $6.7 \%$ compared to control rates. Additionally, the development of the aerial parts from the shoot apical meristem was severely limited in wild-type seedlings at the concentration of $0.05 \mu \mathrm{M} \mathrm{ABA}$, whereas the $35 S$ :AtHD2C transgenic seedlings continued to develop cotyledons and true leaves at a concentration of $0.1 \mu \mathrm{M}$ ABA (Figure 21D and 21B). Upon further increasing ABA concentrations to $0.15 \mu \mathrm{M}$, the transgenic cotyledons displayed growth arrest, thus succumbing to retardation. These results reflect the ability of 
A

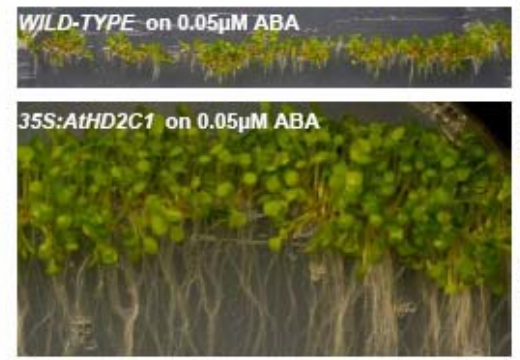

B
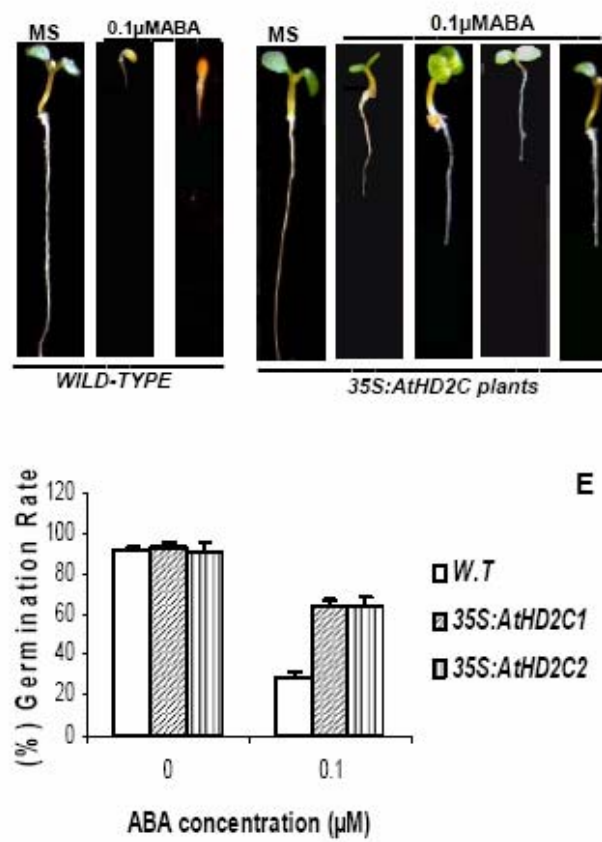

E

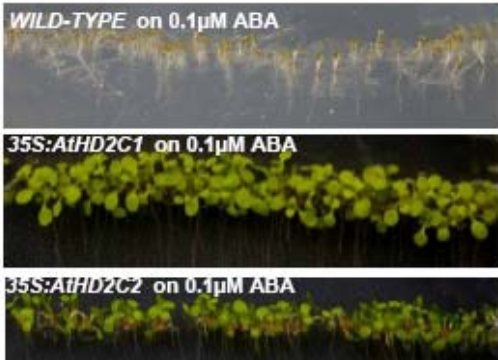

D
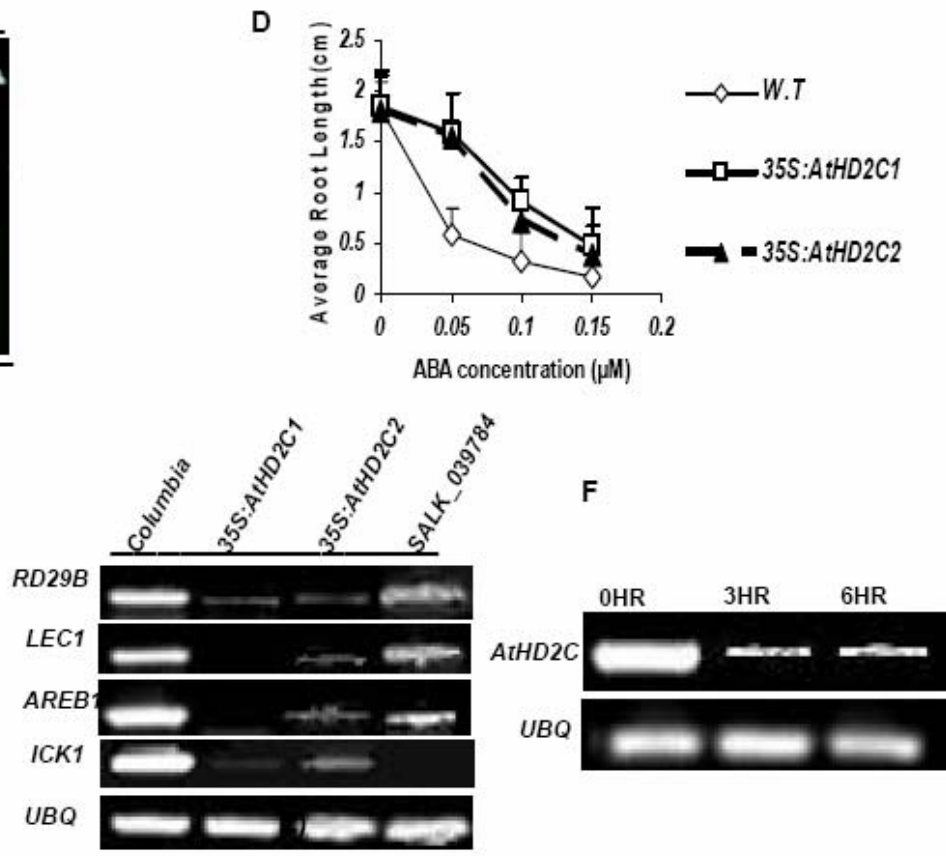
Figure 21. ABA sensitivity of the 35S:AtHD2C1 and 35S:AtHD2C2 lines in germination and post-germination stage. (A) Growth of WT, 35S:AtHD2C1 and 35S:AtHD2C2 transgenic seedlings on MS medium containing $0.05 \mu \mathrm{M}$ and $0.1 \mu \mathrm{M}$ of ABA respectively. Seeds were germinated and grown for 12 days. (B) Growth of WT, 35S:AtHD2C1 and 35S:AtHD2C2 transgenic seedlings on MS medium containing $0.1 \mu \mathrm{M}$ ABA. Seeds were germinated on the medium for 4 days, and representative plants (out of forty examined) were shown. (C) Germination rate of WT, 35S:AtHD2C1 and 35S:AtHD2C2 transgenic seeds on ABA. 8week old T3 seeds were pre-chilled for 2 days at $4^{\circ} \mathrm{C}$ and were germinated on MS medium containing $0.1 \mu \mathrm{M}$ of ABA. Seedlings with fully emerged radicles and cotyledons were scored to obtain percent germination. Experiments were performed in triplicate (n=100 each), and the bars show standard errors. (D) Root growth of WT, 35S:AtHD2C1 and 35S:AtHD2C2 transgenic seedlings on ABA. 8-week old T3 seeds were germinated on MS medium containing varying concentrations of $\mathrm{ABA}$ ranging from $0-0.2 \mu \mathrm{M}$. Root elongation was measured 5 days after incubation. The experiments were performed more than three times. The bars represent standard errors $(n=40)$. (E) Expression of ABA-regulated genes in the germination/post-germination phase in WT, 35S:AtHD2C1 and 35S:AtHD2C2 transgenic lines, and SALK_039784 (T-DNA Line), ABA-responsive genes were determined by RTPCR using total RNAs isolated from 1-week-old plants grown on MS plates. Ubiquitin served as the internal control. (F) Expression of $A t H D 2 C$ in WT treated with ABA; RNA levels of AtHD2C were determined by RT-PCR using total $1 \mu \mathrm{g}$ RNAs isolated from 1-weekold wild-type seedlings. 
AtHD2C to interfere with ABA-mediated growth retardation at the germination and postgermination growth stages.

$L E C 1, R D 29 B$ and $A R E B 1$ genes are typical markers of the different phases of embryonic maturation (Finklestein and Rock, 2002). Therefore, we examined the alteration in expression patterns of these genes in the 35S:AtHD2C transgenic seedlings (Figure 21E). 35S:AtHD2C transgenic seedlings were collected immediately after cotyledon formation and embryonic root establishment (4 days post-germination) and were assayed for ABA-inducible gene expression patterns. $L E C 1$ functions at the terminal stage of the cell division phase of embryogenesis to prevent further cell division and precocious germination (Holdsworth et al, 1999). The expression of this gene was down-regulated in the $35 S$ :AtHD2C transgenic seedlings. Corresponding to this observation, the expression of the AREBI was also down- regulated. AREB proteins are bZIP class transcription factors that work synergistically during embryonic growth (reviewed in Holdsworth et al, 1999, 2001). The ICK1 gene works hand-in-hand with $L E C 1$ in the process of cell division termination as it is an inhibitor of cyclin dependant kinases that propagate cell division (Finklestein and Rock, 2002). The expression of LEA (Late embryogenesis abundant) gene, RD29B that is essential for maintaining dormancy (Delseny et $a l, 2001)$ was also decreased. Transcript accumulation of all these genes was also examined in the SALK_039784 (T-DNA insertion line) line (characterized in Figure 20). Expression of these genes was weaker in the SALK_039784 line compared with wild-type. There is speculation about role of post-germination down-regulation of embryogenesis promoting regulators such as $L E C 1$ by epigenetic modification mechanisms (Ogas et al., 1999). To analyze the response of AtHD2C to ectopic application of $\mathrm{ABA}$ in the seedling stage, the transcript accumulation of $A t H D 2 C$ in response to 6 hours $\mathrm{ABA}(100 \mu \mathrm{M})$ treatment was analyzed. 
A
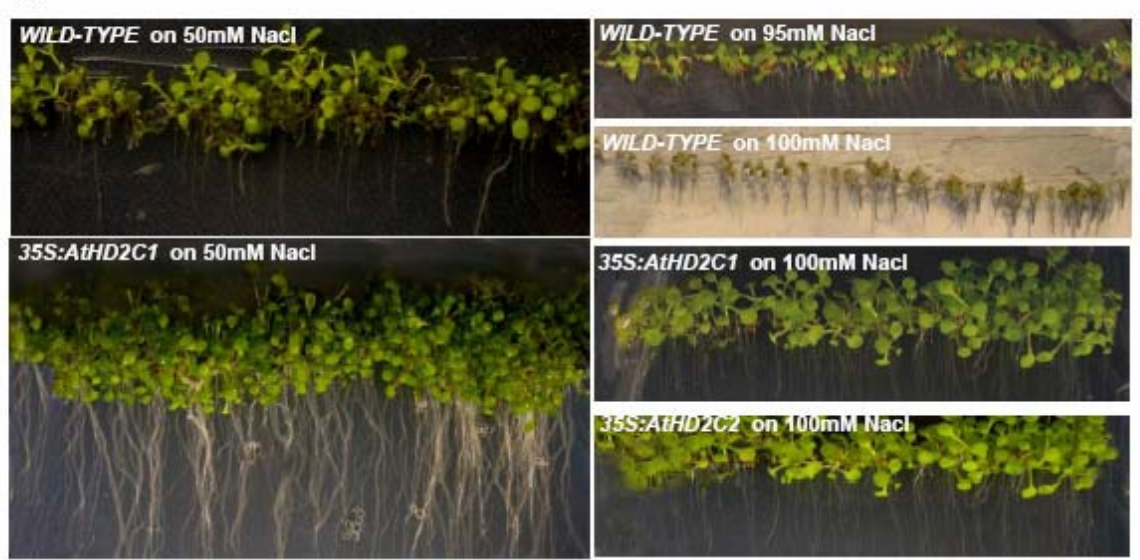

B

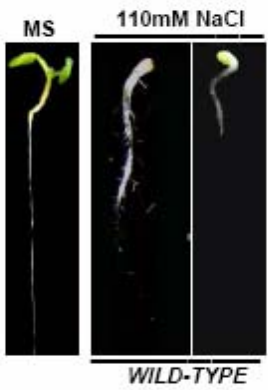

C

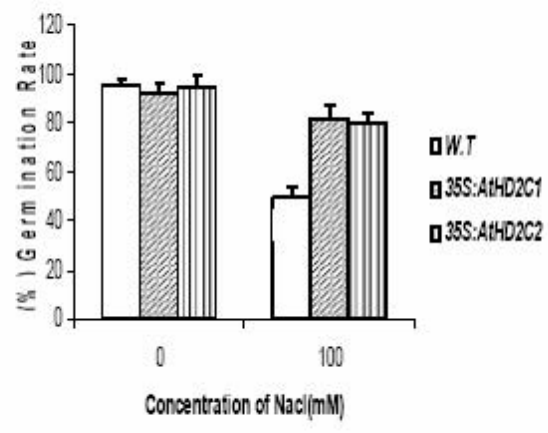

D

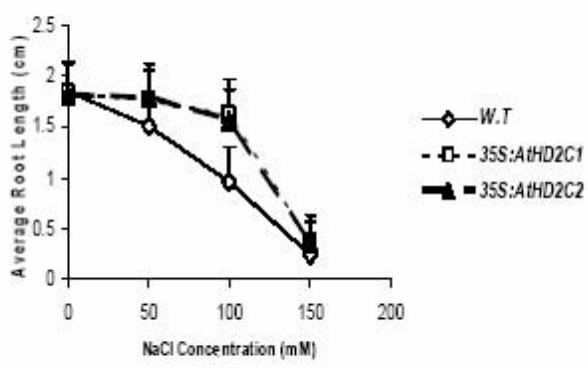


Figure 22. $\mathrm{NaCl}$ sensitivity of the $35 \mathrm{~S}: \mathrm{AtHD} 2 \mathrm{C1}$ and $35 \mathrm{~S}$ : AtHD2C2 lines in germination and post-germination stage . (A) Growth of WT, 35S:AtHD2C1 and 35S:AtHD2C2 transgenic seedlings on MS medium containing $50 \mathrm{mM}$ and $100 \mathrm{mM}$ of Nacl, respectively. Seeds were germinated and grown for 12 days. (B) Growth of WT, 35S:AtHD2C1 and 35S:AtHD2C2 transgenic seedlings on MS medium containing $100 \mathrm{mM} \mathrm{Nacl}$. Seed were germinated on the medium for 4 days, and representative plants (out of forty examined) are shown. (C) Germination rate of WT, 35S:AtHD2C1 and 35S:AtHD2C2 transgenic seeds on NaCl. 8week old T3 seeds were pre-chilled for 2 days at $4^{\circ} \mathrm{C}$ and were germinated on MS medium containing $100 \mathrm{mM}$ of $\mathrm{NaCl}$. Seedlings with fully emerged radicles and cotyledons were scored to obtain percent germination. Experiments were performed in triplicate $(n=100$ each), and the bars represent standard errors. (D) Root growth of WT, 35S:AtHD2C1 and 35S:AtHD2C2 transgenic seedlings on $\mathrm{NaCl}$ media. Seeds were germinated on MS medium containing varying concentrations of $\mathrm{NaCl}$ from $0-200 \mathrm{mM}$. Root elongation was measured 5 days after incubation. The bars represent standard errors $(n=40)$. 
It was observed that the $A t H D 2 C$ transcript was partially reduced in the seedlings by ABA treatment (Figure 21F). This observation supports the idea that ABA regulates AtHD2C expression negatively at certain steps in the signaling cascade, probably to de-repress essential signal transducers. Both germination and post-germination growth stages are insensitive to $\mathrm{ABA}$ and this is supported by the down-regulation of the ABA-inducible genes in the 35S:AtHD2C seedlings.

\section{$\mathrm{NaCl}$ response}

There now is substantial evidence for cross talk between signaling pathways regulating response to $\mathrm{ABA}$ and assorted stresses (e.g., drought, salinity, and cold) (Ishitani et al, 1997), sugars (Arenas-Huertero et al, 2000; Finkelstein and Lynch, 2000; Huijser et al, 2000; Laby et al, 2000), and even meristem function (Ziegelhoffer et al, 2000). Therefore, we tested the salt sensitivity of the AtHD2C overexpression line based on its resistance to ABA. All ABAdeficient $(a b a)$ and ABA-insensitive (abi) mutants tend to exhibit salt insensitivity during germination (Leon-Kloosterziel et al., 1996). Figure 22C depicts that $100 \mathrm{mM}$ of $\mathrm{NaCl}$ was able to reduce germination of the wild-type plants by a margin of $45.9 \%$ whereas the germination efficiencies of the 35S:AtHD2C1 and 35S:AtHD2C2 lines were reduced by mere margins of $11.2 \%$ and $14.17 \%$ respectively. Additionally, the $35 S: A t H D 2 C$ overexpression lines demonstrated healthy germination, radicle emergence, cotyledon expansion and true leaf formation when grown on increasing concentrations of $\mathrm{NaCl}$ ranging from $50-110 \mathrm{mM}$ (Figure 22A), after that root elongation was curbed and growth was halted. 
A

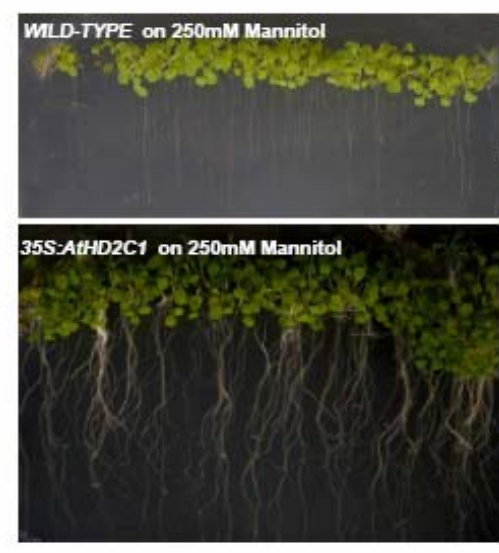

C
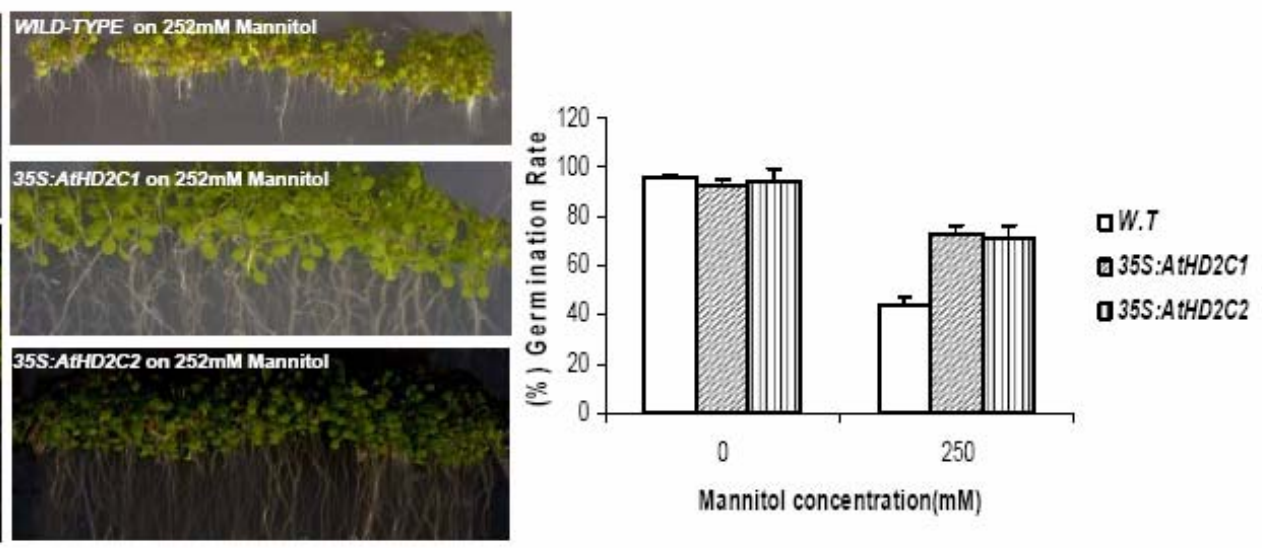

D

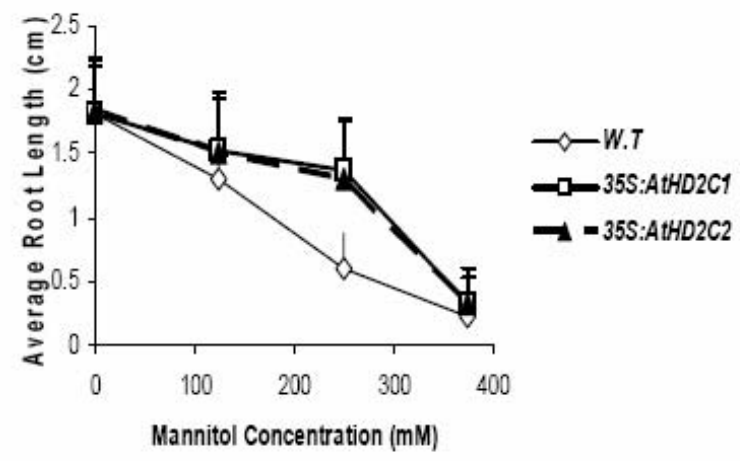


Figure 23. Mannitol sensitivity of the 35S:AtHD2C1 and 35S:AtHD2C2 lines in germination and post-germination stage. (A) Growth of WT, 35S:AtHD2C1 and 35S:AtHD2C2 transgenic seedlings on MS medium containing $50 \mathrm{mM}$ and $250 \mathrm{mM}$ of mannitol respectively. Seeds were germinated and grown for 12 days. (B) Growth of WT, 35S:AtHD2C1 and 35S:AtHD2C2 transgenic seedlings on MS medium containing $250 \mathrm{mM}$ mannitol. Seeds were germinated on the medium for 4 days, and representative plants (out of forty examined) are shown. (C) Germination rate of WT, 35S:AtHD2C1 and 35S:AtHD2C2 transgenic seeds on a mannitol medium. Seeds were pre-chilled for 2 days at $4^{\circ} \mathrm{C}$ and were germinated on MS medium containing $250 \mathrm{mM}$ concentration of mannitol. Seedlings with fully emerged radicles and cotyledons were scored to obtain percent germination. Experiments were performed in triplicate $(\mathrm{n}=100$ each), and the bars represent standard errors. (D) Root growth of WT, 35S:AtHD2C1 and 35S:AtHD2C2 transgenic seedlings on mannitol. 8-week old T3 seeds were germinated on MS medium containing varying concentrations of mannitol ranging from 0-400 mM. Root elongation was measured 5 days after incubation. The bars represent standard errors $(n=40)$. 
At $50 \mathrm{mM}$ of $\mathrm{NaCl}$, the wild-type root elongation dropped by $18 \%$, whereas the $35 \mathrm{~S}:$ AtHD2C transgenic lines lost 3.9\% and 3\% of their root elongation efficacy at the same concentration for 35S:AtHD2C1 and 35S:AtHD2C2 lines respectively (Figure 22D). At a $100 \mathrm{mM}$ concentration of $\mathrm{NaCl}$ could we observed a distinct difference in the behavior of the wildtype and transgenic lines; wild-type plants showed a decrease in root length by $48 \%$ as compared to the $11.9 \%$ and $14.4 \%$ drop of the $35 S: A t H D 2 C 1$ and $35 S: A t H D 2 C 2$ lines, respectively (Figure 22B). Further increase in $\mathrm{NaCl}$ concentration proved to be toxic and growth inhibitory for the transgenic plants. The root elongation pattern differences can be evidenced in Figure 20B. Down-regulation of $L E C$ and $R D 29 B$ in the 35S:AtHD2C lines (Figure 22E) was regarded as a marker for reduction in $\mathrm{ABA}$ mediated $\mathrm{NaCl}$ signaling in these lines as salt inhibits cell division and enhances desiccation tolerance via ABA signaling.

\section{Mannitol response}

Mannitol accumulation increases when plants are exposed to low water potential (Patonnier et al, 1999), and accumulation is regulated by inhibition of competing pathways and decreased mannitol consumption and catabolism (Pharr et al, 1995; Stoop et al, 1996). Mannitol is used to asses the response of plants to osmotic stress. 35S:AtHD2C transgenic seedlings were germinated 2 days post-stratification on MS medium containing 0-400 mM concentrations of mannitol; Columbia wild-type seedlings could grow and develop on medium containing $225-240 \mathrm{mM}$ of mannitol. A $250 \mathrm{mM}$ concentration of mannitol arrested their post-germination development. However, the wild-type seedlings could germinate and develop true-leaves, but the seedlings were unhealthy (yellow in color). Whereas, the 35S:AtHD2C transgenic plants demonstrated insensitivity to the same concentrations of 
mannitol as germination was robust and root elongation was expansive (Figure 23A). Germination was reduced by $52.2 \%$ in wild-type seeds at $252 \mathrm{mM}$ of mannitol, whereas the 35S:AtHD2C1 and 35S:AtHD2C2 lines lost only $19.8 \%$ and $22.8 \%$ of their germination efficiency, respectively, at the same concentration of mannitol (Figure 23C).

Additionally, root development was monitored for embryonic root extension and cotyledon expansion. Wild type seedlings did not develop healthy green cotyledons subsequent to germination and radicle establishment on medium containing $250 \mathrm{mM}$ concentration of mannitol. Rather, they incurred a massive reduction of $67.3 \%$ in root growth that declined further on higher concentrations. The 35S:AtHD2C1 and 35S:AtHD2C2 lines however were able to establish embryonic root and form healthy green cotyledons and suffered a relatively minor loss of $28.5 \%$ and $18.2 \%$ in their root growth, respectively (Figure 23B and 23D). This data indicates a role for AtHD2C not only in ionic stress response, but also in regulation of osmotic stress networks.

\section{(d) 35S:AtHD2C plants demonstrate vegetative stress tolerance in response to $\mathrm{NaCl}$ and drought}

Apart from its critical function in maintaining seed dormancy regulating germination and seedling growth, ABA helps in optimizing vegetative growth during environmental stress conditions by maintaining osmotic homeostasis. At the cellular level, ABA is known to promote tolerance to abiotic stresses such as cold, drought and salinity (reviewed in Rock, 2000; Shinozaki and Yamaguchi-Shinozaki, 2000; Xiong and Zhu, 2001; Larkindale and Knight, 2002). Our results indicated a function for AtHD2C in the ABA mediated regulation of germination and post-germinative programming. We sought to investigate the response of the 35S:AtHD2C transgenic plants to abiotic stress imposition by exposing them to physiological concentrations of salt and low-water stress. 
Wild-type plants and 35S:AtHD2C transgenic, 30-day old plants were watered with 300 $\mathrm{mM}$ of $\mathrm{NaCl}$ for a period of 25 days. Differences between wild-type and transgenic plants in their ability to tolerate ion toxicity and osmotic stress became evident $5^{\text {th }}$ day onwards. The wild-type leaves demonstrated yellowing and manifestation of senescence, whereas the transgenic leaves maintained a healthy green appearance and very little cellular decay. This survival efficiency was measured as the percentage of green leaves over the time-span. On the $5^{\text {th }}$ day after treatment (DAT), $63 \%$ of the wild-type leaves were green whereas $93.9 \%$ and $90.9 \%$ of the $35 S: A t H D 2 C 1$ and 35S:AtHD2C2 leaves survived, respectively. The 35S:AtHD2C1 and 35S:AtHD2C2 leaves stayed green and the plants bolted, with senescence setting in at 20 days after treatment $(60.4 \%$ and $56.5 \%)$, at that point onwards there was a sharp decline to $20.4 \%$ and $15.6 \%$ survival rates respectively. This was in significant contrast to the wild-type counterparts, that senesced to $34.3 \%$ by the $10^{\text {th }}$ day and further perished by the $20^{\text {th }}$ day, when their survival rate was just $5.2 \%$. The wild- type plants never bolted and consequently never transited to flowering (Figure 24) ABA has been shown to be involved in the regulation of many stress-induced genes, and in some instances has been shown to be required for changes in gene expression in response to water-deficit stress (Bray, 1997). Twenty-two day old wild-type and transgenic plants were grown in pots that were left unwatered for a period of 25 days. Significant difference between wild-type and transgenic plants was observed 10 days after the plants were left unwatered. 
A
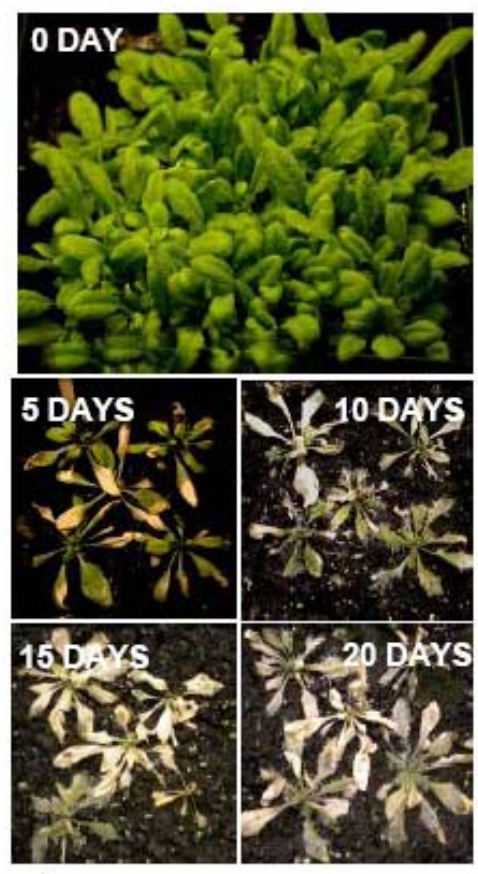

Wild-type
B

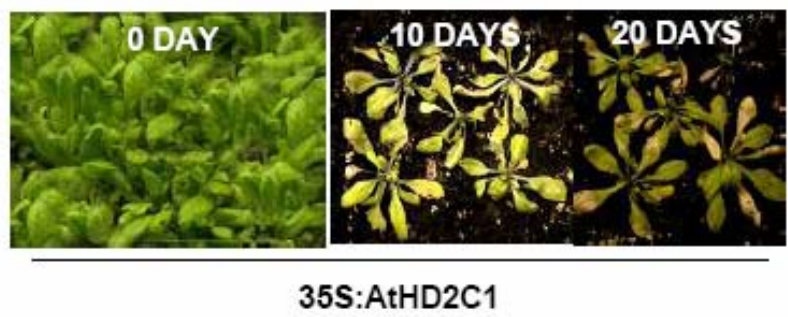

D

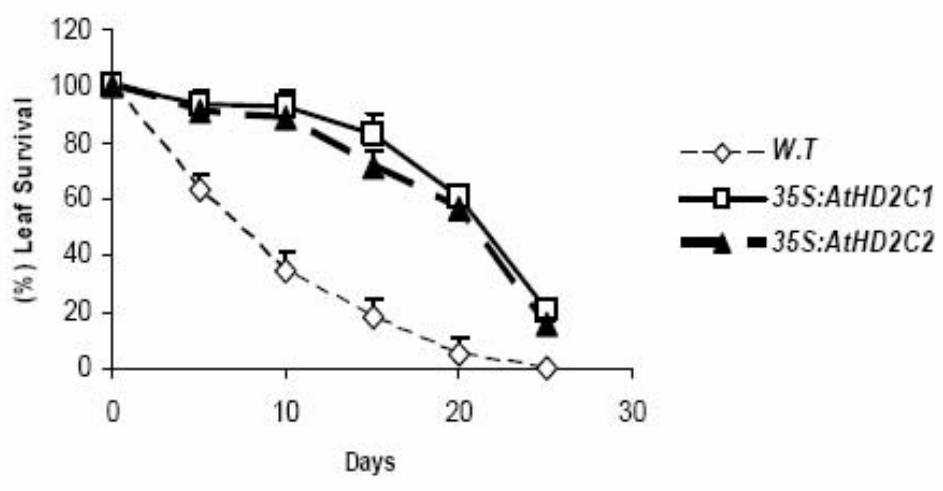


Figure 24. Salt tolerant phenotype of the $35 S$ :AtHD2C plants in the vegetative stage. (A) Salt sensitivity of WT plants. Plants were germinated and grown on soil for 22 days and the mature rosettes were subsequently supplemented with water containing $300 \mathrm{mM}$ of $\mathrm{NaCl}$ for 25 days. The photographs were taken at every five day intervals. (B) Salt tolerance of 35S:AtHD2C1 and transgenic plants. Transgenic plants were germinated and grown on soil for 22 days and the mature rosettes were subsequently supplemented with water containing $300 \mathrm{mM} \mathrm{NaCl}$ for 25 days. The photographs were taken at very five day intervals. (C) Salt tolerance of $35 S: A t H D 2 C 2$ and transgenic plants. Transgenic plants were germinated and grown on soil for 22 days and the mature rosettes were subsequently supplemented with water containing $300 \mathrm{mM}$ of $\mathrm{Nacl}$ for 25 days. The photographs were taken at very five day intervals. (D) Leaf survival rate of the WT, 35S:AtHD2C1 and 35S:AtHD2C2 transgenic plants in salt stress conditions. Plants were germinated and grown on soil for 30 days and the mature rosettes were subsequently supplemented with water containing $300 \mathrm{mM}$ of $\mathrm{NaCl}$ for 25 days. Number of green leaves in a rosette were counted at five day intervals for 40 plants to obtain the survival curve. Bars depict standard error $(n=40)$. 
The marker for survival here also, was the percentage of leaves sustaining chlorophyll after treatment. On the $10^{\text {th }}$ day, the survival count dropped to $44.4 \%$ for the wild-type plants, whereas it was relatively stable for the two transgenic lines at $88.6 \%$ and $80 \%$, respectively. From this point onwards both wild-type and transgenic lines demonstrated sharp declines in their respective survival rates, but the transgenic plant decayed at much slower rate when compared with wild-types. On the $15^{\text {th }}$ day, $6.7 \%$ of the wild-type leaves survived whereas 35S:AtHD2C1 and 35S:AtHD2C2 plants maintained $47.6 \%$ and $45.1 \%$ leaf survival, respectively (Figure25A, 25C and 25D).

We also measured the fresh weights of the wild-type and transgenic plants with these treatment conditions. As shown in Figure 25B, the 35S:AtHD2C1 and 35S:AtHD2C2 plants maintained a slow decline from their pre-treatment weights as compared with the wildtype plants that experienced a drastic drop in their weight when exposed to drought. Additionally, the stomatal aperture was investigated in the wild-type and transgenic plants in the middle of the dehydration treatment. It was evident that, the stomata in the $\mathrm{AtHD} 2 \mathrm{Cl}$ and AtHD2C2 leaves were either partially or completely open as opposed to the wild-type stomata that were closed in dehydrating conditions (Figure 26). Water-deficit or high-salt conditions induce dehydration of plant cells, that may trigger physiological and biochemical responses against such stresses. Most of the genes that respond to dehydration, salinity and low temperature are inducible by ABA (Nordin and Palva, 1992). Many genes that respond to $\mathrm{ABA}$ are also expressed at the late stages of embryogenesis during the development of seeds and are thought to function in the protection of cell dehydration. Therefore, we checked the expression levels (Figure 27) of LEA class genes, $R D 29 B$ and $R A B 18$ that function 

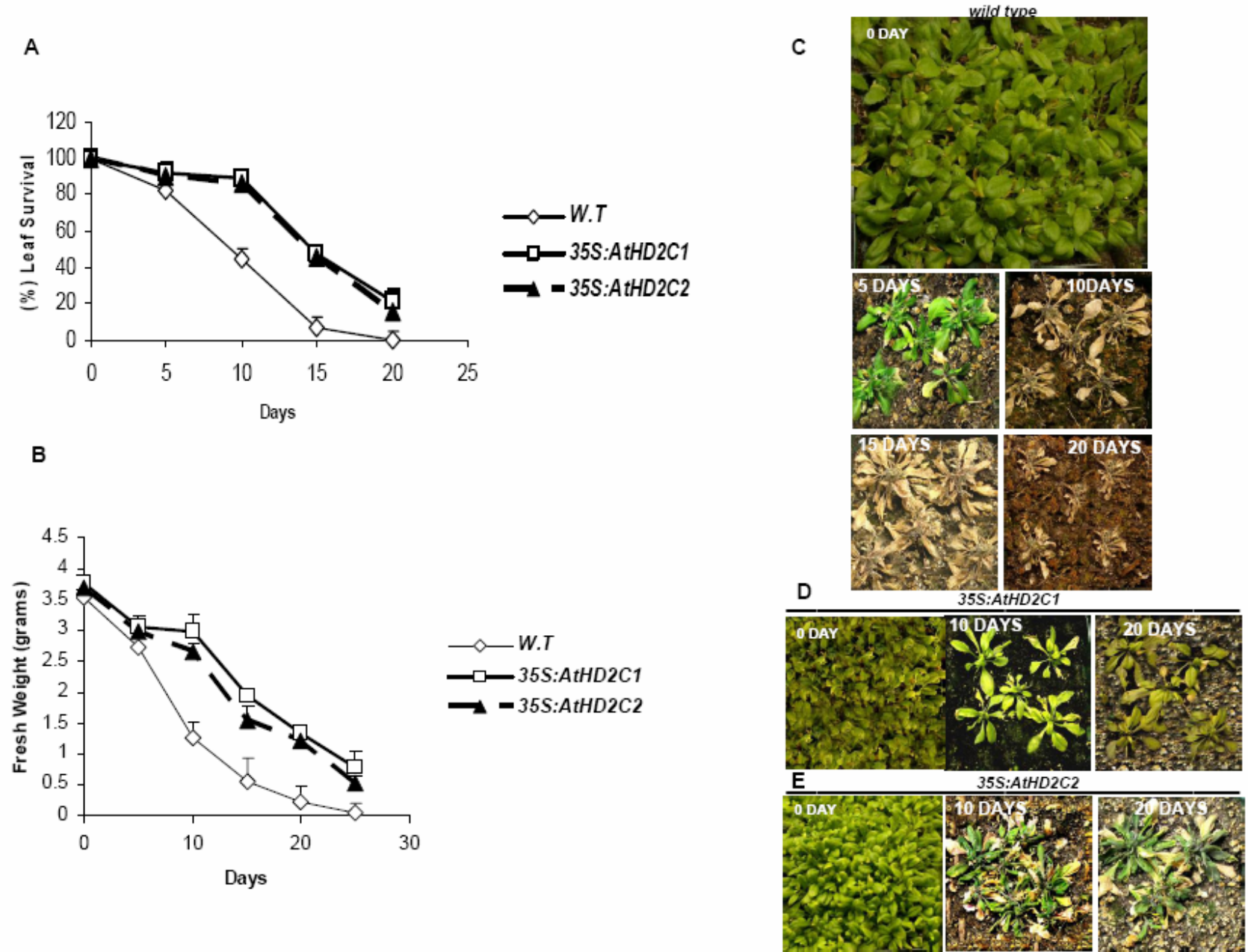
Figure 25. Drought tolerance of the 35S:AtHD2C plants; (A) Leaf survival rate of the WT, 35S:AtHD2C1 and 35S:AtHD2C2 transgenic plants in draught stress conditions. Plants were germinated and grown on soil for 30 days and the mature rosettes were subsequently withheld from water for 25 days. Number of green leaves in a rosette were counted at five day intervals for 40 plants to obtain the survival curve. Bars represent standard error $(n=40)$. (B) Fresh weight loss of the WT, 35S:AtHD2C1 and 35S:AtHD2C2 transgenic plants in draught stress conditions. Plants were germinated and grown on soil for 22 days and the mature rosettes were subsequently withheld from water for 25 days. The fresh weight of detached rosettes was measured at every five day intervals for 20 plants. Bars represent standard error $(n=20)$. (C) Draught sensitivity of wild-type plants. Plants were germinated and grown on soil for 22 days and the mature rosettes were subsequently withheld from water for 25 days. The photographs were taken at every five day intervals. (D) Drought tolerance of 35S:AtHD2C1 and transgenic plants. Transgenic plants were germinated and grown on soil for 22 days and the mature rosettes were subsequently withheld from water for 25 days. The photographs were taken at very five day intervals. 
during the late phase of seed maturation to confer desiccation tolerance to the seed and are known to accumulate during dehydration stress in the vegetative stage.A distinct upregulation of these genes was observed in 35S:AtHD2C1 and 35S:AtHD2C2 transgenic tissue, collected from mature rosette leaves (30 days after germination). Genetic studies have established that $A B I 1$ and $A B I 2$ are negative regulators of $\mathrm{ABA}$ transduction signals (Gosti et al, 1999; Leung et al, 2001). The concomitant increases of $A B I 1$ and $A B I 2$ mRNA levels and corresponding protein phosphatase activities induced by ABA have led to a model (Merlot $e t$ al, 1997) in that $A B I 1$ and $A B I 2$ take part in a negative feedback regulatory loop that continuously resets the $\mathrm{ABA}$ signaling cascade to adjust the response to the $\mathrm{ABA}$ level (Cherel et al, 2002). These two genes are positioned upstream to $\mathrm{Ca}^{2+}$ induced S-type anion channel activation whereby, $\mathrm{K}^{+}$efflux is initiated in the guard cells leading to stomatal closure (Hamilton et al, 2000). ABII accumulation was unaffected in the 35S:AtHD2C transgenic lines, but $A B I 2$ levels were severely reduced in the transgenic lines. These results were complemented by a weak rescue of $A B I 2$ expression in the $\$ 28601$ line, indicating specific targeting of the $A B I 2$ dependant signal processing. This led us to examine expression of $A B I 2$ inducible gene $A D H 1$, as de Bruxelles et al, (1996) demonstrated a reduction in $A D H 1$ accumulation in the abi2 mutants. Accordingly, a down-regulation of $A D H 1$ was observed in the 35S:AtHD2C transgenic lines. KAT1 and KAT2 are $\mathrm{K}+$ inward rectifying channels that are regulated by their phosphorylation status and are inhibited by ABA production during dehydration stress (Gaymard et al, 1998). This mediates the closing of stomata due to turgor loss and membrane depolarization that permits retention of water during deficit. The expression of both of these genes was reduced in the 35S:AtHD2C 

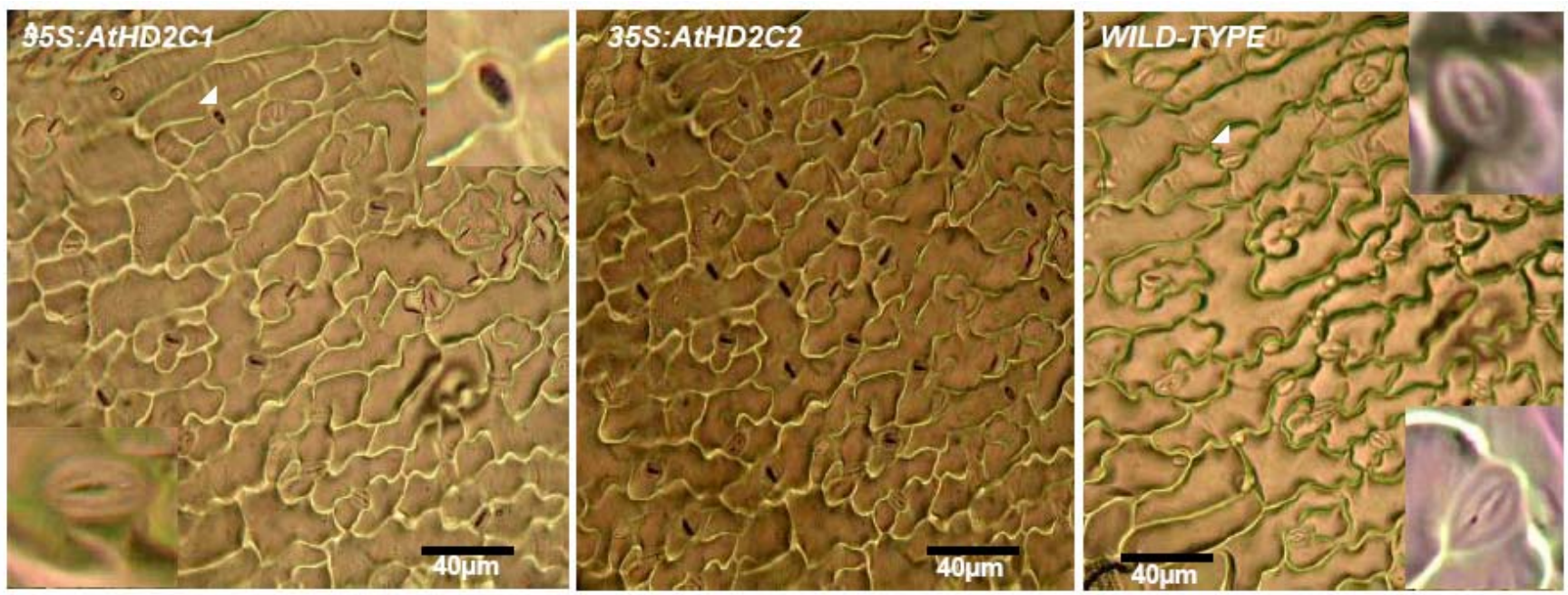

TABLE IX. Depicts Average percentage of closed stomata (adaxial surface) counted for 10 wild-type and transgenic leaves respectively.

\begin{tabular}{lcc}
\hline \multicolumn{3}{c}{ Average percentage (\%) of open stomata* } \\
\hline Wild type & 35S:AtHD2C1 & 35S:AtHD2C2 \\
\hline & & \\
$83.3 \pm 1.667$ & $42.4 \pm 0.645$ & $35.05 \pm 1.656$ \\
\hline
\end{tabular}

* Individual percentages were calculated as the number of number of closed stomata from the total number of 400 stomata on the adaxial surface of each leaf. $( \pm$ ) values indicate standard error for $n=10$

Figure 26. Stomatal aperture of the WT, 35S:AtHD2C1 and 35S:AtHD2C2 transgenic plants; Stomatal guard cells were observed in the middle of the dry period (15 days after dewatering). Arrows indicate guard cells, and the insets show representative stomata. The bars at the bottom of the pictures represent the magnification under which these bright field pictures were taken. 
transgenic lines and rescued in the SALK_039784 lines, further supporting a positive role for AtHD2C in vegetative ABA mediated stress signaling Xylem $\mathrm{K}^{+}$content is regulated by activity of a stelar $\mathrm{K}^{+}$outward rectifier (SKOR) (Gaymard et al, 1998) that is repressed by ABA. Repression of its expression has been suggested to be part of adaptive water stress response mediated by ABA. Expression of this gene was significantly reduced in the 35S:AtHD2C transgenic lines indicating a positive role for AtHD2C in ABA signaling. The ABA-regulated genes, expression patterns in the 35S:AtHD2C vegetative tissues delineated a positive regulatory role for $\mathrm{AtHD} 2 \mathrm{C}$ in $\mathrm{ABA}$ mediated stress signaling. As the results appear, ABA signaling mediators and AtHD2C seem to share a positive as well as a negative relationship at distinct spatial windows of germination.

(iv) Interaction between HD2-Type HDACs and RPD3-Type HDACs

\section{(a) AtHD2B/AtHD2C and AtHDA1 do not interact}

To better understand the molecular mechanism of the HD2 family, we thought it important to determine, proteins they form complexes with. HDACs are recruited in complexes with other HDACs and co-repressors (Pandey et al, 2002). Therefore, we tested if HD2 genes were indeed HDACs, associate with other HDACs. Hence, a yeast two hybrid screen was conducted to examine if AtHD2B and AtHD2C could interact with AtHDA1 that is a class I HDAC. $A t H D 2 B$ and $A t H D 2 C$ were subcloned downstream to the DNA binding domain of the yeast GAL4 gene (Figure 28A and 28C). HDAl was subcloned downstream to the activation domain of the GAL4 gene. The AtHD2B/AtHD2C-GAL4BD constructs and the AtHDA1-GAL4AD construct pairs were transformed sequentially into a yeast host strain (HF7C). 


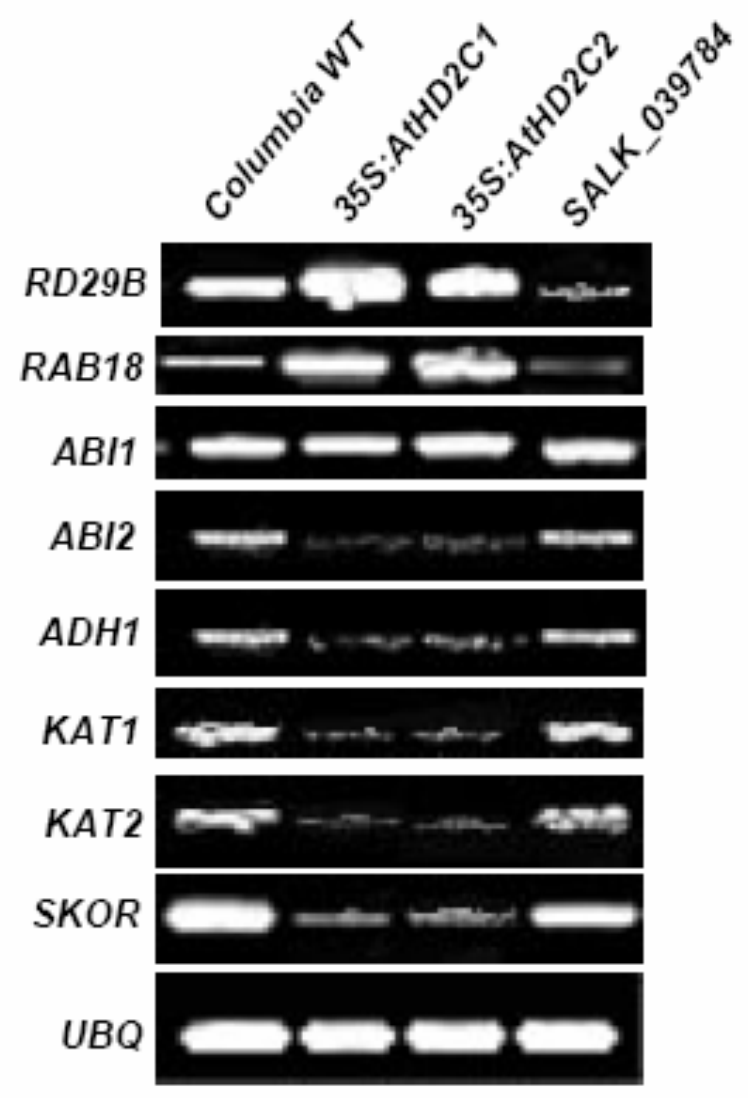

Figure 27. Expression of ABA-regulated genes in the vegetative phase in wild-type, 35S:AtHD2C1 and 35S:AtHD2C2 transgenic lines and SALK_039784 (T-DNA Line); RNA levels of ABA-responsive genes were determined by RT-PCR using total RNAs isolated from 4week old plants grown in soil in 16 hour light photoperiod. 
No interaction was observed between AtHD2B and AtHDA1 (Figure 28B) and between AtHD2C and AtHDA1 (Figure 28D). This conclusion was based on the disability of the cotransformants to thrive on the histidine free medium as compared to the positive control. Additionally, interaction was not detected between AtHD2B/AtHD2C and AtHDA1 in the LacZ assay as compared to the positive control (data not shown). The HD2 family members might interact with some other transcription factors and this is yet to be uncovered. 

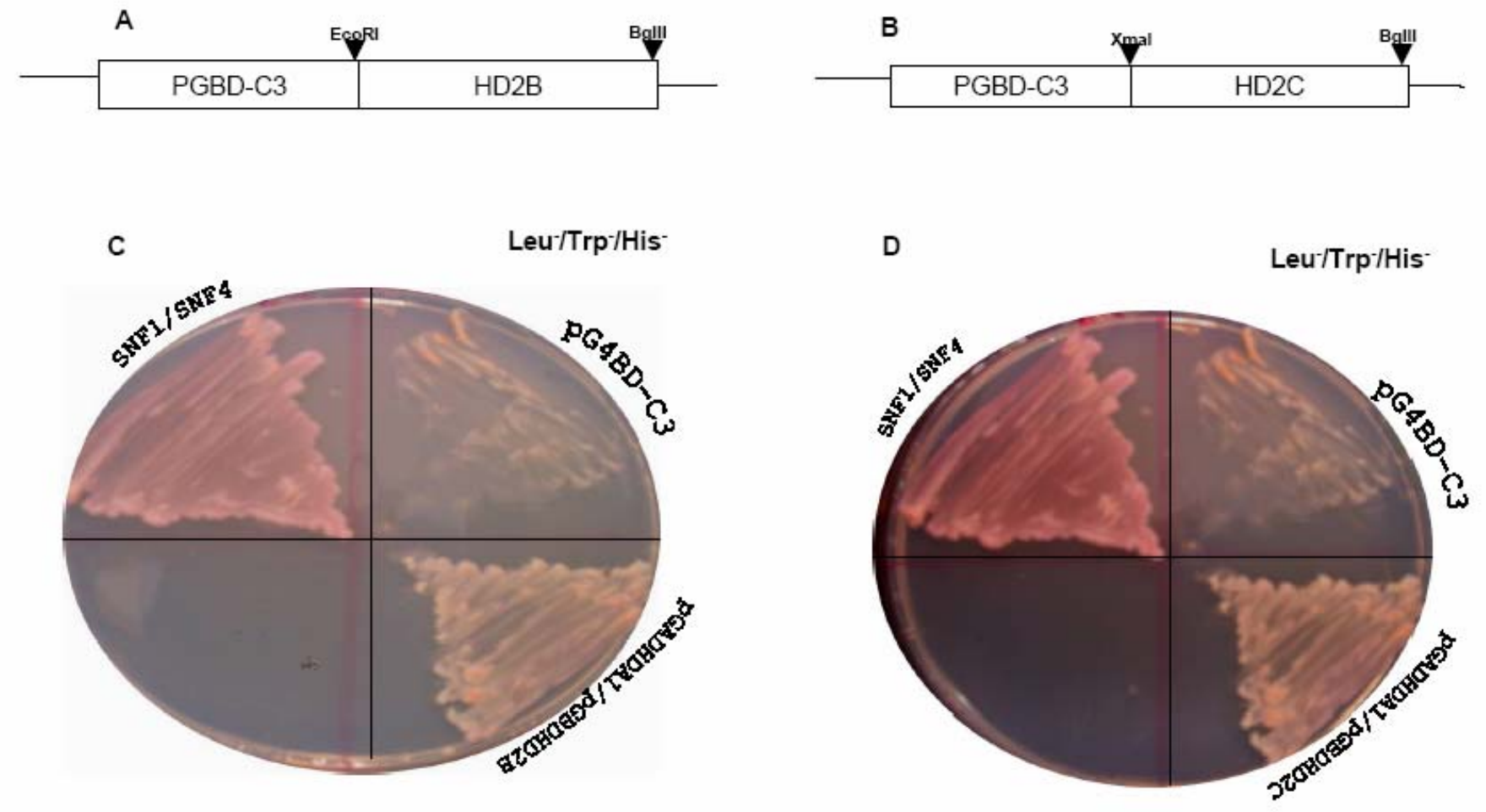

Figure 28. Yeast two hybrid screen for interaction between AtHD2B/AtHD2C and HDA1. (A) Map of PGBDHD2B. (B) Plate assay to test interaction between PGBDHD2B and PGADHDA1 (C) Map of PGBDHD2C. (D) Plate assay to test interaction between PGBDHD2C and PGADHDA1. 


\section{DISCUSSION AND CONCLUSIONS}

\section{(i) HD2 proteins act as transcription repressors}

Studies conducted on the HD2 gene family, have been channeled towards deciphering the functional significance of these genes in the developmental context (Wu et al, 2000; Lusser et al, 1997). To further characterize this family, we demonstrated that the AtHD2A, AtHD2B, AtHD2C had the same spatial pattern of expression as they accumulated in all the organs examined, but at different levels. Similar spatial patterns of expression have been observed for genes that control embryogenesis, such as WUSCHEL and somatic embryogenesis receptor kinase $(S E R K)$ (Mayer et al, 1998) where they are involved in the maintenance of both shoot apical meristems and embryonic stem cells. An in situ hybridization performed by Zhou et al, (2004) showed the strongest expression of the AtHD2A, AtHD2B, and AtHD2C genes in embryos, implicating that the aborted seed phenotype that was observed in the AtHD2A antisense plants (Wu et al, 2000) might result from a defect in embryogenesis, resulting from the silencing of $A t H D 2 A$. Additionally, in this same report, ectopic expression of $B B M$ that can induce somatic embryogenesis allowed for the expression of $A t H D 2 A$, $A t H D 2 B$, and $A t H D 2 C$, particularly in pre-embryonic tissues and somatic embryos. This data indicated that the expression of these genes is tightly correlated with both somatic and zygotic embryogenesis and is likely to be essential for embryo development. AtHD2D on the other hand, formed the exception in this group by accumulating selectively in the flowers and to a much smaller extent in the stems. It might play a specialized role in flower development that is yet to be investigated. The expansive pattern of expression of this gene family implicates that these genes have some special function in the developmental pathways of the 
plants. However, the similarity of $A t H D 2 A, A t H D 2 B$, and $A t H D 2 C$ expression patterns also raises the possibility of functional redundancy.

The control of intracellular location is an important regulatory mechanism for HDAC proteins in yeast and mammalian cells (Hirschler-Laszkiewicz et al, 2001). It was demonstrated that mammalian HDA1-type HDACs were mobilized from the cytoplasm to the nucleus by phosphorylation. Using GFP fusions, we demonstrated that HD2A, HD2B, and $\mathrm{HD} 2 \mathrm{C}$ accumulated in the nuclei of Arabidopsis cells. Recently, it was found that Arabidopsis HD2A is present in the Arabidopsis nuclear matrix using ESI tandem mass spectrometry to study the nucleoprotein complexes (Calikowsk et al, 2003). In addition, maize HD2 was also localized in the nucleolus (Lusser et al, 1997). This study indicated that Arabidopsis HD2 proteins may also be localized into nucleolus. The nucleolar localization of other types of HDACs has also been demonstrated in yeast and mammalian cells (HirschlerLaszkiewicz et al, 2001). The nucleolus is recognized as the site of rRNA transcription, rRNA processing, and ribosome assembly. However, recent studies suggest that the nucleolus functions more broadly in gene expression (Pederson, 1998) and may play a crucial role in cellular processes such as the control of cell cycle, aging, and mRNA export. Therefore, the HD2 proteins might play crucial roles in these essential developmental processes.

Most $Z m \mathrm{HD} 2 \mathrm{a}$ homologs show a characteristic domain structure. A conserved $\mathrm{NH}_{2}$-terminal region, a central part consisting of two acidic stretches interrupted by a region rich in basic residues and another basic domain adjacent to the second acidic stretch, that contains putative nuclear localization signals (Dangl et al, 2000). The amino terminal of these proteins consists of an invariable pentapeptide motif (MEFWG) as well as two 
conserved amino acid residues, that have been postulated to be critical for catalytic activity (Aravind and Koonin, 1998), a histidine at position 25 surrounded by hydrophobic amino acids and an aspartate (glutamate in At-HD2c) at position 72. The presence of these residues in all sequences analyzed strongly suggests that they are indeed HDACs, although enzymatic activity has not yet been determined. Three distinct domains have been identified in the HD2 family of proteins: the predicted $\mathrm{N}$-terminal deacetylase catalytic domain, the middle region consisting of the extended acidic domain, and the C-terminal domain (Aravind and Koonin, 1998; Dangl et al, 2001; Lusser et al, 1997; Wu et al, 2000). Both AtHD2A and AtHD2C have a putative zinc-finger domain in their C-terminal, whereas AtHD2B and AtHD2D do not. Deletion of the C-terminal domain from AtHD2A did not affect gene repression activity, indicating that this domain is not required for gene repression (Wu et al, 2000). Deletion of the extended acidic domain and the domain containing predicted catalytic residues of AtHD2A resulted in the loss of gene repression activity, suggesting that both domains may be essential for AtHD2A function. At the very C-terminus, six of the eight proteins show a single, putative zinc-finger motif. The study conducted here, indicated that the N-terminal EFWG motif is essential, and H25 is important for gene repression activity of AtHD2A. H25 has been suggested to be important for the activity in HD2-type HDACs (Aravind and Koonin, 1998). It is speculated that the invariant aspartic acid is the nucleophile involved directly in lysine deacetylation, that may be facilitated through a charge relay system with the conserved histidine (arginine), thus making the histidine essential for catalysis.

\section{(ii) AtHD2C expression is regulated by ABA}

Upon examination of the $A t H D 2 B$ and $A t H D 2 C$ promoters, several motifs involved in seeddevelopment regulation and $\mathrm{ABA}$ regulation were found. These elements are grouped into 
Tables in figure 15 and 16 where the core consensus sequences and functions of these motifs are outlined. The cis-acting sequences essential for ABA responsiveness can be classified into four main groups (reviewed by Finklestein and Rock, 2002): the G-box elements designated ABREs (CACGTG) and the functionally equivalent CE3 (coupling element)-like sequences, the RY/Sph (CATGCATG) elements, and recognition sequences for MYB (YAAC (G/T) G) and MYC (CANNTG) class transcription factors (Rock, 2000). The AtHD2C promoter has ABRE (ABA response element) and RY elements. Both of these elements are involved in ABA response. The bZIP class transcription factors such as ABI5 bind to the ABRE in the target genes by interacting with the $\mathrm{B} 3$ domain transcription factor $\mathrm{ABI} 3$ and tether them onto their target promoters (Nakamura et al, 2001). On the other hand the ABI3 transcription factors are known to bind the RY motifs (Kim et al, 1997; 2000; Uno et al, 2000). Additionally, Chandrasekharan et al, (2003) demonstrated that there is RY module specific activation of the phaseolin promoter during embryogenesis, further confirming that the presence of the RY elements in the promoter implicates involvement in seed maturation. It could be possible that these transcription factors could be targeting the AtHD2C promoter and recruiting other repressors to, to down-regulate its expression. Additionally, the $A t H D 2 C$ promoter also contained the cell-cycle regulation motif MSA (Mspecific activator) that suggests that these proteins might be recruited to enhance cell-cycle progression rates and therefore $M S A$ needs to be silenced in the early phase of seed maturation when cell-cycle is arrested for developmental transition (Ito et al, 2001). The periodic expression of B-type cyclin genes is regulated at least in part by a periodic change in the activity of their promoters in the cell cycle (Shaul et al, 1996; Ito et al, 1998; ColónCarmona et al, 1999; Tréhin et al., 1999). It was demonstrated that the promoter activation 
timing of the cyclin B1 gene, CycB1, from Catharanthus roseus during the cell cycle, is determined by a single type of cis element called MSA (M-specific activator), that is necessary and sufficient for periodic promoter activation (Ito et al, 1998a). MSA-like motifs are found in B-type cyclin promoters from various plant species. Additionally, these elements are bound by MYB class of transcription activators that are ABA-inducible (Ito et al, 2001). Therefore, the presence of this element in the $H D 2 B$ and $H D 2 C$ promoter implicates that these genes may be targeted by ABA-regulated transcription factors that in turn control the timing of cell cycle progression that has an intricate involvement with histone acetylation status (Jasencakova et al, 2001). The MBS or MYB binding site (CAACTG) element found in the $H D 2 B$ and $H D 2 C$ promoters is drought inducible and is bound by the MYB class transcription factors, that are bHLH- type proteins (Yamaguchi-Shinozaki and Shinozaki, 1994; Abe et al, 1997). The presence of this motif might explain the involvement of HD2C in drought response of the 35S:AtHD2C transgenic plants. The HD2C promoter could be upregulated by the binding of the MYB transcription factors during drought to de-repress stress response genes. The $\mathrm{HD} 2 \mathrm{C}$ promoter also contained endosperm-expression motifs Skn1(GTCAT) and GCN4 (GTCA) that indicate a function for this protein in some aspects of seed development (Hoecker et al, 1995). These elements were previously identified to be essential for endosperm expression in the rice storage protein glutelin GLU-B1HAT. This is quite interesting as the repressor is activated in some situations. We speculate that the expression of HD2 genes expression could be up-regulated by seed maturation factors, either dependant or independent of $\mathrm{ABA}$ to regulate endosperm formation.

The $A t H D 2 B$ and $A t H D 2 C$ promoter driven GUS expression patterns were also examined in the vegetative stage to determine if the expression patterns were the same as that 
observed in the spatial profiling of the HD2 gene family. Additionally, we wanted to confirm if the HD2 proteins are expressed in vegetative and flowering phases of plant development that would indirectly implicate a function for them in these stages. GUS was found to be expressed in almost all mature tissues examined including leaves, flowers, siliques and all parts of the flower except the petals. These results suggest that the HD2 protein accumulation in the vegetative phase might facilitate their positive regulatory role during stress impositions. Why the HD2 proteins might act as a developmental switch is very complicated as there are very few examples in nature when proteins exercise different levels of control in different developmental stages. One of the examples where a protein exercises a dual role in stage-specific manner is c-myc protein that was found to be expressed in the embryogenesis stages of development of mice, but down-regulated in the adult stages (Cre'ancier et al, 2000).

We examined GUS reporter expression driven by the AtHD2C promoters in the germination stage to check if it supports the results observed in the ABA sensitivity assay. Accordingly, the GUS expression was down-regulated in seedlings at early (2 days) and late (6 days) post-germination stages. This observation signifies that ABA down-regulates AtHD2C expression in the post-germination phase. This can be interpreted in a way that when there is a stressful environment during the time of germination or post-germination, ABA down-regulates post-germinative growth promoting factors such as HD2 proteins to induce transient dormancy to tide over the challenging period. Post-germinative growth involves a range of biochemical processes to function smoothly including lipid catabolism and activation of the glyoxalate cycle (Eastmond et al, 2000). It is possible that the HD2 proteins might be involved in propitiating these processes to help keep the transition smooth. 
Although the precise roles of the $A B I s$ in regulating lateral root growth are not understood, it is noteworthy that $A B I 5$ is specifically expressed in root tips from emergence onward (Brocard et al, 2002). We found an accumulation of GUS at the root tips after ABA treatment. It has been demonstrated that root meristems and shoot meristems have different responses to hypoxic stress (Ellis et al, 1999). This result led us to speculate if AtHD2C accumulates in the root tips concomitantly with ABI5 to down-regulate any growth inhibition attempts by the ABA signal cascade. Alternatively, HD2 proteins could also be part of the ABA feedback loop mechanism. When stress levels increase, ABI5 and AtHD2C (and other HD2 proteins) might accumulate in the root tips and the ABI5 will enhance growth inhibition and transient dormancy. On the other hand, AtHD2C might just sit in that location 'poised' for action. Once the stressful period is over, HD2 proteins will serve to down-regulate the ABI5 (AREB) proteins, thereby relieving ABA mediated repression. Also, as can be seen the GUS accumulation was very high in the post-imbibition seeds, i.e., seeds that are ready to germinate. This indicated that at the time of phase transition to post-germinative growth, the HD2 proteins accumulate in high levels. Therefore, results thus far indicate that ABA and HD2 proteins share an antagonistic relationship that is to be further analyzed.

\section{(iii) AtHD2C is involved in $\mathrm{ABA}$ response}

The AtHD2C was ectopically expressed in Arabidopsis to asses the range of developmental processes this gene might regulate. To complement this study, an AtHD2C T-DNA insertion line was also analyzed. The $A t H D 2 C$ overexpression lines had some obvious phenotypes. Marked early flowering, reduction in seed number, stunted siliques and early germination. Ectopic expression of $A t H D 2 A$ as a fusion protein disrupted normal development and generated many pleiotropic effects in a variety of somatic and reproductive tissues (Zhou et 
$a l, 2004)$. This observation indicated that the components needed for specificity may be absent in non-target tissues and/or that ectopically expressed $G F P-H D 2 A$ may be acting on atypical non-specific target sites. However, the results obtained from overexpressing genes needs to be interpreted carefully. Overexpression may induce direct or secondary effects on gene expression. For example, overexpressing AtHD2A may induce silencing of endogenous HD2 genes. Overexpression might lead to hierarchical cascades that result in the apparent phenotypes rather than gene-specific abnormality (Finklestein et al, 2002). However, the early germination phenotype is consistent with the involvement of the HD2 proteins in embryo development. Additionally, the effects on flowering were consistent upon several examinations and were very prominent. This indicates that the HD2 proteins might be involved in flowering time regulation. The role of histone deacetylases and other repressors in regulating transition from vegetative to reproductive phase is gradually coming to light (Kornreef et al, 1998). It is a quite well known fact that the polycomb group of proteins control the embryo and floral development by regulating respective homeotic genes (Chanvivattana et al, 2004). Additionally, there have been reports about the interaction between PcG proteins and HDACs speculating that the PcGs might recruit the HDACs to achieve repression (Finklestein and Rock, 2002). The HD2 proteins might be a part of this repression complex as it was initially isolated in a large 400KDa complex (Lusser et al, 1997). Also, these proteins have Zn-fingers at their C-terminal ends through which they can mediate protein-protein or protein-DNA interactions (Dangl et al, 2001). The abnormal leaf phenotypes demonstrated by the overexpression lines might be due to the role of the HD2 proteins in multiple development pathways or it might be an artifact of overexpression. The reduced fruit and seed phenotype may also be due to the involvement of the HD2 gene family 
with seed maturation and development and partly due to the exaggerated environment of ectopic expression. It can be observed in Tables VII, VIII and IX that there is a very low frequency of naturally occurring abnormalities in the wild-type plants itself. However, the frequency in the overexpression lines was markedly different from that of wild-type supporting a vital role for the HD2 proteins in the overall developmental context.

Since the HD2 proteins accumulated in the ovules (Zhou et al, 2004), knockout of AtHD2A led to aborted seed development (Wu et al, 2000) and the 'seed-specific' gene expression was found to be down-regulated in the AtHD2A overexpression lines, it was speculated that the HD2 proteins might be involved in a process regulated by another embryo development regulator, Abscisic acid (ABA). The common method for identifying involvement with ABA signaling is the germination and post-germination growth sensitivity assay (Gazzarrini and McCourt, 2001). The distinguishing feature between hormone biosynthetic mutants and response mutants is that the response mutants are insensitive even to ectopic application of the hormone, whereas the biosynthesis mutants will have restored phenotype upon hormone application (Finklestein and Rock, 2002). The AtHD2C and $A t H D 2 B$ overexpression lines had early germination, even on ABA supplemented plates indicating that are deficient in ABA response. Subsequently, these lines were able to establish cotyledons and begin the vegetative development process when their wild-type counter-parts were unable to form the aerial parts on the same or higher concentrations of $\mathrm{ABA}$. At the gene regulation level, the four ABA-inducible or responsive genes were downregulated in the overexpression lines. LEC1 and ICK1 are essential for embryo transition from first phase of maturation to the second (Finklestein and Rock, 2002). Also, AREB, that is a bZIP class transcription factor, will induce the expression of LEA gene RD29B to initiate 
desiccation tolerance and dormancy (Bray, 2004, 2001). When seeds exit from the dormancy phase to enter the vegetative growth phase, they need to down-regulate the factors that might prevent this process (Delseny et al, 2001), such as ABA signaling factors. It was reported that PICKLE (PKL), that is a transcription factor belonging to the PcG group of repressors, represses post-germination expression of embryogenesis promoting regulators such as $L E C 1$ (Ogas et al, 1999). Since the HD2 overexpression led to repression of $L E C 1$ and three other embryogenesis promoting and maintenance factors, it led us to speculate that HD2 proteins might be involved in the transition from dormancy to germination by down-regulating 'gate keeping ‘ ABA signals. The down-regulation of $L E C I$ and ICKI might also explain the early germination, as these two genes ensure termination of cell division to prevent precocious germination.

Salt, drought, and to some extent, cold stress cause an increased biosynthesis and accumulation of $\mathrm{ABA}$, that can be rapidly catabolized following the relief of stress (Shinozaki and Yamaguchi-Shinozaki, 2000). The role of ABA in osmotic stress signal transduction was previously addressed by studying the stress induction of several of these genes in the Arabidopsis ABA-deficient mutants (Akaba et al., 1998; Assmann et al, 2001; Audran et al, 1998; Audran et al, 2000; Chernys and Zeevaart, 2000). In genetic screens, a group of mutants that exhibit diminished expression of $R D 29 A-L U C$ under osmotic stress compared with Wild-type plants was recovered (Lee et al, 1998; Zhu, 2000). Two of the loci defined by these mutants, LOS5 and LOS6, have been characterized and the genes isolated. In los5, the expression of several stress-responsive genes, such as RD29A, COR15, COR47, $R D 22$, and P5CS, was severely reduced or even completely blocked during salt stress (Ingram and Bartels, 1996). The molecular cloning of los 5 revealed that LOS5 encodes a 
molybdenum cofactor sulfurase (MCSU) and is allelic to $A B A 3$ and the $\operatorname{los} 5$ plants were defective in drought-induced ABA biosynthesis (Bittner et al, 2001). When exogenous ABA was applied, salt induction of $R D 29 A-L U C$ was restored to the wild-type level, demonstrating that the ABA deficiency was responsible for the defect in osmotic stress regulation of gene expression (Finklestein and Rock, 2002). These findings suggested that osmotic stress induction of these stress-responsive genes is almost entirely dependent on ABA. Therefore, we expected that if a mutant is unresponsive to ABA, it would show insensitivity even to osmotic stress such as salt and sugar. Accordingly, the $A t H D 2 C$ and $A t H D 2 B$ overexpression lines demonstrated insensitivity to salt application depicted in the germination assay graphs and root length curve in figure 22. The commitment to germinate is irreversible that is why there are many checkpoints before the seed can enter into this process. The most major checkpoint is the environment-sensitive $\mathrm{ABA}$ response. If there is the slightest hint of osmotic stress or environmental shock, the ABA biosynthesis is induced, that results in the accumulation of the ABI3-5 (AREBs) transcription factors and the consequent accumulation of the LEA proteins, such as RD29B that maintain the dormancy and prevent mobilization of reserves (Ingram and Bartels, 1996). Therefore, we perceived the down-regulation of RD29B and AREB in the overexpression lines as a marker for ability to germinate in salt medium. $\mathrm{NaCl}$ resistance of the HD2 overexpression lines implicates that they are not only resistant to osmotic stress, but also to ion toxicity. However, the effects of mannitol were less severe on the wild-type as compared with ABA or salt. Mannitol is an important stress management factor that plants accumulate in harsh environments (Abebe et al, 2003). Although the wildtype plants were able to germinate and establish true leaves, the plants were extremely unhealthy and very few of them survived to set seed in the mannitol supplemented medium. 
On the other hand, the overexpression line flourished on the mannitol supplemented medium displaying healthy transitions and development. These results indicate a definite role for AtHD2C in the regulation of dormancy to post germination growth switch. It is most likely that the other HD2 family members may play the same role during this phase owing to their intra-familial homology interaction potential. Additionally, these HD2 proteins might be working in conjunction with other regulatory factors such as PcG proteins and other HDAC class members, but this remains to be tested.

To complement the overexpression study, we incorporated an AtHD2C T-DNA insertion line into the experiment with the expectation that the T-DNA line would most probably give the opposite phenotype to the overexpression thereby, making our results comprehensive. Upon examination of the response of the T-DNA lines to stress treatment, it appeared that the plants had the same phenotype as Wild-type in the post-germination stage and in the vegetative stress environment when exposed to ABA, salt, mannitol and drought. This is not consistent with our expectation but there could be a few reasons, as to why we obtained this result. $A t H D 2 C$ is just one of the members of the HD2 protein family and its loss may be substituted by the presence of other HD2 family members. Therefore, the functional loss of the gene is not evident as a phenotype. We would have to do multiple gene knockouts to examine importance of these proteins function. Alternatively, RNAi lines can be used as they might be able to achieve obliteration of HD2 protein family by using the RNA specific sequence for one member. Nevertheless, the T-DNA line was able to demonstrate some differences at the gene expression level as can be seen in Figure 20. This could be possible although the gene could not affect the plants development at a visually manifested level, it could introduce subtle changes in expression of specific target genes. 
However, it can be seen that the rescue of the various genes examined is not very robust owing to the HD2 family gene redundancy in the system.

The down-regulation of $A t H D 2 C$ in response to $\mathrm{ABA}$ was confirmed by examining actual $\mathrm{AtHD} 2 \mathrm{C}$ expression in response to ABA. It was observed that there was a partial reduction in AtHD2A, AtHD2B, AtHD2C message levels upon 3-6 hours of ABA treatment. The partial reduction pattern can be explained by that. HD2 proteins may not be the only proteins exercising this level of control, i.e., they may be part of a huge complex (Lusser et al, 1997), and therefore, they are not targeted to obliteration, maybe below functional threshold levels. Alternatively, even the proteins may play a crucial role in this process, the applied ABA treatment and time of action were not enough to detect acute reduction levels.

A critical function of ABA during vegetative growth is to optimize growth during environmental stress by maintaining osmotic homeostasis (Finklestein and Rock, 2002). At the cellular level, $\mathrm{ABA}$ can promote tolerance of some abiotic stresses including drought, salinity, and cold or heat (reviewed in Rock, 2000; Shinozaki and Yamaguchi- Shinozaki, 2000; Xiong and Zhu, 2001; Larkindale and Knight, 2002). In addition, it can induce tolerance of hypoxic stress in roots, but not shoots (Ellis et al., 1999). Within the first 3 hours of stress induction, ABA levels are known to peak, inducing the MAPK pathway to subsequently led to activation of transcription factors that can induce LEA protein accumulation within the next 10 hours when ABA levels peak again (reviewed in Shinozaki and Yamaguchi-Shinozaki., 2000; Xiong and Zhu., 2001). Therefore, ABA is not only a germination checkpoint regulator, it is also an important stress-relief agent in the later stages of the plant life. We wanted to examine if the HD2 proteins had some functional role at this 
developmental stage owing to their involvement in the germination stage. Therefore, mature AtHD2C overexpression plants were exposed to artificial salt stress and drought stress. To our surprise, the overexpression lines were resistant to both these conditions (Figure $24 \&$ 25). Interestingly, the number of closed stomata in the overexpression lines was much reduced in comparison to wild-type stomata (Table X) under drought conditions. This observation was different from our expectations as the partially open stomata in the transgenic lines did not support their drought resistant phenotype. The accumulation of inorganic ions, organic acids, sugars, and other compounds is required to maintain the internal water balance (Leigh, 1997). In principle, increased vacuolar solute accumulation could confer salt and drought tolerance. The sequestration of ions such as sodium could increase the osmotic pressure of the plant and at the same time reduce the toxic effects of this cation. Also, plants accumulate a variety of organic osmoprotectant solutes through a biochemical mechanism which improves their ability to withstand stresses. Of these solutes, betaines (fully $\mathrm{N}$-methylated amino acids) appear to play a major role in conferring resistance to drought, salinity and temperature stresses. Additionally, when stomata remain open, $\mathrm{Co}_{2}$ is fixed and the plants photosynthetic accumulation increases. Therefore, the paradoxical finding of open stomata in the transgenic plants during drought stress indicates that the 35S:AtHD2C plants are using alternate biochemical pathways other than shutting down stomata to achieve stress tolerance. HD2C might upregulate pathways leading to the accumulation of osmoprotectants such as glycine betaine or may be enhancing photosynthetic efficiencies by increasing $\mathrm{Co}_{2}$ fixation. These theories have to be investigated to identify the molecular reason behind the open stomata supporting stress tolerance phenotype. As we established a negative regulatory role for AtHD2C in the germination 
stage, it was expected that the ABA insensitive plants would succumb to environmental stress. This paradoxical finding was further investigated at the gene expression level. RNA collected from mature rosette leaves of the overexpression lines and several ABA signaling pathway genes were examined. It was observed that $R D 29 B$ that was repressed in the seedling stage, was up-regulated in the vegetative phase that could explain the survival of the transgenic plants for longer periods of time. Additionally, the $A R E B$ gene that was downregulated during the germination phase was also up-regulated in the vegetative phase supporting the up-regulation of the RD29B gene. $A B I 1$ that is a negative regulator of $\mathrm{ABA}$ signaling was unaffected in the transgenic lines indicating that HD2 protein regulation of the signaling cascade was independent of ABI1 targeting. On the other hand, ABI2 was distinctly down-regulated. $\mathrm{ABI} 1$ and $\mathrm{ABI} 2$ act either at distinct steps or in parallel pathways (Pei et al., 1997). Yeast two-hybrid studies have shown an interaction between ABI2 and SOS2 (Xiong and Zhu, 2001). SOS2 is a serine/threonine protein kinase identified on the basis of its role in salt-stress signaling (Liu et al., 2000). Both the ABI4 and ABI5 gene products contain ser/thr-rich domains that could be sites of phosphorylation (Finkelstein et al., 1998; Finkelstein and Lynch., 2000) and recent studies have demonstrated that ABI5 protein is stabilized by ABA induced phosphorylation (Lopez-Molina et al., 2001). It is quite possible that the PP2C proteins might dephosphorylate ABI4/5 and thereby inhibit their accumulation and $\mathrm{ABA}$ signal. The down-regulation of $A B I 2$ and $\mathrm{ABI} 2$ controlled target ADH1 (de Bruxelles et al., 1996) indicated that the HD2 proteins may play a positive regulatory role during this developmental stage.

To further support this idea, the $\mathrm{K}^{+}$inward rectifying channels KAT1 and KAT2 genes were down-regulated in the transgenic lines. Stomatal closing is another essential 
aspect of coping with water deficit in addition to accumulation of LEA proteins that help overcome desiccation (Liu et al., 2000). Stomatal closing is induced by ABA by inhibiting $\mathrm{K}^{+}$inward rectifying channels so that the guard cells can be de-polarized (Gaymard et al., 1998; Allan et al., 1994). Therefore, down-regulation of these ABA-regulated $\mathrm{K}^{+}$inward rectifying channels in the $A t H D 2 C$ overexpression lines indicates that AtHD2C may be involved in helping mediate the ABA inhibition of these channels. SKOR is a $\mathrm{K}^{+}$outward rectifier that is repressed by $\mathrm{ABA}$ to maintain $\mathrm{K}^{+}$content in the apoplast during loss of $\mathrm{K}^{+}$ from the individual cells (Lancombe et al., 2000). The repression of this gene in the AtHD2C overexpression lines indicates that AtHD2C helps maintain apoplastic osmotic potential by enhancing ABA mediated repression of $\mathrm{K}^{+}$outward rectifiers in this location. All the results obtained from this part of the study underscore the relevance of a new type of regulator that can exercise opposite effects in different developmental stages.

\section{(iv) AtHD2B and AtHD2C do not interact with AtHDA1}

Based on the structural analysis of the $\mathrm{HD} 2 \mathrm{C}$ protein sequence, we expected it to associate with a protein complex as HD2 proteins were first isolated in a large complex (Lusser et al., 1997). The reason for our expectation was the presence of a $\mathrm{Zn}$ finger motif at the Cterminus as the $\mathrm{Zn}$ finger is instrumental in direct DNA contact and protein interactions (Dangl et al., 2001). Additionally, Zn-finger proteins have been identified to be involved in stress responses by directly contacting core ACGT sequences (Sakamoto et al., 2004). This led us to speculate if $\mathrm{HD} 2 \mathrm{C}$ might have ability to directly contact target genes. However, the ideal way to examine the complex members would have been a library screen. We started the

process by conducting a two-hybrid screen. We chose to test interaction between AtHD2C and AtHDA1 (Class I HDAC) because there are reports of HDACs being recruited to target 
sites as HDAC complexes consisting of different class members. Therefore, we wanted to investigate if $\mathrm{HD} 2$ proteins also participate in this HDAC complex targeting. Neither AtHD2B nor AtHD2C interact with AtHDA1 proteins (Figure 28). However, we don't rule out the possibility that there might be interaction between these proteins, owing to the nonreliable heterologus yeast system to examine plant protein interactions. 


\section{SPECULATION}

\section{(i) Model during seed maturation}

Seed maturation consists of two phases; early and late. In the early phase, ABA- inducible LEC/FUS3 repress cell-division via recruiting mediators such as ICK1 to the CDPKs (Finklestein and Rock., 2002). From our results, we will tentatively place AtHD2C (and other HD2 proteins) upstream of $L E C 1$ based on the down-regulation of this gene in our investigation. Therefore, at this upstream position if HD2 proteins can inhibit cell-cycle arrest by indirectly inhibiting ICKI expression, then they can inhibit the protein accumulation in the second phase or affect AREB (ABI5), RD29B (LEA) expression. This is sequence of events might be executed in the post-germinative growth phase when $\mathrm{ABA}$ signaling is not needed. However, in the embryo-maturation phase, although HD2 proteins are present at particular positions, they do not execute their function as they are silenced by ABA peaks in these stages. This idea stems from the observation that the HD2 genes were down-regulated by ABA application. What ABA-signaled factors silence the HD2 genes is not known (Figure 29). It could it be the cell-cycle regulation factors, as there is a cell-cycle regulation motif in the promoter of $A t H D 2 C$.

\section{(ii) Model during post-germination growth}

Essentially, the paradigm here is a continuation of the model presented above. As we established HD2 proteins upstream to $L E C 1$ in the seed maturation phase, the repressor function is not executed due to down-regulation of HD2 genes expression by unknown ABA signaled factors. But in the post-germination phase, as the ABA 


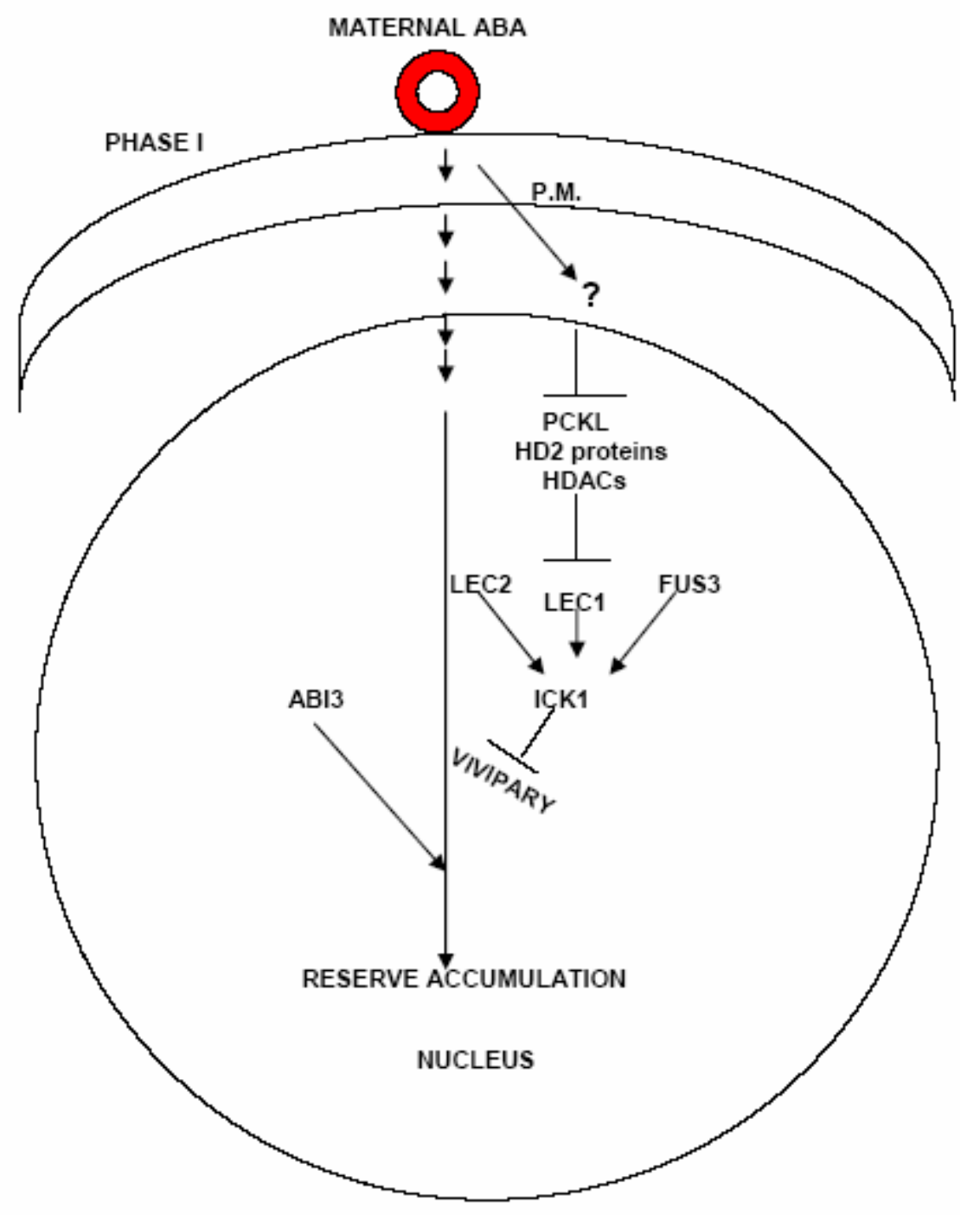




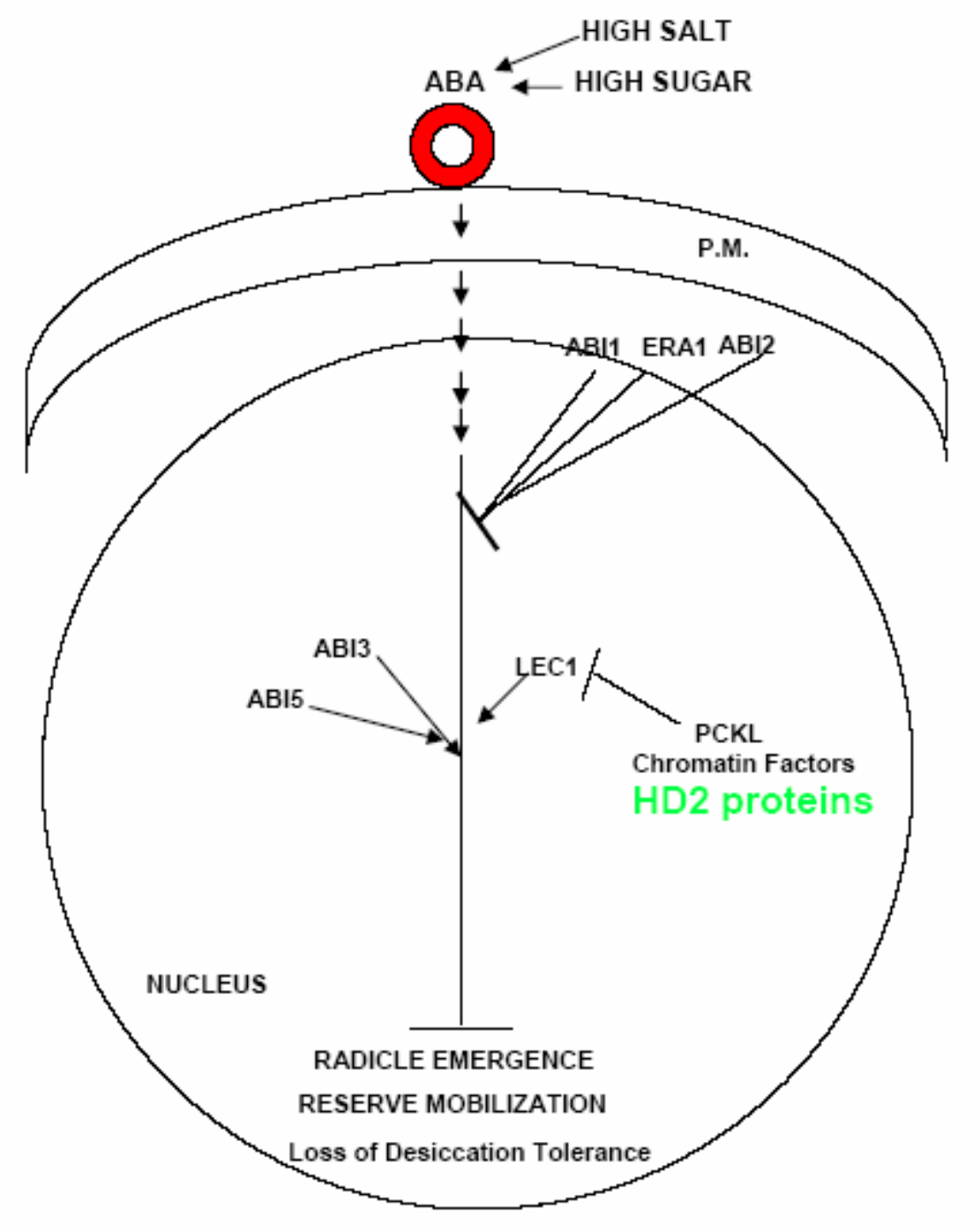


levels go down, the HD2 expression is de-repressed and thereby, $L E C 1$ down-regulation mediated repression of the ABA- response pathway is down-regulated to prevent growth inhibition (Figure 30).

\section{(iii) Model during vegetative stress response}

In the vegetative phase, a switch in the function of the HD2 proteins was observed. This role reversal led us to speculate that the HD2 proteins can function downstream to some ABAresponsive kinases that can phosphorylate the HD2 proteins and led to their activation. Once the HD2 proteins are activated, they might led to down-regulation of phophoprotein phosphatases (ABI2) that negatively regulate $\mathrm{ABA}$ - responsive transcription factors such as $\mathrm{ABI} 3 / 5$ and ser/thr protein kinases. $\mathrm{ABI} 1$ and $\mathrm{ABI} 2$ take part in a negative feedback regulatory loop that continuously resets the ABA signaling cascade to adjust the response to endogenous $\mathrm{ABA}$ levels. Also, protein phosphorylation is one of the most important mechanisms in ion transport in guard cells (Liu et al, 2000). KAT1 guard cell channel has been shown to be phosphorylated by calcium-dependent and (ABA)-regulated protein kinase activities ( $\mathrm{Li}$ et al., 1998; Mori et al., 2000). ABI1/2 phosphatases have been implicated in regulating the $\mathrm{K}^{+}$opening and closing (Chérel et al., 2002). We propose that the HD2 proteins may have additional level of regulation other than controlling $L E C 1$ downstream signals. We place HD2 proteins in the early ABA signaling cascade, i.e., on the plasma membrane location. HD2 can repress $A B I 2$ expression and thereby, prolong the ABA signal relay. Also, the $\mathrm{HD} 2$ proteins can regulate $\mathrm{K}^{+}$inward rectifying channel gene expression by a mechanism independent of $A B I 2$. It cannot be concluded from these results if all the genes affected by HD2 overexpression are directly contacted by the HD2 proteins, but certainly they are in the path of the HD2 regulation loop (Figure 31). 


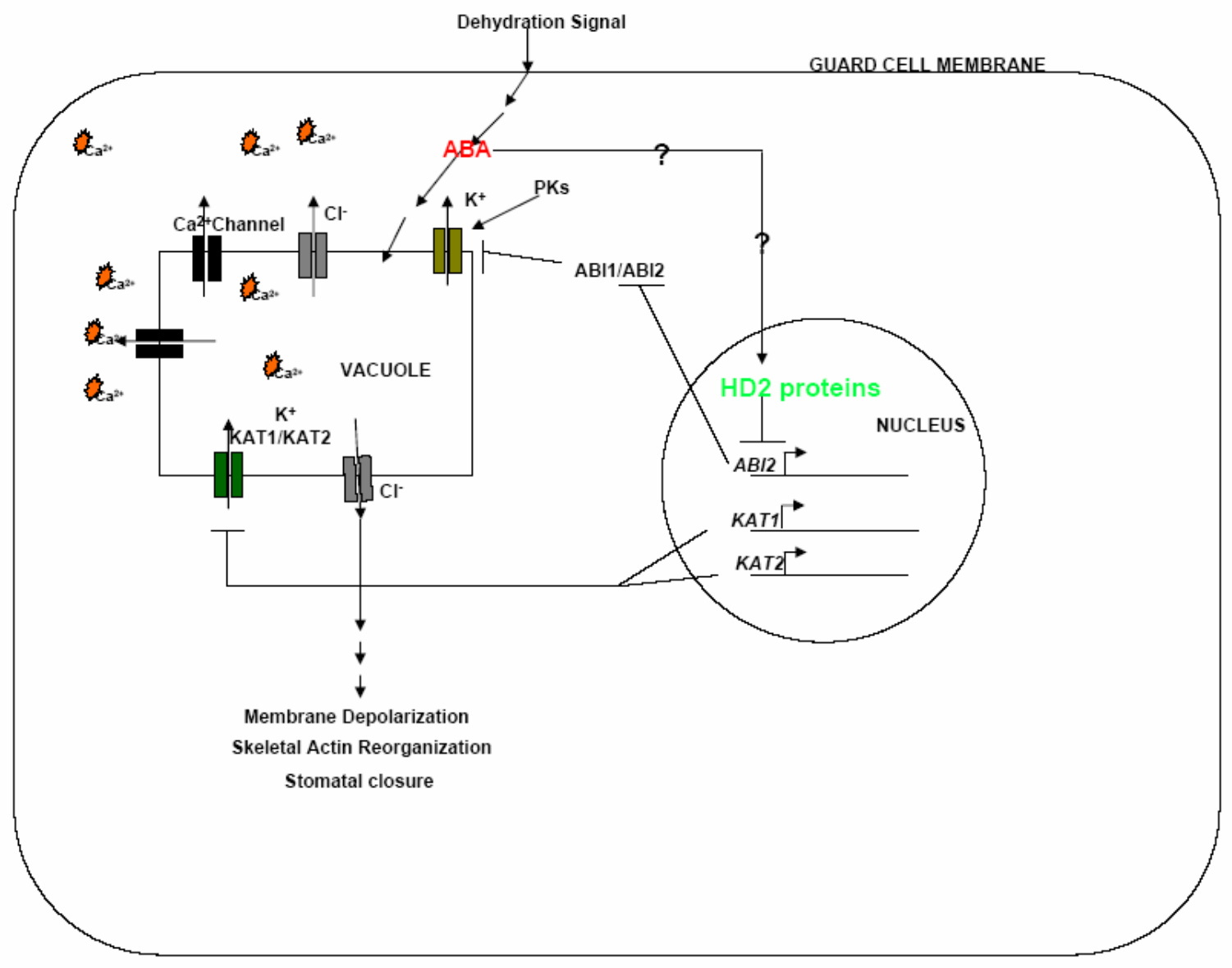




\section{REFERENCES}

1) Abe, H., Yamaguchi-Shinozaki, K., Urao, T., Iwasaki, T., Hosokawa, D., and Shinozaki, K. (1997) Role of Arabidopsis MYC and MYB homologs in drought- and abscisic acid regulated gene expression. Plant Cell 9, 1859-1868.

2) Abebe, T., Guenzi, A.Z., Martin, B., and Cushman, J.C. (2003) Tolerance of Mannitolaccumulating transgenic wheat to water stress and salinity. Plant Physiology, 131, 17481755.

3) Agrawal, G.K., Yamazaki, M., Kobayashi, M., Hirochika, R.,Miyao, A., and Hirochika, H. (2001) Screening of the rice viviparous mutants generated by endogenous retrotransposon tos 17 insertion. tagging of a zeaxanthin epoxidase gene and a novel OsTATC gene. Plant Physiol, 125, 1248-1257.

4) Ahringer J. (2000) NuRD and SIN3 histone deacetylase complexes in development. Trends Genet, 16, 351-6.

5) Akaba, S., Leydecker, M.-T., Moureaux, T., Oritani, T., and Koshiba, T. (1998) Aldehyde oxidase in Wild type and abal mutant leaves of Nicotiana plumbaginifolia. Plant Cell Physiol, 39, 1281- 1286.

6) Albinsky, D., Masson, J. E., Bogucki, A., Afsar, K., Vass, I., Nagy, F., and Paszkowski, J. (1999) Plant responses to genotoxic stress are linked to an ABA/salinity signaling pathway. Plant J, 17, 73-82.

7) Allan, A. C., Fricker, M. D., Ward, J. L., Beale, M. H., and Trewavas, A. J. (1994) Two transduction pathways mediate rapid effects of abscisic acid in Commelina guard cells. Plant Cell, 6, 1319-1328. 
8) Allfrey,V.G., Faulkner,R. and Mirsky,A.E. (1964) Acetylation and methylation of histones and their possible role in regulation of RNA synthesis. Proc. Natl Acad, Sci, 51, 786.

9) Alnemri ES, Fernandes-Alnemri T, Pomerenke K, Robertson NM, Dudley K, Du Bois GC, Litwack G. (1994) FKBP46, a novel Sf9 insect cell nuclear immunophilin that forms a protein-kinase complex. J Biol Chem, 269, 30828-30834.

10) Altschul,S.F., Madden,T.L., Schaffer,A.A., Zhang,J., Zhang,Z., Miller,W. and Lipman,D.J. (1997) Gapped BLAST and PSI-BLAST: a new generation of protein database search programs. Nucleic Acids Res, 25, 3389-3402.

11) Altschul, S.F., Gish, W., Miller, W., Myers, E.W. and Lipman, D.J. (1990) Basic local alignment search tool. J. Mol. Biol, 215, 403-410.

12) Anderson, B.E., Ward, J.M., and Schroeder, J.I. (1994) Evidence for an extracellular reception site for abscisic acid in Commelina guard cells. Plant Physiol, 104, 1177-1183.

13) Aravind,L., Koonin,E.V., Dangl,M., Lusser,A., Brosch,G., Loidl,A., Haas,H. and Loidl,P. (1998) Second family of histone deacetylases. Science, 280, 1167.

14) Arenas-Huertero, F., Arroyo, A., Zhou, L., Sheen, J., and Leon, P. (2000) Analysis of Arabidopsis glucose insensitive mutants, gin 5 and $\operatorname{gin} 6$, reveals a central role of the plant hormone $\mathrm{ABA}$ in the regulation of plant vegetative development by sugar. Genes Dev, 14, 2085-2096.

15) Arenas-Huertero, F., Arroyo, A., Zhou, L., Sheen, J., and Leon, P. (2000) Analysis of Arabidopsis glucose insensitive mutants, gin 5 and gin6, reveals a central role of the plant hormone $\mathrm{ABA}$ in the regulation of plant vegetative development by sugar. Genes Dev, 14, 2085-2096. 
16) Assmann, S. M., Snyder, J. A., and Lee, Y.-R. J. (2000) ABAdeficient (abal) and ABAinsensitive (abi1-1, abi2-1) mutants of Arabidopsis have a Wild-type stomatal response to humidity. Plant Cell Envir, 23, 387-395.

17) Audran, C., Borel, C., Frey, A., Sotta, B., Meyer, C., Simonneau, T., and Marion-Poll, A. (1998) Expression studies of the zeaxanthin epoxidase gene in Nicotiana plumbaginifolia. Plant Physiol, 118, 1021-1028.

18) Audran, C., Liotenberg, S., Gonneau, M., North, H., Frey, A., Tap-Waksman, K., Vartanian, N., and Marion-Poll, A. (2001) Localisation and expression of zeaxanthin epoxidase mRNA in Arabidopsis in response to drought stress and during seed development. Aust. J. Plant Physiol, 28, 1161-1173.

19) Beaudoin, N., Serizet, C., Gosti, F., and Giraudat, J. (2000) Interactions between abscisic acid and ethylene signaling cascades. Plant Cell , 12, 1103-1115.

20) Berger, S.L. (2002) Histone modifications in transcriptional regulation. Curr. Opin. Genet. Dev, 12, 142-148.

21) Bittner, F., Oreb, M., and Mendel, R.R. (2001) ABA3 is a molybdenum cofactor sulfurase required for activation of aldehyde oxidase and xanthine dehydrogenase in Arabidopsis thaliana. J. Biol. Chem, 276, 40381-40384.

22) Blatt, M. R. (2000) Ca2+ signalling and control of guard-cell volume in stomatal movements. Curr. Opin. Plant Biol, 3, 196-204.

23) Bray,E.A. (2004) Genes commonly regulated by water-deficit stress in Arabidopsis thaliana. Journal of Experimental Botany, 55, 2331-2341 
24) Bray,E.A. (2002) Abscisic acid regulation of gene expression during water deficit stress in the era of the Arabidopsis genome. Plant, Cell and Environmen,. 25,153-16.

25) Brocard, I., Lynch, T., and Finkelstein, R. (2002) Regulation and role of the Arabidopsis ABA-insensitive (ABI5) gene in ABA, sugar and stress response. Plant Physiol. in press.

26) Brosch G, Georgieva EI, Lopez-Rodas G, Lindner H, Loidl P. (1992) Specificity of Zea mays histone deacetylase is regulated by phosphorylation. $J$ Biol Chem Oct, 267, 2056120564.

27) Brown, D.C.W., Tian, L.-N., Buckley, D.J., Lefebvre, M., McGrath, A. and Webb, J. (1994) Development of a simple particle bombardment device for gene delivery into plant cells. Plant Cell Tissue Org. Cult. 37, 47-53.

28) Burbidge, A., Grieve, T., Terry, C., Corlett, J., Thompson, A., and Taylor, I. (1997) Structure and expression of a cDNA encoding zeaxanthine epoxidase, isolated from a wilt-related tomato (Lycopersicon esculentum Mill.) J. Exp. Bot, 48, 1749-1750.

29) Burnett, E. C., Desikan, R., Moser, R. C., and Neill, S. J. (2000) ABA activation of an MBP kinase in Pisum sativum epidermal peels correlates with stomatal responses to ABA. J. Exp. Bot, 51, 197-205.

30) Cairns, B.R. (1998) Chromatin remodeling machines: similar motors, ulterior motives. Trends Biochem. Sci, 23, 20-25.

31) Carmen,A.A., Grifin,P.R., Calaycay,J.R., Rundlett,S.E., Suka,Y. and Grunstein,M. (1999) Yeast HOS3 forms a novel trichostatin Ainsensitive homodimer with intrinsic histone deacetylase activity. Proc. Natl Acad. Sci, 96, 2356-12361. 
32) Chanvivattana1, Y., Bishopp1, A., Schubert, D., Stock, C., Moon, H.Y., Sung, Z.R., and Goodrich, J. (2004) Interaction of Polycomb-group proteins controlling flowering in Arabidopsis. Development, 131, 5263-5276.

33) Chen ZJ and Pikaard CS. (1997) Epigenetic silencing of RNA polymerase I transcription: a role for DNA methylation and histone modification in nucleolar dominance. Genes Dev, 11, 2124-36.

34) Chernys, J.T., and Zeevaart, J.A.D. (2000) Characterization of the 9-cis-epoxycarotenoid dioxygenase gene family and the regulation of abscisic acid biosynthesis in avocado. Plant Physiol, 124, 343-353.

35) Chérel, Michard, E., Platet, N., Mouline, K., Alcon, C., Hervé Sentenac, H., and Thibaud, J.B. (2002) Physical and functional interaction of the Arabidopsis channel AKT2 and phosphatase AtPP2CA. The Plant Cell, 14, 1133-1146.

36) Choi, H., Hong, J., Ha, J., Kang, J., and Kim, S. (2000) ABFs, a family of ABAresponsive element binding factors. J. Biol. Chem, 275, 1723-1730.

37) Clough, S.J. and Bent, A.F. (1998) Floral dip: a simplified method for Agrobacteriummediated transformation of Arabidopsis thaliana. Plant J, 16, 735-743.

38) Colón-Carmona, A., You, R., Haimovitch-Gal, T., and Doerner, P. (1999) Spatiotemporal analysis of mitotic activity with a labile cyclin-GUS fusion protein. Plant $J, 20$, $503-508$.

39) Cowan, A.K. (2001) Abscisic acid biosynthesis in vascular plants is a constitutive process. S. African J. Bot, 67, 497-505. 
40) Cre'Ancier, L., Mercier,P., Prats, A.C., and Morello, D. (2001) c-myc Internal ribosome entry site activity is developmentally controlled and subjected to a strong translational repression in adult transgenic mice. Mol. Cell. Biol,21, 1833-1840.

41) Cutler, S., Ghassemian, M., Bonetta, D., Cooney, S., and cCourt, P. (1996) A protein farnesyl transferase involved in abscisic acid signal transduction in Arabidopsis. Science, 273, 239-1241.

42) Dangl M, Brosch G, Haas H, Loidl P, Lusser A. (2001) Comparative analysis of HD2 type histone deacetylases in higher plants. Planta Jun, 213, 280-5.

43) De Bruxelles, C.L., Peacock, W.J., Dennis, E.S., and Dolferus, R. (1996) Abscisic acid induces the alcohol dehydrogenase gene in Arabidopsis. Plant Physiol. 111, 381-391.

44) Delseny, M., Bies-Etheve, N., Carles, C., Hull, G., Vicient, C., aynal, M., Grellet, F., and Aspart, L. (2001) Late mbryogenesis Abundant (LEA) protein regulation during Arabidopsis seed maturation. J. Plant Physiol, 158, 419-427.

45) Eastmond, P. J., Germain, V., Lange, P. R., Bryce, J. H., Smith, . M., and Graham, I. A. (2000) Postgerminative growth and lipid catabolism in oilseeds lacking the glyoxylate cycle. Proc. Natl. Acad. Sci. 97, 5669-5674.

46) Ellis, M., Dennis, E., and Peacock, W. (1999) Arabidopsis roots and shoots have different mechanisms for hypoxic stress tolerance. Plant Physiol. 119, 57-64.

47) Eun, S.-O., and Lee, Y. (1997) Actin filaments of guard cells are reorganized in response to light and abscisic acid. Plant Physiol, 115, 1491-1498.

48) Ezcurra, I., Wycliffe, P., Nehlin, L., Ellerstrom, M., and Rask, L. (2000) Transactivation of the Brassica napus napin promoter by $\mathrm{ABI} 3$ requires interaction of the conserved $\mathrm{B} 2$ 
and $\mathrm{B} 3$ domains of $\mathrm{ABI} 3$ with different cis-elements: $\mathrm{B} 2$ mediates activation through an ABRE, whereas B3 interacts with an RY/Gbox. Plant J, 24, 57-66.

49) Fan, L., Zheng, S., and Wang, X. (1997) Antisense suppression of phospholipase D $\alpha$ retards abscisic acid- and ethylene-promoted senescence of postharvest arabidopsis leaves. Plant Cell, 9, 2183-2196.

50) Finkelstein, R., Gampala, S., and Rock, C. (2002) Abscisic acid signaling in seeds and seedlings. Plant Cell ,14, S15-S45.

51) Finkelstein, R., and Lynch, T. (2000a) The Arabidopsis Abscisic Acid Response Gene ABI5 Encodes a Basic Leucine Zipper Transcription Factor. Plant Cell ,12, 599-609.

52) Finkelsteina, R.R., and Rock, C.D. (2002) Abscisic Acid Biosynthesis and Response. The Arabidopsis Book; American Society of Plant Biologists.

53) Finkelstein, R., and Somerville, C. (1990). Three classes of abscisic acid (ABA)insensitive mutations of Arabidopsis define genes that control overlapping subsets of ABA responses. Plant Physiol. 94, 1172-1179.

54) Finnegan EJ (2001) Is plant gene expression regulated globally? Trends Genet Jul. 17, $361-5$.

55) Frye,R.A. (1999) Characterization of ${ }^{\circledR} v e$ human cDNAs with homology to the yeast SIR2 gene: Sir2-like proteins (sirtuins) metabolize NAD and may have protein ADPribosyltransferase activity. Biochem. Biophys. Res. Commun., 260, 273-279.

56) Fischle, W., Wang, Y., and Allis, C.D. (2003). Histone and chromatin cross-talk. Curr. Opin. Cell Biol. 15, 172-183.

57) Fischle, W. et al. (2001) The emerging role of class II histone deacetylases. Biochem. Cell Biol. 79, 337-348. 
58) Fischle, W. et al. (1999) A new family of human histone deacetylases related to Saccharomyces cerevisiae HDA1p. J. Biol. Chem. 274, 11713-11720.

59) Gampala, S., Hagenbeek, D., and Rock, C. (2001b). Functional interactions of lanthanum and phospholipase D with the abscisic acid signaling effectors VP1 and ABI1-1 in rice protoplasts. J. Biol. Chem. 276, 9855-9860.

60) Gaymard, F., Pilot, G., Lacombe, B., Bouchez, D., Bruneau, D., Boucherez, J., MichauxFerriere, N., Thibaud, J.-B., and Sentenac, H. (1998). Identification and disruption of a plant shaker-like outward channel involved in $\mathrm{K}+$ release into the xylem sap. Cell 94, 647-655.

61) Gazzarrini, S., and McCourt, P. (2001). Genetic interactions between ABA, ethylene and sugar signaling pathways. Curr. Opin. Plant Biol. 4, 387-391.

62) Ghelis, T., Dellis, O., Jeannette, E., Bardat, F., Cornel, D., Miginiac, E., Rona, J.-P., and Sotta, B. (2000). Abscisic acid specific expression of RAB18 involves activation of anion channels in Arabidopsis thaliana suspension cells. FEBS Lett. 474, 43-47.

63) Ghelis, T., Dellis, O., Jeannette, E., Bardat, F., Miginiac, E., and Sotta, B. (2000). Abscisic acid plasmalemma perception triggers a calcium influx essential for RAB18 gene expression in Arabidopsis thaliana suspension cells. FEBS Lett. 483, 67-70.

64) Gilroy, S., Read, N. D., and Trewavas, A. J. (1990). Elevation of cytoplasmic calcium by caged calsium or caged inositol trisphosphate initiates stomatal closure. Nature 343, 769771.

65) Gomez-Cadenas, A., Verhey, S. D., Holappa, L. D., Shen, Q., Ho, T.-H. D., and WalkerSimmons, M. K. (1999). An abscisic acid-induced protein kinase, PKABA1, mediates 
abscisic acidsuppressed gene expression in barley aleurone layers. Proc. Natl. Acad. Sci. $96,1767-1772$.

66) Gosti, F., Beaudoin, N., Serizet, C., Webb, A., Vartanian, N., and Giraudat, J. (1999). ABI1 protein phosphatase $2 \mathrm{C}$ is a negative regulator of abscisic acid signaling. Plant Cell 11, 1897-1909.

67) Grabher A, Brosch G, Sendra R, Lechner T, Eberharter A, Georgieva EI, Lopez-Rodas G, Franco L, Dietrich H, Loidl P. (1994) Subcellular location of enzymes involved in core histone acetylation. Biochemistry .33, 14887-95.

68) Graessle,S., Loidl,P. and Brosch,G. (2001) Histone acetylation: plants and fungi as model systems for the investigation of histone deacetylases. Cell. Mol. Life Sci., 58, 704-720.

69) Grozinger,C.M., Hassig,C.A. and Schreiber,S.L. (1999) Three proteins define a class of human histone deacetylases related to yeast Hda1p. Proc. Natl Acad. Sci. USA, 96, 48684873.

70) Grunstein,M. (1992) Histones as regulators of genes. Sci. Am., 267, 68B-74B.Imhof,A., Yang,X.J., Ogryzko,V.V., Nakatani,Y., Wolffe,A.P. and Ge,H. (1997) Acetylation of general transcription factors by histone acetyltransferases. Curr. Biol., 7, 689-692.

71) Grunstein,M. (1996) HDA1 and ATHDA1 are members of distinct yeast histone deacetylase complexes that regulate silencing and transcription. Proc. Natl Acad. Sci. USA, 93, 14503-14508.

72) Hagen G, Murfett J, Wang XJ, Guilfoyle TJ (2001) Identification of Arabidopsis histone deacetylase HDA6 mutants that affect transgene Expression. Plant Cell May. 13, 104761. 
73) Hagenbeek, D., Quatrano, R., and Rock, C. (2000). Trivalent ions activate abscisic acidinducible promoters through an $A B I 1$-dependent pathway in rice protoplasts. Plant Physiol. 123, 1553-1560.

74) Hamilton, D.W.A., Hills, A., Kohler, B., and Blatt, M.R. (2000). Ca2+ channels at the plasma membrane of stomatal guard cells are activated by hyperpolarization and abscisic acid. Proc. Natl. Acad. Sci. USA 97, 4967-4972.

75) Hirayama, T., Ohto, C., Mizoguchi, T., and Shinozaki, K. (1995). A gene encoding a phosphatidylinositol-specific phospholipase $\mathrm{C}$ is induced by dehydration and salt stress in Arabidopsis thaliana. Proc. Natl. Acad. Sci. USA 92, 3903-3907.

76) Hirschler-Laszkiewicz, I., Cavanaugh, A., Hu, Q., Catania, J., Avantaggiati, M.L. and Rothblum, L.I. (2001) The role of acetylation in rDNA transcription. Nucl. Acids Res. 29, $4114-4124$.

77) Hobo, T., Kowyama, Y., and Hattori, T. (1999). A bZIP factor, TRAB1, interacts with VP1 and mediates abscisic acidinduced transcription. Proc. Natl. Acad. Sci. 96, 1534815353.

78) Hoecker, U., Vasil, I. K., and McCarty, D. R. (1995). Integrated control of seed maturation and germination programs by activator and repressor functions of Viviparous1 of maize. Genes Dev. 9, 2459-2469.

79) Holdsworth, M., Kurup, S., and McKibbin, R. (1999). Molecular and genetic mechanisms regulating the transition from embryo development to germination. Trends Plant Sci. 4, 275-280. 
80) Holdsworth, M., Lenton, J., Flintham, J., Gale, M., Kurup, S., McKibbin, R., Bailey, P., Larner, V., and Russell, L. (2001). Genetic control mechanisms regulating the initiation of germination. J. Plant Physiol 158, 439-445.

81) Hong, S. W., Jon, J. H., Kwak, J. M., and Nam, H. G. (1997). Identification of a receptorlike protein kinase gene rapidly induced by abscisic acid, dehydration, high salt, and cold treatments in Arabidopsis thaliana. Plant Physiol. 113, 1203-1212.

82) Hornberg, C., and Weiler, E. (1984). High affinity binding sites for ABA on the plasmalemma of Vicia guard cells. Nature 310, 321-324.

83) Hu E, Chen Z, Fredrickson T, Zhu Y, Kirkpatrick R, Zhang GF, Johanson K, Sung CM, Liu R, Winkler J. (2000) Cloning and characterization of a novel human class I histone deacetylase that functions as a transcription repressor. J Biol Chem. 275, 15254.

84) Hugouvieux, V., Kwak, J., and Schroeder, J. (2001). A mRNA cap binding protein, ABH1, modulates early abscisic acid signal transduction in Arabidopsis. Cell 106, 477487.

85) Huijser, C., Kortstee, A., Pego, J., Weisbeek, P., Wisman, E., and Smeekens, S. (2000). The Arabidopsis SUCROSE UNCOUPLED-6 gene is identical to ABSCISIC ACID INSENSITIVE- 4: involvement of abscisic acid in sugar responses. Plant Journal 23, 577585.

86) Hwang, J.U., and Lee, Y. (2001). Abscisic acid-induced actin reorganization in guard cells of dayflower is mediated by cytosolic calcium levels and by protein kinase and protein phosphatase activities. Plant Physiol. 125, 2120-2128. 
87) Imai,S., Armstrong,C.M., Kaeberlein,M. and Guarente,L. (2000) Transcriptional silencing and longevity protein Sir2 is an NAD dependent histone deacetylase. Nature, 403, 795-800.

88) Ingram, J., and Bartels, D. (1996). The molecular basis of dehydration tolerance in plants. Annu. Rev. Plant Physiol. Plant Mol. Biol. 47, 377-403.

89) Irving, H., Gehring, C., and Parish, R. (1992). Changes in cytosolic pH and calcium of guard cells precede stomatal movements. Proc. Natl. Acad. Sci. USA 89, 1790-1794.

90) Ishitani, M., Xiong, L., Stevenson, B., and Zhu, J.-K. (1997). Genetic analysis of osmotic and cold stress signal transduction in Arabidopsis: Interactions and convergence of abscisic acid-dependent and abscisic acid-independent pathways. Plant Cell 9, 19351949.

91) Ito, M. (1998). Cell cycle dependent gene expression. in plant cell division, London, Portland Press, pp. 165-186.

92) Ito, M, Araki, S, Matsunaga, S, Itoh, T, Nishihama, R, Machida, Y, Doonan, J.H, and Watanabe, A. (2001) G2/M-Phase-Specific Transcription during the Plant Cell Cycle Is Mediated by c-Myb-Like Transcription Factors. The Plant Cell, 13, 1891-1905.

93) Jacob, T., Ritchie, S., Assmann, S., and Gilroy, S. (1999). Abscisic acid signal transduction in guard cells is mediated by phospholipase D activity. Proc. Natl. Acad. Sci. USA 96, 12192-12197.

94) Jasencakova, Z., Meister, A., and Schubert, I. (2001). Chromatin organization and its relation to replication and histone acetylation during the cell cycle in barley. Chromosoma 110, 83-92. 
95) Jasencakova, Z., Meister, A., Walter, J., Turner, B.M., and Schubert, I. (2000). Histone $\mathrm{H} 4$ acetylation of euchromatin and heterochromatin is cell cycle dependent and correlated with replication rather than with transcription. Plant Cell 12, 2087-2100.

96) Jeannette, E., Rona, J.P., Bardat, F., Cornel, D., Sotta, B., and Miginiac, E. (1999). Induction of Rab18 gene expression and activation of $\mathrm{K}+$ outward rectifying channels depend on an extracellular perception of ABA in Arabidopsis thaliana suspension cells. Plant J. 18, 13-22.

97) Jefferson, R.A., Kavanagh, T.A. and Bevan, M.W. (1987) GUS fusion: $\beta$-glucuronidase as a sensitive and versatile gene fusion marker in higher plants. EMBO J. 6, 3901-3907.

98) Johnson, L., Cao, X., and Jacobsen, S. (2002). Interplay between two epigenetic marks. DNA methylation and histone H3 lysine 9 methylation. Curr. Biol. 12, 1360-1367.

99) Kadonaga,J.T. (1998) Eukaryotic transcription: an interlaced network of transcription factors and chromatin-modifying machines. Cell, 92, 307-313.

100) Kang, J.Y., Choi, H.I., Im, M.Y. and Kim, S.Y. (2002) Arabidopsis basic leucine zipper proteins that mediate stress-responsive abscisic acid signaling. Plant Cell, 14, 343-357.

101) Karssen, C., Brinkhorst-van der Swan, D., Breekland, A., and Koornneef, M. (1983). Induction of dormancy during seed development by endogenous abscisic acid: studies of abscisic acid deficient genotypes of Arabidopsis thaliana (L.) Heynh. Planta 157, 158165.

102) Katagiri, T., Takahashi, S., and Shinozaki, K. (2001). Involvement of a novel Arabidopsis phospholipase D, AtPLD $\delta$, in dehydration-inducible accumulation of phosphatidic acid in stress signalling. Plant J. 26, 595-605. 
103) Khochbin,S. and Wolffe,A.P. (1997) The origin and utility of histone deacetylases. FEBS Lett., 419, 157-160.

104) Kim, S. Y., Chung, H.-J., and Thomas, T. L. (1997). Isolation of a novel class of bZIP transcription factors that interact with ABA-responsive and embryo-specification elements in the Dc3 promoter using a modified yeast one-hybrid system. Plant J. 11, $1237-1251$.

105) Knetsch, M. L. W., Wang, M., Snaar-Jagalska, B. E., and Heimovaara-Dijkstra, S. (1996). Abscisic acid induces mitogen- activated protein kinase activation in barley aleurone protoplasts. Plant Cell 8, 1061-1067.

106) Koornneef, M., Léon-Kloosterziel, K.M., Schwartz, S.H., and Zeevaart, J.A.D. (1998). The genetic and molecular dissection of abscisic acid biosynthesis and signal transduction in Arabidopsis. Plant Physiol. Biochem. 36, 83-89.

107) Kornberg,R.D. and Lorch,Y. (1999) Twenty-five years of the nucleosome, fundamental particle of the eukaryote chromosome. Cell, 98, 285-294.

108) Kurup, S., Jones, H., and Holdsworth, M. (2000). Interactions of the developmental regulator ABI3 with proteins identified from developing Arabidopsis seeds. Plant J. 21, $143-155$.

109) Laby, R., Kincaid, M., Kim, D., and Gibson, S. (2000). The Arabidopsis sugar-insensitive mutants sis4 and sis5 are defective in abscisic acid synthesis and response. Plant J. 23, 587-596.

110) Lacombe, B., Pilot, G., Gaymard, F., Sentenac, H., and Thibaud, J.B. (2000). pH control of the plant outwardly rectifying potassium channel SKOR. FEBS Lett. 466, 351-354. 
111) Lagger, G., O'Carroll, D., Rembold, M., Khier, H., Tischler, J.,Weitzer, G., Schuettengruber, B., Hauser, C., Brunmeir, R.,Jenuwein, T., and Seiser, C. (2002). Essential function of histone deacetylase 1 in proliferation control and CDK inhibitor repression.EMBO J. 21, 2672-2681.

112) Larkindale, J., and Knight, M. (2002). Protection against heat stress-induced oxidative damage in Arabidopsis involves calcium, abscisic acid, ethylene, and salicylic acid. Plant Physiol. 128, 682-695.

113) Lechner,T., Lusser,A., Pipal,A., Brosch,G., Loidl,A., Goralik- Schramel,M., Sendra,R., Wegener,S., Walton,J.D. and Loidl,P. (2000) ATHDA1-type histone deacetylases in maize embryos. Biochemistry, 39, 1683-1692.

114) Leon-Kloosterziel, K., Van De Bunt, G., Zeevaart, J., and Koornneef, M. (1996). Arabidopsis mutants with a reduced seed dormancy. Plant Physiol. 110, 233-240.

115) Leipe,D.D. and Landsman,D. (1997) Histone deacetylases, acetoin utilization proteins and acetylpolyamine amidohydrolases are members of an ancient protein superfamily. Nucleic Acids Res., 25, 3693-3697.

116) Leon-Kloosterziel, K., Van De Bunt, G., Zeevaart, J., and Koornneef, M. (1996). Arabidopsis mutants with reduced seed dormancy. Plant Physiol. 110, 233-240.

117) Lee, Y.H., and Chun, J.Y. (1998). A new homeodomain-leucine zipper gene from Arabidopsis thaliana induced by water stress and abscisic acid treatment. Plant Mol. Biol. $37,377-384$.

118) Leigh, R. A. (1997). The Plant Vacuole. 25, 171-194. 
119) Leung, J., Merlot, S., and Giraudat, J. (1997). The Arabidopsis ABSCISIC ACIDINSENSITIVE2 (ABI2) and ABI1 genes encode homologous protein phosphatases $2 \mathrm{C}$ involved in abscisic acid signal transduction. Plant Cell .9, 759-771.

120) Levi, M., Brusa, P., Chiatante, D., and Sparvoli, E. (1993). Cell cycle reactivation in cultured pea embryo axes: Effect of abscisic acid. In Vitro Cell. Dev. Biol. Plant 29P, 4750.

121) Liu, J., Ishitani, M., Halfter, U., Kim, C.-S., and Zhu, J.-K. (2000). The Arabidopsis thaliana SOS2 gene encodes a protein kinase that is required for salt tolerance. Proc. Natl. Acad. Sci. USA 97, 3730-3734.

122) Liu, K, Fu, H, Bei, Q and Luan. S. (2000). Inward Potassium Channel in Guard Cells As a Target for Polyamine Regulation of Stomatal Movements. Plant Physiology. 124, 13151325.

123) Lusser A, Brosch G, Loidl A, Haas H, Loidl P.(1997)Identification of maize histone deacetylase HD2 as an acidic nucleolar phosphoprotein. Science . 277, 88-91.

124) LusserA. (2002)Acetylated, methylated, remodeled: chromatin states for gene regulation. Curr Opin Plant Biol. 5, 437-43.

125) Lusser,A., Kolle,D. and Loidl,P. (2001) Histone acetylation: acetylation: lessons from the plant kingdom. Trends Plant Sci., 6, 59-65.

126) Mayer, K.F., Schoof, H., Haecker, A., Lenhard, M., Jurgens, G. and Laux, T. (1998) Role of WUSCHEL in regulating stem cell fate in the Arabidopsis shoot meristem. Cell. 95, $805-815$. 
127) Molina, L., Mongrand, S., Kinoshita, N., and Chua, N.H. (2002). AFP is a novel negative regulator of $\mathrm{ABA}$ signaling that promotes $\mathrm{ABI} 5$ protein degradation. Genes \& Development. 17, 410-418.

128) Mori, I.C., Uozumi, N., and Muto, S. (2000). Phosphorylation of inward rectifying potassium channel KAT1 by ABR kinase in vicia guard cells. Plant cell physiol. 41, 850856.

129) Murashige, T. and Skoog, F. (1962) A revised medium for rapid growth and bioassay with tobacco tissue cultures. Physiol. Plant. 15, 473-497.

130) Murfett, J., Wang, X., Hagen, G. and Guilfoyle, T.J. (2001) Identification of Arabidopsis histone deacetylase HDA6 mutants that affect transgene expression. Plant Cell, 13, $1047-1061$.

131) Nakamura, S., Lynch, T., and Finkelstein, R. (2001). Physical interactions between ABA response loci of Arabidopsis. Plant J. 26, 627-635.

132) Nordin, K., Heino, P., and Palva, E. T. (1991). Separate signal pathways regulate the expression of a low-temperature induced gene in Arabidopsis thaliana (L.) Heynh. Plant Mol. Biol. 16, 1061-1071.

133) Norton VG, Imai BS, Yau P, Bradbury EM. (1989) Histone acetylation reduces nucleosome core particle linking number change. Cell. 57, 449-57.

134) Ogas, J., Kaufmann, S., Henderson, L. and Somerville, C. (1999) PICKLE is a CHD3 chromatin-remodeling factor that regulates the transition from embryonic to vegetative development in Arabidopsis. Proc. Natl. Acad. Sci. USA, 96, 13839-13844.

135) Pandey R, Muller A, Napoli CA, Selinger DA, Pikaard CS, Richards EJ Bender J, Mount DW, Jorgensen RA.(2002) Analysis of histone acetyltransferase and histone deacetylase 
families of Arabidopsis thaliana suggests functional diversification of chromatin modification among multicellular eukaryotes. Nucleic Acids Res. 30, 5036-5055.

136) Patonnier MP, Peltier JP, Marigo G (1999) Drought-induced increase in xylem malate and mannitol concentration and closure of stomata. $J$ Exp Bot . 50, 1223-1229.

137) Pederson, T. (1998) The plurifunctional nucleolus. Nucl. Acids Res. 26, 3871-3876.

138) Probst,V.A., Fagard, M., Proux, F., Mourrain, P., Boutet, S., Earley, K., Lawrence, J.R., Pikaard, C.S., Murfett, J., Furner,I., et al. (2004). Arabidopsis histone deacetylase HDA6 is required for maintenance of transcriptional gene silencing and determines nuclear organization of rDNA repeats. The Plant Cell. 16, 1021-1034.

139) Pei, Z.-M., Kuchitsu, K., Ward, J. M., Schwarz, M., and Schroeder, J. I. (1997). Differential abscisic acid regulation of guard cell slow anion channels in Arabidopsis Wild-type and abil and abi2 mutants. Plant Cell 9, 409-423.

140) Pharr DM, Stoop JMH, Williamson JD, Studer Feusi ME, Massel MO, Conkling MA.(1995). The dual role of mannitol as osmoprotectant and photoassimilate in celery. Hort Science .30, 1182-1188.

141) Raz, V., Bergervoet, J., and Koornneef, M. (2001). Sequential steps for developmental arrest in Arabidopsis seeds. Development 128, 243-252.

142) Robyr,D., Suka,Y., Xenarios,I., Kurdistani,S.K., Wang,A., Suka,N. and Grunstein,M. (2002) Microarray deacetylation maps determine genomewide functions for yeast histone deacetylases. Cell, 109, 437-446.

143) Rohde, A., Van Montagu, M., and Boerjan, W. (1999). The ABSCISIC ACIDINSENSITIVE 3 (ABI3) gene is expressed during vegetative quiescence processes in Arabidopsis. Plant Cell Envir. 22, 261-270. 
144) Rossi V, Locatelli S, Lanzanova C, Boniotti MB, Varotto S, Pipal A, Goralik-Schramel M, Lusser A, Gatz C, Gutierrez C, Motto M. (2003) A maize histone deacetylase and retinoblastoma-related protein physically interact and cooperate in repressing gene transcription. Plant Mol Biol .51, 401-13.

145) Sakamoto, H., Maruyama, K., Sakuma, Y., Meshi, T., Iwabuchi, M., Shinozaki, K., and Shinozaki, Y. (2004) Arabidopsis cys2/his2-type zinc-finger proteins function as transcription repressors under drought, cold and high-salinity stress conditions. Plant Physiology. 136, 2734-2746.

146) Sambrook, J. and Russell, D.W. (2001) Molecular Cloning: a Laboratory Manual, edn. 3. Cold Spring Harbor, NY: Cold Spring Harbor Laboratory Press.

147) Schwartz, S.H., Léon-Kloosterziel, K.M., Koornneef, M., and Zeevaart, J.A.D. (1997). Biochemical characterization of the aba2 and aba3 mutants in Arabidopsis thaliana. Plant Physiol.114, 161- 166.

148) Sendra,R., Rodrigo,I., Salvador,M.L. and Franco,L. (1988) Characterization of pea histone deacetylases. Plant Mol. Biol., 11, 857-866.

149) Shaul, O., Mironov, V., Burssens, S., Van Montagu, M., and Inzé, D. (1996). Two Arabidopsis cyclin promoters mediate distinctive transcriptional oscillation in synchronized tobacco BY-2 cells. Proc. Natl. Acad. Sci. 93, 4868-4872.

150) Shaw, C.H. (1995) Introduction of cloning plasmids into Agrobacterium tumefaciens. Meth. Mol. Biol. 49, 33-37.

151) Shinozaki, K., and Yamaguchi-Shinozaki, K. (2000). Molecular responses to dehydration and low temperature: Differences and cross-talk between two stress signaling pathways. Curr. Opin. Plant Biol. 3, 217-223. 
152) Soppe, W.J. (2002) DNA methylation controls histone H3 lysine 9 methylation and heterochromatin assembly in Arabidopsis. EMBO J. 21, 6549-6559.

153) Steber, C. M., Cooney, S. E., and McCourt, P. (1998). Isolationof the GA-response mutant sly1 as a suppressor of ABI1-1 inArabidopsis thaliana. Genetics 149, 509-521.

154) Steimer, A., Scho“, H., and Grossniklaus, U. (2004). Epigenetic control of plant development: new layers of complexity. Current Opinion in Plant Biology.7, 11-19.

155) Stoop JMH, Pharr DM.(1996). Effect of different carbon sources on relative growth rate, internal carbohydrates, and mannitol-1-oxidoreductase activity in celery suspension cultures. Plant Physiol. 103, 1001-1008.

156) Strommer, J., Gregerson, R. and Vayda, M. (1993) Isolation and characterization of plant mRNA. In Methods in Plant Molecular Biology and Biotechnology (Glik, B.R. and Thompson, J.E., eds). Boca Raton: CRC Press, pp. 49-66.

157) Struhl,K., Kadosh,D., Keaveney,M., Kuras,L. and Moqtaderi,Z. (1998) Activation and repression mechanisms in yeast. Cold Spring Harb. Symp. Quant. Biol., 63, 413-421.

158) Taunton,J., Hassig,C.A. and Schreiber,S.L. (1996) A mammalian histone deacetylase related to the yeast transcriptional regulator AtHDA1p. Science, 272, 408-411.

159) Thompson, A.J., Jackson, A.C., Symonds, R.C., Mulholland, B.J., Dadswell, A.R., Blake, P.S., Burbidge, A., and Taylor, I.B. (2000b). Ectopic expression of a tomato 9-cisepoxycarotenoid dioxygenase gene causes over-production of abscisic acid. Plant J. 23, 363- 374.

160) Tian L, Chen ZJ. (2001)Blocking histone deacetylation in Arabidopsis induces pleiotropic effects on plant gene regulation and development. Proc Natl Acad Sci USA; 98, 200-205. 
161) Tréhin, C., Glab, N., Perennes, C., Planchais, S., and Bergounioux, C. (1999). M phasespecific activation of the Nicotiana sylvestris cyclin B1 promoter involves multiple regulatory elements. Plant J.17, 263-273.

162) Uno, Y., Furihata, T., Abe, H., Yoshida, R., Shinozaki, K., and Yamaguchi-Shinozaki, K. (2000). Arabidopsis basic leucine zipper transcription factors involved in an abscisic aciddependent signal transduction pathway under drought and high-salinity conditions. Proc. Natl. Acad. Sci. 97, 11632- 11637.

163) Verbsky ML, Richards EJ Chromatin remodeling in plants. (2001) Curr Opin Plant Biol. 4, 494-500.

164) Volpe TA, Kidner C, Hall IM, Teng G, Grewal SIS, Martienssen RA. (2002) Regulation of heterochromatic silencing and histone H3 lysine- 9 methylation by RNAi. Science, 297, 1833-1837.

165) Weigel, D. and Glazebrook, J. (2002) Arabidopsis: a Laboratory Manual. Cold Spring Harbor, NY: Cold Spring Harbor Laboratory Press.

166) Wu K, Malik K, Tian L, Brown D, Miki B.(2000a) Functional analysis of a ATHDA1 histone deacetylase homologue in Arabidopsis thaliana. Plant Mol Biol .44, 167-76.

167) Wu K, Tian L, Malik K, Brown D, Miki B.(2000b)Functional analysis of HD2 histone deacetylase homologues in Arabidopsis thaliana. Plant J. 22, 19-27.

168) Wu, K., Tian, L., Brown, D. and Miki, B. (2003) Repression of gene expression by Arabidopsis HD2 histone deacetylases. Plant J. 34, 241-247.

169) Xiong, L., and Zhu, J.K. (2001). Abiotic stress signal transduction in plants: Molecular and genetic perspectives. Physiol. Plant. 112, 152-166. 
170) Yang, X. and Seto, E. (2003) Collaborative spirit of histone deacetylases in regulating chromatin structure and gene expression. Curr. Opin. Genet. Devel. 13, 143-153.

171) Ziegelhoffer, E., Medrano, L., and Meyerowitz, E. (2000). Cloning of the Arabidopsis WIGGUM gene identifies a role for farnesylation in meristem development. Proc. Natl. Acad. Sci. 97, 7633-7638

172) Zhu, J.K. (2000). Genetic analysis of plant salt tolerance using Arabidopsis. Plant Physiol. 124, 941-948.

173) Zuo, J., Niu, Q.-Wm, Frugis, G. and Chua, N.-H. (2002) The WUSCHEL gene promotes vegetative-to-embryonic transition in Arabidopsis. Plant J. 30, 349-359. 